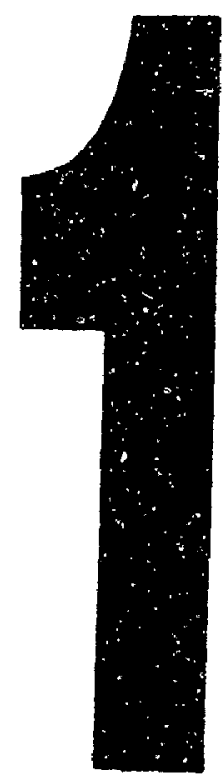

PM-1 31/2"x4" PHOTOGRAPHIC MICROCOPY TARGET NBS 1010a ANSJ/ISO H2 EQUIVALENT

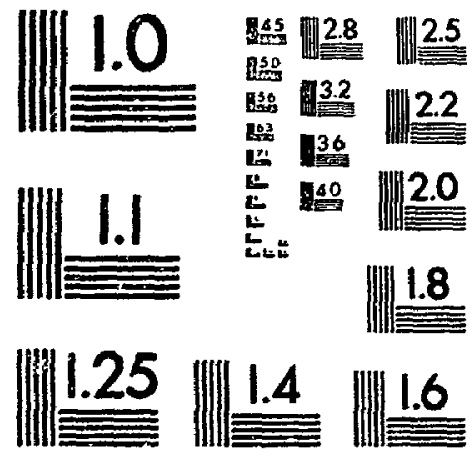

PRECISIONGM RESOLUTION TARGETS 
Acquisitions and Bibliographic Services Branch 395 Wellington Street Ontawa. Ontano Y.1A ON4
Bibliothifque nationale

du Caneda

Direction cles acquisitions et des services bibliographiques

395, rue Wellington

Ottawa (Ontarn)

rou file volre eference

Our filt Notre seterence

NOTICE

AVIS

The quality of this microform is heavily dependent upon the quality of the original tresis submitted for microfilming. Every effort has been made to ensure the highest quality of reproduction possible.

If pages are missing, contact the university which granted the degree.

Some pages may have indistinct print especially if the original pages were typed with a poor typewriter ribbon or if the university sent us an inferior photocopy.
La qualité de cette microforme dépend grandement de la qualité de la thèse soumise au micrctilimage. Nous avons tout fait pour assurer une qualité supérieure de reproduction.

S'il manque des pages, veuillez communiquer avec l'université qui a conféré le grade.

La qualité d'impression de certaines pages peut laisser à désirer, surtout si les pages originales ont été dactylographiées à l'aide d'un ruban usé ou si l'université nous a fait parvenir une photocopie de qualité inférieure.

La reproduction, même partielle, de cette microforme est soumise à la Loi canadienne sur le droit d'auteur, SRC 1970, c. C-30, ef ses amendements subséquents.
Reproduction in full or in part of this microform is governed by the Canadian Copyright Act, R.S.C. 1970, c. C-30, and subsequent amendments. 


\title{
Personal Communications Networks and Call Interception for Law Enforcement
}

\author{
by \\ Todd P. McDermott, B.A.Sc. (EE)
}

A thesis submitted to the Faculty of Graduate Studies and Research in partial fulfillment of

Master of Engineering Degree

Carleton University

Ottawa, Ontario

September 20, 1994

(C) copyright

1994, Todd McDermott 
National Library

of Canada

Acquisitions and Bibliographic Services Branch

395 Welington Street Ottawa, Ontario KIA ON4
Bibliotheque nationale

du Canada

Direction des acquisitions el des services bibliographiques

395. nue Wellington Ottawa (Ontario)

KIA ONA
Yout ito Votrenesterence

Our sto Notrenotorence
THE AUTHOR HAS GRANTED AN IRREVOCABLE NON-EXCLUSIVE LICENCE ALLOWING THE NATIONAL LIBRARY OF CANADA TO REPRODUCE, LOAN, DISTRIBUTE OR SELL COPIES OF HIS/HER THESIS BY ANY MEANS AND IN ANY FORM OR FORMAT, MAKING THIS THESIS

AVAILABLE TO I TTERESTED PERSONS.
L'AUTEUR A ACCORDE UNE LICENCE IRREVOCABLE ET NON EXCLUSIVE PERMETTANT A LA BIBLIOTHEQUE NATIONALE DU CANADA DE REPRODUIRE, PRETER, DISTRIBUER OU VENDRE DES COPIES DE SA THESE DE QUELQUE MANIERE ET SOUS QUELQUE FORME QUE CE SOIT POUR METTRE DES EXEMPLAIRES DE CETTE THESE A LA DISPOSITION DES PERSONNE INTERESSEES.
THE AUTHOR RETAINS OWNERSHIP OF THE COPYRIGHT IN HIS/HER THESIS. NEITHER THE THESIS NOR SUBSTANTIAL EXTRACTS FROM IT MAY BE PRINTED OR OTHERWISE REPRODUCED WITHOUT HIS/IER PERMISSION.
L'AUTEUR CONSERVE LA PROPRIETE DU DROIT D'AUTEUR QUI PROTEGE SA THESE. NI LA THESE NI DES EXTRAITS SUBSTANTIELS DE CELLECI NE DOIVENT ETRE IMPRIMES OU AUTREMENT REPRODUITS SANS SON AUTORISATION.

ISBN $\quad 0-315-98583-6$ 
The undersigned recommend to the Faculty of Graduate Studies and Rissearch acceptance of the thesis

\title{
Personal Communications Networks and Call Interception for Law Enforcement
}

\author{
submitted by \\ Todd P. McDermott, B.A.Sc. (EE) \\ in partial fulfillment of the requirements for the degree of \\ Master of Engineering \\ Ouspiele - \\ Thesis Supervisor \\ Chair, Department of'Systems \& Computer Engineering
}

Carleton University 


\section{ABSTRACT \\ Personal Communications Networks \& Call Interception \\ for Law Enforcement}

With the development of the next generation cordless telephone systems, the general public will be offered an ability to take their personal telephone and access communications networks outside the physical boundaries of their home. The network developed to support this technology is referred to as Personal Communications Networks (PCN). The services and features made available to the consumer are referred to as Personal Communications Services (PCS).

The market forecast for PCN estimates over 60 million subscribers by the year 2002 . The unit price for a telephone unit will be approximately $\$ 250$ and an access fee of approximately $\$ 45$ a month. The fee for air time is in the order of 50 cents per minute. PCN telecommunications services will compete with the local exchange carrier for the primary telephone service to the consumer.

The advanced technology implemented in PCN telephone units and the supporting network infrastructure will create a significant obstacle for Law Enforcensent in their attempts to perform a court authorized intercept of private communications. The PCN sadio link is fully digital with encryption and the network access is multi-layered with dynamic routing based on the call scenario.

This thesis outlines the concepts and features of PCN / PCS. It will provide a technical threat assessment for Law Enforcement on this new telecommunications technology and afford some altematives and recommendations on techniques for the interception of communications on a PCN.

The recommended technique for the interception of communications on a PCN for Law Enforcement is through network access. Specifically, the techniques will target the Group Switch portion of the network to accommodate the requirements for the lawfully authorized interception of PCN commur:zations. 


\section{Acknowledgments}

I would like to take this opportunity to thank Professor Asrar Sheikh from the Department of Systems and Computer Engineering at Carleton University, Ottawa, for all his time and effort in assisting me in the preparation of the thesis. His guidance was instrumental to the completion of this document.

I would especially like to thank my wife, Leslie McDermott, for not only proof reading this document but for having the patience to allow me the time away from my family responsibilities so that I could complete this thesis. Without this and her continuous reassurance and motivation this document and my entire graduate level study effort may not have come to a successful conclusion. Thank you. 


\section{Table of Contents}

Acceptance Sheet

ii

Abstract

iii

Acknowledgments

iv

Table of Contents

v

List of Tables

viii

List of Figures

ix

Glossary of Terms

$\mathbf{x}$

CHAPTER 1: Introduction

1.1 Overview

1.1.1 General

1.1.2 Wiretap Technology

6

1.1.3 Cellular vs. PCN

1.1.4 Possible PCN Effects on the Cellular Telephone Industry 10

1.2 Legalities of Interception

1.3 Possible PCS / PCN Service Providers

1.4 Media Reports on PCN

CHAPTER 2: Definitions

2.1 Definition of the Problem

2.1.1 General

2.1.2 Expectations of Security with Emerging Technologies 25

2.2 Concept of Personalized Numbers

2.3 System Concepts

28

2.3.1 System Mobility

28

2.3.2 Comparison of Competing PCN Standards

2.3.3 CT2Plus Adoption by the

Department of Communications

2.3.4 Cordless Telephones and PCN

CHAPTER 3: Wireline Network for PCN 
3.2 Service Features With the Introduction of AIN 44

3.3 CCITT IN Concepts $\quad 48$

3.4 Bellcore Standards for AIN $\quad 54$

3.5 Probable PCN Architectures With AIN

CHAPTER 4: PCN RF Communications 66

4.1 General 66

4.2 Telepoint Services $\quad 69$

4.3 Microcell Technology 71

4.4 Comparison of Competing Standards 72

4.5 Global System for Mobile Communications (GSM) 76

4.6 CT2Plus Cirannel Frequency Specification 82

4.7 Description of CT2Plus RF Data Transmission 84

4.8 Canadian CT2Pius Common Air Interface 87

4.9 Scrambling and Encryption $\quad 90$

4.9.1 Northern Telecom Security for PCN 91

4.10 Comparison of Multiple Access Schemes 97

4.11 FCC Issues on PCN 101

CH.APTER 5: Call Processing 105

5.1 General 105

5.2 PCN Call Routing 106

5.3 Radio Network Hand-off Routing $\quad 110$

5.3.1 Radio Base Station Functionality $\quad 114$

5.4 CT2Plus Call Processing Details 117

5.4.1 CT2Plus Common Signaling Channel Functionality $\quad 119$

5.4.2 CSC Layer 1 Signaling Functionality 121

5.4.3 CSC Hand-off Signaling Functionality 123

CHAPTER 6: Concepts for the Interception of Communications on a PCN 128

6.1 General 128

6.2 Intercept Technical Requirements $\quad 129$

6.3 Problems With the Interception of Cellular Communications $\quad 132$

6.3.1 General 132

6.3.2 Problems With RF Based Cellular Intercepts 133

6.3.3 Limitation Due to Cellular Phone Characteristics 136 
6.3.4 Operational Considerations for Cellular Intercepts $\quad 138$

6.4 Strategies for the Intercept of Communications on PCN 141

6.4.1 General 141

6.4.2 RF / Off-air Interception of PCN Communications $\quad 142$

6.4.3 Wireline Network Access for PCN Intercept 147

6.4.3.1 An Example of a PCN Architecture for Wireline $\quad 154$

Network Access

CHAPTER 7: Conclusions and Recommendations 162

7.1 Gene:al Observations $\quad 162$

7.2 PCN Technology 163

7.3 PCN Intercepion Recommendations $\quad 164$

$\begin{array}{ll}\text { 7.3.1 General Recommendations } & 166\end{array}$

$\begin{array}{ll}\text { References } & 170\end{array}$ 


\section{LIST OF TABLES}

\begin{tabular}{|c|c|c|}
\hline ABLE & DESCRIPTION & PAGE \\
\hline 2.1 & $\begin{array}{l}\text { Technical Comparison of Competing Standards } \\
\text { for PCN }\end{array}$ & 34 \\
\hline 3.1 & Call Model Trigger Points & 43 \\
\hline 3.2 & PCN End User Feature Requirements & 46 \\
\hline 4.1 & $\begin{array}{l}\text { Comparison of Competing Radio Standards } \\
\text { Second Generation Digital Cordless Telephone }\end{array}$ & 75 \\
\hline 4.2 & Telephony Features; GSM vs. IS-41 & 78 \\
\hline 4.3 & $\begin{array}{l}\text { Carrier Frequencies (MHz) For Radio Traffic } \\
\text { Channels For CT2 PLUS Cordless Telephone } \\
\text { Systems }\end{array}$ & 83 \\
\hline 4.4 & $\begin{array}{l}\text { Carrier Frequencies for Common Signaling } \\
\text { Channels For CT2 PLUS Cordless Telephone } \\
\text { Systems }\end{array}$ & 84 \\
\hline 4.5 & $\begin{array}{l}\text { Capacity Comparison of TDMA \& CDMA vs. } \\
\text { Cellular AMPS }\end{array}$ & 99 \\
\hline 6.1 & $\begin{array}{l}\text { Distribution of Intended Call Destination } \\
\text { Probabilities }\end{array}$ & 158 \\
\hline
\end{tabular}




\section{LIST OF FIGURES}

FIGURE DESCRIPTION

PAGE

1A CCIR Functional Reference Model; Future Land 13

Public Mobile Telecommunications Systems

3A PCS Environment 40

3B Intelligent Network Overview 42

3C IN Conceptual Model 5\%

3D IN CS-1 Physical Plane Architecture 53

3E Bellcore AIN Release 1 Architecture 57

3 PCN Core Network as an Integrator of Islands 60 of Mobility

3G PCN Target Functional Architecture 61

3H Basic Personal Communications Network 63

Architecture

4A GSM Network Architecture 80

4B GSM Authentication Procedure 96

5A Basic Personal Communications Network 108

Architecture

5B PCN Network Call Rou'ing Flow Diagram 109

5C PCN Base Station Hand-off Network Connection 112

Flow Chart

6A Basic Personal Communications Network 149

Architecture

6B PCN Network Call Routing Flow Diagram 151

6C Hierarchical Distributed Database Design 156 


\section{Glossary of Terms}

$\begin{array}{ll}\text { ADPCM } & \text { Adaptive Differential Pulse Code Modulation } \\ \text { AIN } & \text { Advanced Intelligent Network } \\ \text { AMFS } & \text { Advanced Mobile Phone System } \\ \text { BNR } & \text { Beil Northern Research } \\ \text { B.S. } & \text { Base Station } \\ \text { CAI } & \text { Common Air Interface } \\ \text { C.C.C. } & \text { Criminal Code of Canada } \\ \text { CCS } & \text { Common Channel Signaling } \\ \text { CDMA } & \text { Code Division Multiple Access } \\ \text { CELP } & \text { Coded Excited Linear Predictor } \\ \text { CFP } & \text { Cordless Fixed Part } \\ \text { CHMF } & \text { Channel Marker bit pattern sent by CFP } \\ \text { CID } & \text { Cell Identity Code } \\ \text { CMIM } & \text { Call Model Int raction Manager } \\ \text { CPP } & \text { Cordless Portable Part } \\ \text { CSC } & \text { Common Signaling Channel } \\ \text { CTA } & \text { Cordless Telephone Apparatus } \\ \text { CTIA } & \text { Cellular Telecommunications Industry Association } \\ \text { DCT } & \text { Digital Cordless Telephone } \\ \text { DOC } & \text { Department of Communications } \\ \text { DQDB } & \text { Distributed Queue Dual Bus } \\ \text { ESN } & \text { Electronic Serial Number } \\ \text { FACCH } & \text { Fast Associated Control Channel } \\ \text { FBI } & \text { Federal Bureau of Investigation } \\ \text { FDMA } & \text { Frequency Division Multiple Access } \\ \text { FEA } & \text { Functional Entity Actions } \\ \text { FPLMTS } & \text { Future Public Land Mobile Telecommunications Systems } \\ \text { GS } & \text { Group Switch } \\ \text { GSM } & \text { Global System for Mobile communications } \\ \text { HLR } & \text { Home Location Register } \\ \text { IAC } & \text { Industry Advisory Committee (part of the DoC) } \\ \text { IMSI } & \text { International Mobile Subscriber Identity } \\ \text { IN } & \text { Intelligent Network } \\ \text { INAP } & \text { Intelligent Network Application Protocol } \\ \text { IP } & \text { Intelligent Peripheral } \\ \text { ISDN } & \text { Integrated Services Digital Network } \\ \text { ITU } & \text { International Telecommunications Union. } \\ \text { LEC } & \text { Local Exchange Carrier } \\ \text { LEO } & \text { Low Earth Orbit } \\ \text { LID } & \text { Link Identity Code } \\ \text { MA } & \text { Metropolitan Area } \\ \end{array}$




$\begin{array}{ll}\text { MAN } & \text { Metropolitan Area Network } \\ \text { MAP } & \text { Mobile Applications Part } \\ \text { MDSS } & \text { Mobile Distributed Switching System } \\ \text { MIN } & \text { Mobile Identification Number } \\ \text { MTSO } & \text { Mobile Telephone Switching Office } \\ \text { OSI } & \text { Open Systems Interconnection } \\ \text { PABX } & \text { Private Automatic Branch Exchange } \\ \text { PCN } & \text { Personal Communications Network } \\ \text { PCS } & \text { Personal Communications Systems } \\ \text { PCT } & \text { Personal Cordless Telephone } \\ \text { PIC } & \text { Points In Call } \\ \text { PID } & \text { Portable Identification Code } \\ \text { PIN } & \text { Personal Identification Number } \\ \text { PSTN } & \text { Public Switched Telephone Network } \\ \text { RECC } & \text { Reverse Analog Control Channel } \\ \text { RF } & \text { Radio Frequency } \\ \text { RSS } & \text { Radio Standards Specification } \\ \text { SACCH } & \text { Slow Associated Control Channel } \\ \text { SCP } & \text { Service Control Point } \\ \text { SIM } & \text { Subscriber Identity Module } \\ \text { SRES } & \text { Subscriber Response } \\ \text { SS7 } & \text { Signaling System Number 7 } \\ \text { SSP } & \text { Service Switching Point } \\ \text { SYNCF } & \text { Synchronization word from CFP } \\ \text { SYNCP } & \text { Synchronization word from CPP } \\ \text { TCP } & \text { Trigger Check Point } \\ \text { TDD } & \text { Time Division Duplexing } \\ \text { TDMA } & \text { Time Division Multiple Access } \\ \text { TIA } & \text { Telecommunications Industry Association } \\ \text { TMSI } & \text { Temporary Mobile Subscriber Identity } \\ \text { UPT } & \text { Universal Personal Telecommunications } \\ \text { VLR } & \text { Visitor Location Register } \\ \text { VPN } & \text { Virtual Private Network } \\ \text { WARC } & \text { World Ad ninistrative Radio Conference }\end{array}$




\section{Chapter 1}

\section{Introduction}

\subsection{Overview}

\subsubsection{General}

Law enforcement agencies within Canada have a wide range of investigative techniques available to them. Most evident to the public is the uniformed officer actually interviewing individuals in an attempt to obtain useful information that could benefit his investigation and, hopefuliy, iring it to a cunclusion. More sophisticated criminals and organized crime has complicated the ability for that officer to obtain information. It is no longer a single investigator who actively works on solving these more involved crimes. A team of investigators will band together as a unit in an attempt to gather enough evidence to bring the suspects to justice. Once all conventional investigative procedures have been attempted and have failed Canadian law enforcement have the right under Part VI of the Criminal Code of Canada to obtain a court authorization for a wiretap. Information and evidence obtained from a wiretap installed against a suspect may and could provide the necessary leads to finalize the investigation and, again, bring the criminals to justice. However, in these days where crime involves contraband worth millions of dollars to the criminal, the criminal element takes many safeguards to protect themselves against law enforcement and their known investigative techniques. Therefore, it is a known fact that members of the criminal element will take advantage of any items that will provide them any level of security against law enforcement. State of the art electronics and communications equipment are easily obtained and used to thwart technical based investigative techniques. Simple items such as radio scanners are commonly used against law enforcement. Furthermore, more sophisticated criminals are concerned about the security of their telephone communications since it is a well known fact that law enforcement can perform wiretaps. If a newly developed electronic or technical device would benefit the operations of the criminal element and provide security for their communications, there is no doubt that it will be exploited and used to hinder the activities of the police. 
It is a well known fact that in recent years telecommunications technology has progressed at an unprecedented rate. Not too long ago subscribing to touch tone service for your residential telephone was considered to be a significant jump forward in technology for the consumer. Iiaving the ability to install up to 5 telephone extensions anywhere in your home was yet another convenience that the telephone companies were offering. The technical issues to perform a wiretap were relatively simple. Law enforcement had to find an appearance of the targeted line and perform the wiretap with a bridging device.

Yet, just a few years later these features seein all but insignificant. The consumer can easily go to the local department store and purchase a cordless telephone that will plug into the residential telephone wall connector and provide the user with tetherless communications, typically, anywhere within their home or surrounding property. Residential telephone services that can be subscribed to now include voice mail, calling line identification with numeric display and an appropriate telephone, call waiting, conference call and programmable cali iorwarding just to mention a few. All these features do cause some concern when reviewing what would be necessary to perform the wiretap but, fundamentally, all it still requires is the physical connection to the target line to obtain all the communications on that circuit.

Not only are the actual telephone sets changing and the fact that the consumer is no longer obligated to rent their phone from the phone company but the type of devices that can be plugged into your telephone line have increased. As mentioned previously, the consumer can purchase a wireless telephone for his residence providing him tetherless voice communications services. Yet, data transmission has become the mode creating the most fundamental change in the primary concept of the voice telephone communications. Facsimile transmissions, FAX, has become an expected capability in today's business world as well as an available device to put in to a home. Today pizza stcres take orders via FAX as well broadcast radio stations song requests via FAX. Not too long ago a statistic was published indicating that approximately 50 percent of all telephone traffic between North America and the Orient are FAX transmissions. The fundamental concept of phones being limited to only voice communications has disappeared. Interception of FAX transmissions was probably a challenge once but law enforcement has succeeded in intercepting this format of telephone communications and submitted printed copies as evidence in court. 
Computer modem communications has also become a technology not limited to large businesses specializing in computers but has been delegated to the common consumer who can purchase a desk top computer for their home. Today, having a home computer is no longer considered an extravagance but is considered a learning tool, a source of entertainment and method to provide household management. One of the more popular options in the desk top computer domain is the modem. For less than $\$ 100$, a modem can be installed into the computer giving the user access to a multitude of on-line services as well as providing an integral FAX communications mode so that the user does not have to buy a separate FAX machine. A recent article estimates that over 20 million people use networks linked by the non-commercial Internet system. These users have access to electronic mail services, numerous data bases and catalogues, can download files from all over the world and can even play long distance computer interactive games. It is inevitable that this is yet another format of telephone communications that law enforcement must be able to process to support their wiretap investigations.

Another telephone technology introduced within the past ten years that has recently really taken off. Cellular telephones were introduced to the consumer telecommunications market to meet the requirements of increasing mobility of modern society. In the early years of cellular telephones cost over $\$ 1000$ each and were strictly limited to in car installations. As with most new and advanced technologies, cellular was restricted to typically business applications where personnel had to be in touch continuously while traveling. Now, just a few years later most, if not all, North American consumers know what a cellular telephone is and can own one for less than $\$ 50$. There have even been promotion where the actual cellular telephone has been provided free of charge on the condition that the consumer subscribe to one particular service provider. In North America this is not a real limitation to the consumer as there are only two cellular telephone service companies for each service area. In Canada there are two national service providers, Cantel and Cell Net Canada. Both service providers are in fierce competition for this lucrative market, their air time pricing packages are comparatively the same and the cellular radio coverage is virtually identical. Wiretap technology now has to expand to include communications services provided by these cellular companies and their communications infrastructure.

The technology has bettered itself and cellular phones are no longer limited to in car installations. Portable and transportable phones are jecoming the more popular style of 
cellular phene to purchase. With the portable style, the consumer can purchase an in car adapter to provide a source of power and enhanced radio communications range. Yet, when the consumer exits the car he can simply grab the phone, place it in his pocket and continue being in cellular contact. The technology is progressing and providing for a more miniature cellular device with very efficient battery usage.

The market trends show that the ultimate consumer demand is for a phone that can be carried, is not bulky or large and can provide immediate access to telephone service no matter where it may be. There is a draw back with the technologies currently offered. The prevalent infrastructure still requires a backbone wireline network to connect all entities together. The residential cordless phone using, what is termed as $\mathrm{Cr}$ (cordless telephone) technology still needs to be connected physically to the residential telephone circuit to obtain its connection to the telephone network. The party using this form of telephone technology has the ability to roam within range of their radio base station but the network features available to this phone are those inherent in the wireline network. Cellular telephones have an overlay network supporting its communications needs but, again, the bulk of the communications to and from the cellular phone comes from the existing landline telephones. The majority of the interconnections to the cellular switching network originate through hardwire connection to the local switching office and, therefore, access to the wireline network.

What this means, in general, is that any one individual must have numerous telephone numbers associated to him or her depending on his or her physical location. The person attempting to contact another party has to have some expectation of where the target person is to be located at this particular time. If that person may be at home, they would dial their home number. Conversely, if the party is expected to be on the road, the dialing would be to the cellular number. No one number could really provide for the contact to any individual no matter where they may be located. The fact that there are overlay telephone networks not truly communicating to each other rather routing calls destined or originating in them, is the fundamental problem.

Personal Communications Networks (PCN) is the upcoming technology that will, apparently, take into account all the consumer trends and attempt to eliminate any limitation of the current telephone technologies. PCN or PCS has been defined by the FCC as a family of mobile or portable radio communications services which could provide services to individuals and businesses and be integrated with a variety of 
competing networks. The primary focus of PCS will be to meet communications requirements of people on the move.

PCN will provide the consumer a universai telephone that will weigh less than 200 grams, cost, when introduced to the market, in the order of $\$ 150$ Canadian and will provide telephone communications no matter where the user may travel. Ultimately no residential personal base station will be required as the PCN design has small radio base stations located not only in public places such as malls and airports or in the city center area but the base stations will make there way out into the suburbs. This will provide communications both at home, at work and in public areas. The telephone number issued to this phone is issued to the individual not to a telephone circuit located and terminated at a specific location. PCN will be supported by an Advance Intelligent Network (AIN) infrastructure so that the network will always know where every phone is, what base station is in range of the phone, so that a call destined to that phone will be routed automatically to the subscriber independent of their physical location.

Communications on a Personal Communications Network now seems to be the next technological challenge for those who have to develop a method to intercept private communications. In Canada, as the first step in the introduction of PCN services Communications Canada has adopted a standard for the radio communications portion of the next generation cordless telephone communications. The standard, CT2Plus, is not a complete definitive standard for the entire PCN. However, at this point in time there are only recommendations for the different entities that make up a total PCN. This Thesis will reviev/ all aspects of the wireless portion of PCN, the wireline infrastructure and the Advanced Intelligent Network and all possible call processing scenarios available in this network. CT2Plus type communications will be used as an example to highlight the interception problem in absence of any other strict standarts. Concepts for the interception of communications on a PCN will be developed with a general approach that can be implied through the investigation on CT2Plus communications intercept. The concepts presented will outline technical and law enforcement operational advantages and disadvantages to the suggested techniques. 


\subsubsection{Wiretap Technology}

The purpose of this Thesis is to outline the possible techniques available for authorized law enforcement agencies and intelligence groups throughout Canada to intercept electronic communications that are being originated, routed through or terminated within an upcoming telephone technology called Personal Communications Network (PCN) also known as Personal Communications Services (PCS). Both of these terms are synonymous with each other and can be used interchangeably.

Law enforcement authorities and intelligence groups have, for many years, used technical means in order to obtain information that will assist them with their investigations. In IEEE Spectrum, an article published in the March 1993 issue begins with a clear statement on interception. "Wiretapping has been a critical tool in combating organized crime, drug trafficking, and acts of extortion, terrorism, kidnapping, and murder. According to the Federal Bureau of Investigation (FBI), many serious crimes can only be solved or prevented with the aid of electronic intercepts. What's more, the FBI estimates the economic benefit accruing from court ordered intercepts to be in the billions of dollars in terms of collecting fines and making restitution, and the savings to society of crime prevention. These benefits are likely to increase with the growth in telecommunications services and facilities."[1] This statement relates specifically to information published by the FBI and how it relates to criminal investigations in the United States. It can likely be directly correlated to the techniques available to law enforcement agencies in Canada including the Royal Canadian Mounted Police who have as their mandate all federal enforcement in Canada. This would include investigations into drug trafficking and organized crime similar to that of the FBI.

Revolutionary advances in telecommunications technology has become one of the most significant threats against successfully achieving a wiretap. In years past the most sophisticated technical challenge has been dealing with a completely analog telephone system. Wiretapping was relatively simple and could be accomplished anywhere on the subscribers telephone circuit, from the telephone pole outside the residence to the central switching office. No matter where the intercept device was placed, all communications transmitted on that subscriber line was captured. New innovations in digital transmission schemes over telephone channels as well as residential telephone 
features available to the consumer have become a technical challenge for law enforcement agencies. Iit the same article in the IEEE Spectrum it is stated that "the introduction of new communications technologies and services now threaten the ability of law enforcement to use wiretaps. Although it is technically feasible to intercept these new communications, not all systems have heen designed or equipped to meet the intercept requirements of law enforcement. According to the FBI, technical problems have prevented numerous court orders from being sought, executed, or fully carried out."[1] In a publication from the FBI it is stated that the "proliferation of digital technology and the introduction of other advanced telecommunications systems will soon make it impossible for law enforcement agencies on the Federal, State and local levels to effect lawful court orders that allow for the interception of electronic communications. In some cases, advanced cellular technology and new digital based features such as call forwarding already frustrate such orders, thereby allowing criminal organizations to carry out illegal activities through the telecommunications system without detection."[2]

In summary, Mr. James K. Kallstrom, chief of investigative technology for the FBI, was quoted as stating " Wiretapping is a critical investigative tool for cases of drug running, kidnapping, and fraud. In recent years court authorized wiretaps have benefited the prosecution in almost every big criminal case, such as the John Gotti Mafia conviction, the IIl Wind investigation of Pentagon contractors, and the July indictment of five computer hackers in New York City. "[3] He is also quoted stating" We see a rocky road ahead for law enforcement because the technology hasn't been designed with the correct feature packages. "[3] referring to the neglect of designers to consider interception of communications in their telecommunications equipment development.

The necessity for court authorized electronic eavesdropping is clear. The benefits of wiretaps tc law enforcement in their quest to bring the major criminal element to justice are unequivocal. The challenge to perform these wiretaps in the age of progressive developments in the telecommunications market place seems to be immeasurable. Personal Communications Networks, with its sophisticated digital wireless technology, will be a formidable technical challenge to law enforcement agencies in the very near future. 


\subsubsection{Cellular VS. PCN}

Cellular communications provided law enforcement with a technical challenge and did, initially, provide the user some security from eavesdropping. This technology is the most comparable to the future PCN service and, therefore, should create similar types of problems for the development of lawful interception techniques. The media has published that radio scanners can monitor cellular radio bands and eavesdrop on active communications. However, in the technical requirements for a lawful intercept, simple monitoring via a scanner would not provide for the technical requirement to immediately and accurateiy identify the target and not intercent the private communications of anyone else.

As the prelude to the discussion on PCN and the possible service providers, the question of whether existing cellular can accommodate PCN has to be answered. After researching numerous documents and publications it has been determined that there are conflicting statements and claims in this regard. The cellular industry gives the idea that their new digital cellular offering is close enough to PCN that the transition to this new service would be simple and require minimal capital cost outlay and, therefore, reduce the cost billed back to the consumer. Other industries such as cable TV companies are set against the cellular companies or wireline service providers getting the chance to take over PCN as well and continue to monopolize terrestrial voice communications services. Independent of the industry claims there are technical considerations that must be evaluated to ascertain whether cellular technology can provide PCN communications.

A section of an article published by the IEEE explains this technical issue. The following is a quote from this article outlining two issues with regard to existing and future digital cellular technology and how it relates to PCN.

"Interpretation I: Can cellular mobile radio technology provide personal commurications?

It should be clear, from the discussion by Steele and throughout this paper, that both the existing analog cellular mobile technology and planned next generation digital cellular mobile technology are optimized for high power vehicular applications. Neither is suited for small, low powered, shirt pocket size, long usage time personal communicators. Thus. the answer to interpretation $I$ is that 
the high power cellular mobile radio technology is well suited to providing the vehicular communications functions needed in a personal communications vision, but such high power technology is not suitable for the wide spread low power tetherless access needed to support shirt pocket personal communicators.

Interpretation II: Can the radio spectrum allocated for cellular mobile radio adequately provide personal communications ?

Given the amount of spectrum currently available to cellular radio carriers to support both vehicular users and low power pocket personal communicators, the answer is "very unlikely". The capacity of cellular mobile systems is stressed in several places today. .... There could easily be 100 million cellular mobile equipped vehicles in the U.S. by early in the next century. "[4]

As stated in this article the possibility that the U.S. cellular industry could modify or upgrade their existing facilities to accommodate PCN is highly unlikely. This fact translates directly to the Canadian cellular industry as the AMPS cellular transmission standard is utilized in both Canada and in the US. Also, the frequency spectrum allocation for cellular is identical in Canada and the US to guarantee interoperability and the ability to ro: $m$ freely between the two countries.

Cellular was originally developed primarily for a high powered, mobile type applications where the actual telephone device could be moving at speeds in excess of $100 \mathrm{~km} / \mathrm{hr}$. The system was originally not designed to accommodate very slow moving, extremely low powered portable radios. The early design was incorporated to movide a contiguous network to allow vehicular traveling users corrmurications as they moved. The cellular system would respond accordingly to track these telephones and process the hand-offs of the radio channels such that there should be no loss of the voice path. The system, when first installed, had very few micro-cells within metreyolitan areas. The majority of the expense to the cellular service providers was the installation of cellular repeaters on mobile routes in an attempt to pride radio coverage over heavily traveled motor routes.

Portable, low powered cellular phones were very expensive and impractical during the early days of cellular. Yet as cellular coverage became more effective, more and more micro-cells began appearing in major metropolitan areas to provide the radio coverage for portable cellular phones. The price of these phones have also dropped significantly and their popularity increased. These portable radios would also, typically, be concentrated in specific geographic locations causing high density requirements for 
specific areas within the system. Radio channels would have to be planned to cover densely packed, high demand setvice areas or islands within the network.

If PCN is accepted readily by consumers, as anticipated, the demand for this service will increase dramatically within the early stages of available service well beyond that of what was experienced in cellular. The radio coverage demands should show increase commensurate with that of cellular if not greater. However, it would require a significantly larger base station equipment foundation because of the shorter RF range design. Also, it should be noted that in North America the cellular spectrum is finite and the channel reuse requirement for PCN would exceed what could be offered from the cellular system. Therefore, it would only seem logical to assign a different piece of the RF spectrum for PCN services.

In conclusion, it is evident that PCN services cannot be offered through enhanced cellular systems. The only option to a cellular company would be to develop yet another communications network and infrastructure in a different portion of radio spectrum to serve $\mathrm{PCN}$ thus creating yet another network requiring an ability to perform a communications intercept.

\subsubsection{Possible PCN Effects on the Celiular Telephone Industry}

Many discussions have taken place regarding competition between the continuously growing cellular telephone industry and the new PCN industry. Different articles in recognized journals in the telecommunications field routinely consider and report on this topic and many issues have been raised. They have all come to the same conclusion. Initial assessments thought $\mathrm{PCN}$ was to be in competition with existing cellular services. However, after reviewing all the intricacies and differences between the two communications services it has been concluded that PCN will not be able to offer telephone services, similar to cellular, that would operate while the subject is moving at a high rate of speed such as in a vehicle. However, PCN will provide services complementary to cellular. The offerings differ enough between the two that direct competition for the same market does not seem to be a concern. 
Early articles including "Personal Communications - A Viewpoint"[4] published in November 1990 details mitigating issues that will always differentiate PCN from cellular. The most important fact that was discussed in this article is that the PCN infrastructure is designed for low powered transmitters and is based on the personalized numbering concept inherent in AIN. in this article the question " Can cellular radio provide PCN ?" is addressed directly. Three different items were discussed. It seems that the first item, "Can cellular mobile radio technology provide personal communications ?" is the most significant. Cellular technology trends were discussed and the conclusion was that the "high powered technology is not suitable for widespread low power tetherless access needed to support the small shirt pocket personal communicators." The other two items related to issues concerning spectrum allocations to PCN and cellular. This has become a non-issue today as both the FCC and DOC have iclentified spectrum. for PCN service.

A follow' up article in the IEEE Communications magazine titled "Trends in Cellular and Corcless Communications" published in June 1991 also addresses the two industries and the possible competitiveness that may arise. One key issue was outlined in this article. "While they differ in many ways, cellular and cordless phones serve the same basic aim : to provide wireless access to the worldwide Public Switched Telecomnunications Network."[5] Again, basic differences start arising when comparisons are made between the network architectures. The evolution of the network architectures are described as they progress from what is used for cellular to the one proposed by the CCIR Task Group 8/2. The model developed by this group is shown in Figure 1.1. The article differentiates in the basic concept of the two communications services. It states that researchers are "anticipating a mass market demand for access to the future wireless networks".[5]

In summary, the industry journals have stated "PCN would compete with both existing landline and cellular services. A multibillion dollar market loomed for whatever carrier won the right to offer PCN."[6] However this claim in this article takes into account the finite market value for telephone type communications not the fundamental technical differences inherent in the three different telephone communications services as outlined previously. Part of the market share will be lost by both landline and celiular as the result of the introduction of a third communications industry, PCN. Users will, however, learn quickly that if they 
require a telephone communications link to their vehicle, PCN technology will not be able to provide the utility as cellular can.

The market is increasing with more organizations attempting to enter the industry. Not only have the existing cellular companies in Canada sponsored PCN trials including Cantel in Ottawa, Ontario but a new service provider has entered the forum. The cable companies are attempting to win the right to offer PCN using the existing cable infrastructure as the communications backbone to the network. "The biggest telecommunications story of the decade may turn out to be not telcos creating broadband networks, but cable technology and archifecture providing to be the most efficient means of delivering the next generation of communications services".[7] Cellular companies are financially driven to seek a market share of PCN especially with the forecast of such great demands. Yet no where does it speculate that the specific cellular market is directly threatened by PCN. In an article in Telephony Magazine it was stated that "therc has been speculation that the FCC might ban cellular carriers from PCS so that new entrant would have a chance to provide competitive wireless services. "[8] Therefore, in tî: US, ceilitar companies may be left with no recourse but to watch and see how popular PCN becomes because they may not be able to enter the market due to federal regulations. The two industries may remain forever separated.

One market that shows that it could be affected by PCN is the actual wireline service to a residence. Cable companies, in the majority of the large cities and a high percentage of populous areas, have an avenue in to the user's home. The existing cable transmission system has enough bandwidth to easily accommodate PCN traffic. Therefore, the landline service providers should look for a competitive market developing as PCN is introduced. How PCN services are marketed to the public should define what existing service market is affected by new competition and where law enforcement has to target to obtain the necessary communications to enable them to carry out an intercept. 


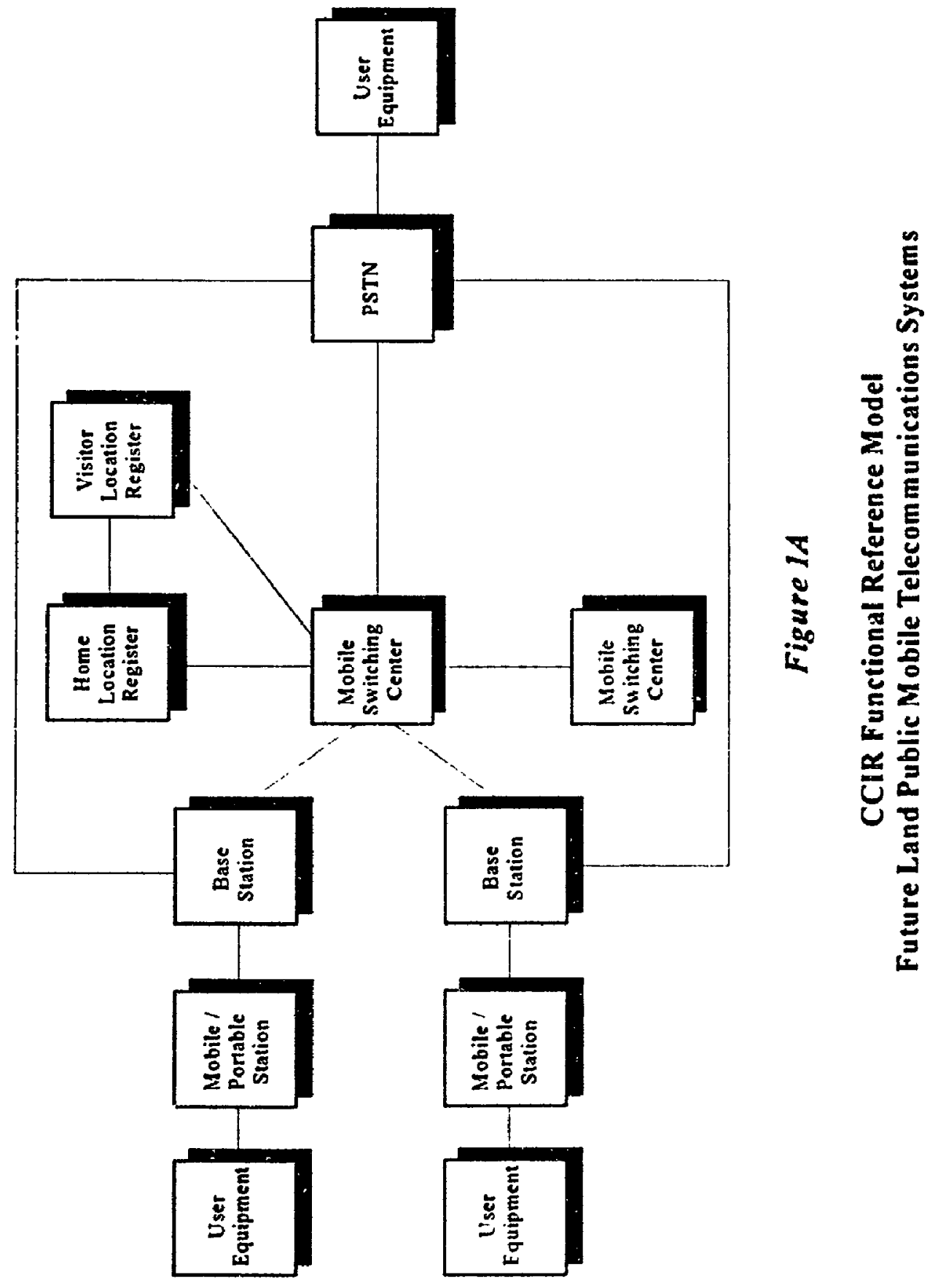




\subsection{Legalities of Interception}

As general background information the authority in which an interception of private communications can take place in Canada must be clear. Law enforcement agencies are regulated under Part VI of the Criminal Code of Canada (C.C.C.) which deals with the invasion of privacy. In Part VI the detailed requirements outlining the ability to obtain an authorization to intercept private communications is defined as well as those individuals who can have intercept devices in their possession.

The term intercept is defined under the criminal code as including listening to, recording or acquiring a communication or acquire the substance, meaning or purport thereof.

Section 184(1) of the sriminal code defines the offense of interception as follows: "Every one who, by means of any electro-magnetic, acoustic, mechanical or other device, willfully intercepts a private communication is guilty of an indictable offense and liable to imprisonment for a term not exceeding five years."

This subsection does not apply to those persons who intercept private communications in accordance with an authorization, defined in the C.C.C. 184(2)b).

Authorization is defined in Part VI as "an authorization to intercept a private communication given under section 186 or subsection 188(2)." Sections 185 and 186 of the C.C.C. present a better description of an authorization to intercept. Section 185 states that an authorization must be made in writing to a judge of a superior court of jurisdiction. Fie Attorney General of the province in which the authorization is requested or his designate has the signing authority for the authorization. Accompanying the application must be an affidavit detailing the facts associated to the case. Also included in the affidavit are the types of private communications proposed to be intercepted and the names, addresses and occupations, if known, of all parties whose private communications will be intercepted. It is based on reasonable grounds that the information obtained by the intercept may assist the investigation. 
Section 186 deals with the fact that the judge has to be "satisfied" to be able to issue an authorization. Satisfied in that it would be in the best interest of the administration of justice, or that other investigative procedures have been tried and failed. The urgency of the matter can be such that it would be impractical to carry out the investigation limited to other investigative procedures only. Again in section 186 of the C.C.C. details of the content of the authorization are laid out. The authorization shall state the offense in which the private communications may be intercepted and state the type of private communications to be intercepted. The identity of the persons whose private communications are to be intercepted as well as generally, the place at which the interception is to take place is stipulated. The judge can dictate terms and conditions to the authorization if he considers it to be in the public interest. The period in which the authorization is to be effective will also be stated and the initial period shall not exceed 60 days. Renewals are available to extend the period of an authorization under the provisions described in section $186(6)$ of the C.C.C.

In the above sections the intent of the authorization is to intercept "private communications". The definition of this term under the C.C.C. is as follows:

"Private communications means any oral communication or any telecommunication made under circumstances in which it is reasonable for the originator ther eof to expect that it will not be intercepted by any person other than the person intended by the originator thereof to receive it."

There has been many annotations made to the meaning of private communications in many rulings. The initial reference is to a definition outlined in Goldman v. The Queen (1979). It read:

"For the purposes of this definition the Originator of the private communication is the person who makes the remarks or series of remarks which the Crown seeks to adduce in evidence. Thus, if a person with a reasonable expectation of privacy, speaking in an electronically intercepted conversation, makes statements which the Crown seeks to use against him he has the protection of this Part."

The reasonable expectation of privacy is the clause that is frequently used to describe the situation where the Crown requires authorization for interception. If there is no reasonable expectation of privacy, the communications cannot be deemed private as per 
the definition and is, therefore, free to obtain without an authorization. If the ruling indicates that there is a reasonable expectation of privacy dealing with the communications, for example standard telephone communications, the Crown requires, by law, an authorization to intercept.

There are many good examples of Canadian case law pertaining to invasion of privacy and interception of private communications. The most recent ruling deals with the Canadian Charter of Rights. In Regina v. Duarte (1990), it was ruled that "surreptitious electronic surveillance constitutes a search or seizure within the meaning of section 8 of the Charter of Rights and Freedoms." Further rulings in reference to invasion of privacy and the charter are expected.

It is clear what authority is required for a law enforcement officer to obtain an authorization for intercept. As the public interest becomes more at the forefront of the rulings, judges have been invoking the right to set terms and conditions to the authorizations. Specifically, the necessity to live monitor an intercept is becoming more commonplace. This condition forces the law enforcement agency to live monitor all intercepted communications and cease the intercept and recording (minimize) in a reasonable length of time if it is determined that the particular communication is being made by an individual not party to the authorization or the communication is not relevant to the ongoing investigation. The annotation from Regina v. Finlay and Grellette (1985) specifically outlines this condition.

"Para. (4)(d) provides that the judge may impose such terms and conditions as he considers advisable in the public interest and this power may and should be resorted to by the authorizing judge to impose a minimization requirement when the circumstances of the interception warrant the imposing of such a term."

In summary, it is clear that there are a set of guidelines that must be adhered to allow the interception of private communications. Part VI of the C.C.C. outlines these guidelines. In these days of public awareness and close scrutiny over the powers of law enforcement court authorizations are becoming quite complicated as well as the supporting affidavit. The facts that must be presented to satisfy the judge s. 185 (1)(c), and the proof that all other investigative procedures have been exhausted, s. 186 (1)(b), are extremely critical items that must be explained in their entirety. If the authorizing 
judge is satisfied, the authorization is granted but, as explained, there may be terms and conditions incorporated to the final document.

\subsection{Possible PCS / PCN Service Providers}

To this point in time there has been a specific decision made for PCN license award in Canada but the United States have not yet awarded licenses to provide PCN services. Yet, it is obvious that law enforcement will probably half to target more than one new communications network so as to provide them with the means to guarantee the ability to intercept all possible forms of private, commercially available, communications. There has been heavy lobbying from numerous industries to obtain these very desirable privileges.

Existing cellular companies are stating that they should be allowed to compete for the ability to provide PCN. In the US, "cellular operators argued that cellular technology can provide PCS." Also it was reiterated in the same article that "cellular already had regulatory approval - Docket 87-390 - to provide innovative services like PCS. "[9] The fact that this statement indicates that cellular companies have the right to investigate PCS seems to defy other lobby groups and industries who categorically are against cellular companies or wireline carriers also obtaining PCS service ownership. Also, indicated in the section outlining whether cellular radio can provide PCN, there are conflicting reports regarding the technical capabilities of digital cellular. Cellular companies are stating that they can easily provide the necessary facilities for PCN. Yet, technically it has been outlined that cellular cannot provide PCN services. The conclusion in this pervious subsection reiterated that the technical limitations inherent in existing analog cellular and even future digital cellular services eliminates the possibility of any simple transition to PCN.

It comes to now who will be competing for the new service. Seemingly it would be logical to give those companies that now have an infrastructure to transport the communications an opportunity at PCS. It would expedite the introduction of PCN to the consumer market and minimize the capital cost outlay and then possibly reducing the cost to the consumer. In this case the cellular industries and more specifically those 
cellular companies that are affiliated to wireline carriers such as Bell Mobility would have access to an existing backbone network. This was brought to the forefront of FCC hearings on PCS by Mr. Craig McCaw, chairman and CEO of McCaw Cellular Communications. He sated that "the commission should recognize that cellular networks can and should provide the wireless infrastructure and highway for new PCS." He continued, " although stand-alone microcellular networks and telepoint type services can provide service in densely populated areas, only the nation's cellular network can provide PCS with a universal reach. The cellular network will provide the connective tissue that allows PCS to live up to the promise - a personal number providing wireless, ubiquitous service."[10]

The prerequisite of having an existing carrier network does not limit it to only cellular or wireline carriers, it also includes the CATV industry. This industry seems, through documentation review, as the one that is striving the hardest to get access to this new lucrative market. Up until this time telephone carriers and CATV carriers have been regulated in such a manner that their service offerings remained distinct and separate. Neither could provide services from the other's market niche. However it is clear that CATV companies are getting into PCS. "Cable powerhouses such as Cox Communications and Time Warner are making well publicized moves, as evidenced this year by the decision of Cox, along with TCI, to acquire Teleport Communications; Cox's high profile breakthrough test of PCS on its San Diego cable system; and Time Warner's building of a state-of-the-art, fiber based cable system in New York City borough of Queens, with the stated intention of offering not just more entertainment channels but likely PCS as well."[11]

In Canada, specifically in the Ottawa Ontario area Cantel completed a well publicized trial of PCN services to select consumers. Rogers/Cantel represents both industries that are vying for the ability to offer PCN. The Rogers portion of this company represents one of the largest CATV companies in Canada. Cantel represents the only private, non-wireline cellular company in Canada. Cantel states that their PCN service will become commercially available specifically in the Ottawa market beginning in the summer on 1993. It was revealed in an article published in the Ottawa Citizen that Communications Minister Perrin Beatty announced that there will be three to five licenses granted for each service area of the country to ensure competition in a market expected to be worth $\$ 3.2$ billion during the first five years. Mr. Beatty also mentioned that his department expects to license national, regional and local applicants 
and that some 85 parties have already filed expressions of interest and have until September 1992 to file formal applications. This means that in comparison to cellular, there will not be two carriers to be concerned with but probably up to five in the major metropolitan areas. These five will not necessarily be five national service providers. It is unknown at this time how many different individual licenses will be granted across Canada for PCN.

In general, there was a statement made to the FCC during PCS hearings by Mr. W. Russel Neuman, author and teacher of communications technology at the Massachusetts Institute of Technology regarding PCS service providers. He told the commission "that independent PCS providers could bring to reality true competition to the LECs. Wireless access to the local loop represents much more than the convenience of a pocket telephone. It represents an opportunity to bring a second revolution to telecommunications regulation, the prospect of an aggressive game plan to establish meaningful competition."[11]

Four PCN licenses were awarded by Communications Canada in March 1994. The four companies awarded these licenses are Rogers Communications, Toronto, Telezone, Toronto, Popfone, Montreal and BCE Mobile also of Toronto.

\subsection{Media Reports On PCN}

The media routinely follow trends in consumer electronics to be able to report to the general public on what is on the horizon and will be available to them. PCN is one of these trends and upcoming technologies that the media has not overlooked. This is not to mention the fact that PCN is currently one of the most popular among topics in the communications industry publications.

However, in regard to those publications commonly available to the public, specifically newspapers, the media has reported on the upcoming release of PCN both in the United States and in Canada. The Washington Post reported, in their business section, on July 16, 1992 that the FCC was considering the licensing of a new telephone technology, PCN. In this article PCN was described as a technology closely similar to cellular. It 
was also mentioned that the companies pursuing the licenses for PCN hope that someday most people will have one of these portable telephones with them at home, in the car and at the office. With a transmitter in every home and business, it is explained, each person could have a single telephone number and the PCN system could send a call to the correct phone no matter where it may be in the network as long as the phone is turned on. This is described as a revolutionary concept; calls would be made to people, not places. This article goes on to further describe general concepts of PCN, what has transpired regarding the FCC awarding over 150 experimental PCN licenses, and the competition or add on service it will introduce to the cellular market.

A cover story in August, 1992 in the nationally circulated USA Today newspaper, PCN is described as the wireless revolution. the article begins by describing a PCN trial ongoing in Pittsburgh. The $\mathbf{5 0 0}$ residents participating in this trial are rapidly seeing the days of phones being tied to a location disappear. The article continues by mentioning the trend in purchasing pocket sized cellular phones and how the market share of these phones sold in the last four years has increased from $7 \%$ of all the sales in the US to $32 \%$ of all the cellular phones sold. They also continue by outlining some of the shortcomings of the cellular industry and how their network, for example, in Los Angeles it cannot handle the volume of users during the peak periods. At this point the article reveals an emerging technology in wireless telephones, PCS, that could steal a considerable amount of the telephone traffic. A comparison is made between cellular offerings and PCN experimental rates. In Orlando Florida, it is reported that PCS service costs consumers $\$ 16$ a month and 15 cents a minute and cellular in the same area would cost $\$ 35$ a month and 35 cents a minute. USA Today states that there are limitations to this new technology, specifically noting that during their tests of a Motorola Silverlink PCS phone there were significant gaps in the call while operating the phone in a car traveling 25 miles per hour. They go on to briefly mention Motorola's proposal for a world wide mobile phone network based on satellite transmissions. USA Today concludes this article by stating that the industry estimates that in the US, that if the FCC licenses PCS technology by 1994, there could be more than 23 million people using PCS phones by the year 1997.

Canadian newspapers have not missed this new trend in electronics. The nationally published Globe and Mail reported in late March, 1992 that the Radio Advisory Board of the federal Department of Communication had adopted a standard for personal communications services. It went on to describe that trials took place to evaluate the 
two competing technologies for PCS. The two were CT3 from L.M. Ericsson Telephone Company and CT2Plus from Northern Telecom. It also mentioned that the Motorola Corporation of Schaumiburg Illinois was in alliance with Northern Telecom and was providing communication hardware adhering to the CT2Plus standard. In the conclusion of the article it was stated that the communication industry agrees that there should be only one standard for PCS and that the Radio Advisory Board unanimously recommended that CT2Plus be adopted for the emerging public PCS systems.

Earlier on January 10, 1992 an article in the business section of the Ottawa Citizen described trials that were beginning from Bell Canada. It was not obvious from the article nor the description of the trials that Bell Canada was testing fundamental principles for PCN. The trials are described as tests of a new concept of a special personalized telephone numbers. The user can pre-program his whereabouts and the Bell network will automatically route the incoming calls associated to the personal number to the location programmed by the user. Nothing more than a slight overview of the trial was offered in the article but it was concluded by stating that the OttawaHull region was chosen for this trail because of the fact that Bell Canada equipment within this region was an advanced digital variety.

Both the Ottawa Citizen and the Hamilton Spectator reported in March 1992 that the Minister of the Department of Cornmunications, Mr. Perrin Beatty, announced at RadioComm 92 the adoption of the standard for the next generation of cordless phones. This standard was CT2Plus. Both of the articles speculate on the possible revenue to be made around the new PCN phone technology. The speculation was that within the first five years after PCN becomes available the consumer market could be valued at $\$ 3.2$ billion. Of this amount $\$ 2$ billion would be in actual hardware sales and $\$ 1.2$ billion in services sold to the consumer. It was estimated that 5 million of these new phones could be in use within the next five years in Canada. Mr. Beatty was quoted as saying that the DOC will grant three to five licenses to different service providers in each service area within Canada to guarantee competition in the market place. Licenses rould be granted to national, regional and local applicants and to date the department had already received 85 applications. Again, both of these articles provide the reader a good insight into this new technology. The Hamilton Spectator dealt mostly with the adoption of the standard but did provide a comparison of costs to the reader. It was stated that the new cordless phone is estimated to be released to the public market with a cost of $\$ 250$ per unit and that the maximum monthly basic service charge would be 
$\$ 40$ compared to $\$ 100$ for existing comparable cellular service. The Ottawa Citizen provided the reader more insight into the phone technology, describing the usable operational range of the phone to be on average 100 meters and that the phone must be within the range of a briefcase sized PCN base station. It further offers details of the Cantel trials of PCN in the Ottawa-Hull area. It is stated that 60 percent of the users of the trial system would use the public cordless service in the future. Cantel was surprised at this high percentage as the trials held in the Ottawa area were very limited. For example only outbound calls were allowed from the PCN phone and only 47 remote base stations were placed throughout the city providing extremely limited coverage. Cantel was quite pleased at the outcome of the trials. Participants said that these phones offered convenience, mobility and freedom. Finally, one key point mentioned in the article was that Canada is approximately 2 years ahead of the United States in PCN. The US FCC is still debating what frequency band should be assigned to these new services.

In a more recent article on April 27, 1993 the Ottawa Citizen again described what was termed as the "Scramble for wireless telephone". In this article the Citizen reports that four companies have been given the right to vi for the lucrative personal communications market. The market value was estimated at $\$ 1$ billion a year. Once more the article provides to the reader a baseline comparison to the now existing and well known cellular telephone market. The biggest feature of PCN is quoted to be the price. The average monthly charge for cellular is currently $\$ 200$ a month. The forecast rate for $\mathrm{PCN}$ is in the order of $\$ 40$ a month. The other cost benefit to PCN compared to cellular is the introductory equipment price. The estimate for PCN varies between $\$ 100$ and $\$ 250$ depending on the features of the phone chosen. When cellular service was instituted the introductory price of the phone was greater than $\$ 1000$. The price has come down substantially since that time but the price of the PCN equipment should be reduced as time goes on as more manufacturers enter the market. The other factor to PCN, as far as the consumer is concerned, is quoted to be the higher quality voice capability inherent in the digital technology.

The other topic addressed in this article and a small side article in the same business section of the Ottawa Citizen deals with the concept of personalized numbering. It is stated that proponents claim that the networks may be the first step toward a totally wireless communications world where consumers get a personal, lifetime phone number at birth and corporations compete to offer local telephone service. It is stated 
in the side article that Stentor, the Canadian alliance of major telephone companies previously known as Teleglobe, has submitted plans for regulations to permit a new service that will allow people to have a single telephone number follow them around. This service is slated to be called "PrimeLine". It is not quite PCN but does introduce somewhat of an advanced intelligent network. The actual subscriber to the service will have to pre-program where to direct their calls during different time periods of the day. The fall back to no answer in this service could be either voice mail or paging or a combination of both. It is basically a manual system compared to the traits of the AIN to be utilized in PCN. However, this service does rely on the fact that a consumer will be issued with one number and that number will follow him as he moves through his normal routines and duties of any given day. The concept of "personalized" numbers is paramount in this wireline based service.

On May 29, 1993 the Edmonton Journal discussed what they term as PCT's, Personal Cordless Telephones. They intervieweci Cairine MacDonald, managing director of EdTel Mobility, who es PCT's as part of an ongoing evolution in telephone communications. The first step, deccribed, will be an enhanced cordless phone with longer range, more privacy and better clarity. This will be followed with the growth of a network of transmitting stations in places where a lot of people gather. Finally, and not likely until the next centuiy, consumers will be able to take their phone to almost any major city and be reached with their home number. again, this article introduces the concept of complete frecdom and mobility through a large radio network providing for enhanced telephone communications through a personal cordless telephone.

No doubt as the time grows nearer to when the PCN service will be available to the consumer thare will be an influx of information presented in the media. Not only will there be reports on this new, revolutionary telephone service, the media should be flooded with advertisements for PCN service from competing service providers. The two competing cellular service providers regularly advertise, offer subscription bonuses and do a lot of marketing to win over perspective clientele. Companies who are competing for the consumer market share of the equipment sales also do a considerable amount of advetising both in the printed media and via other regular avenues such as broadcast radio and television. If the estimates outlined by the Minister of Communications come true or are close, the competition will be great once PCN becomes available. In comparison with the abundance of advertising for cellular service and equipment sales, it would be minimal in comparison to what should be 
expected for PCN. Currently, there are less than one million registered cellular phones within Canada. If the estimates are true and the market for PCN grows to 5 million units in the next five years, consumers will be overwhelmed by PCN and PCN related advertising and marketing.

In summary, once PCN is offered to the public, the media will play a key role in informing the general public on this new service as well as providing the method for the service providers and the equipment retailers to advertise and compete for this lucrative market. Furthermore, with this high profile media coverage, the criminal element will be made aware of PCN communications. As stated previously, if a new technology is released to the market and can be obtained by the criminal element with the belief it would afford some security from interception, it will be purchased immediately. 


\section{CHAPTER 2}

\section{Definitions}

\subsection{Definition of the Problem}

\subsubsection{General}

It is critical to define the scope and complication of the technical problem associated with the interception of communications on personal communications networks. With all the details of the problem defined, possible solutions can be formulated to achieve all the technical requirements of an intercept.

The basis on which the majority of the technical problems relate to the interception of PCN deals with an earlier problem that has been now well defined. The introduction of sophisticated, mobile based radio telephone service called cellular telephone has sensitized law enforcement to the upcoming introduction of PCN communications. It is necessary for law enforcement to take a progressive attitude towards the interception of PCN since experience shows that it is quite difficult for an engineer to retrofit the capability once the service infrastructure is in place and functional.

\subsubsection{Expectations of Security with Emerging Technologies}

It is also a well known fact that the criminal element will always attempt to exploit any device or technology to undermine law enforcement's ability to obtain technical evidence against them and protect themselves against interception. Budgetary constraints are not one of the limitations to criminal organizations, therefore, when a new sirvice, system or device is introduced in the market place, and has any possibility that it tnay give them a technical advantage over law enforcement they $u$ ul obtain such a device no matter what the cost.

Law enforcement is continually coming up against more and more technically sophisticated targets. The procurement of counter intelligence equipment is becoming more prevalent every day and is available off the shelf at so called "spy shops" in the 
United States and Cairada. Again, the price is excessive for the quality of the equipment but it provides some level of technical protection to the criminal that was previously unavailable. Simple devices such as scanning receivers which provide some limited information and intelligence to the criminal are common place and these can be purchased at any Radio Shack. It has been published that over 600,000 scanner are in use by the public in Canada.

In regards to the introduction of new forms of public communications, again the criminal element are the first to buy the new equipment and subscribe to the service. If they believe that this new form of communication will protect them against law enforcement intercepting their conversations and messages you can be sure that they will obtain them quickly. Technologies such as facsimile, cellular telephone and computer modem communications probahlv once afforded the criminal with a level of security against intercept, but now law enforcement has developed the necessary equipment and techniques to intercept these forms of telecommunications and bring them to court as admissible evidence.

The intent of this document is to outline a technical strategy to intercept the new personal communications network while taking into accoul.. the known evidentiary requirements. If acted upon early enough, ideally this approach could be implemented prior to the public introduction of the service. This approach, which does not eliminate other possible technical methods to facilitate the same result, would give law enforcement an immediate method to intercept PCN when the service is brought on line and would then not afford the criminal element any security against eavesdropping because of newly introduced technology.

\subsection{Concept of Personalized Numbers}

Within the existing telephone infrastructure, since the introduction of the telephone, a number was associated with a target location. One person would dial a number anc another phone at a predetermined physical location would ring. The dialing party would expect the individual trying to be reached to be in proximity to the phone at that specific location. The typical routine once the telephone has been answered is that the individual originating the call would request, of the individual answering the phone, to 
speak to the party required. To intercept communications to and from a specified telephone number all law enforcement had to do was find, in the telephone network, a physical appearance of the target line. Once the line had been located and identified a bridging device would be placed on the physical wire, thus performing and intercept. One of the most fundamental changes in the concepts of telephone communications which will be antiquated by personal communications networks is the concept of personalized telephone numbers associated to a specific pair of wires. PCN will introduce the idea of personalized telephone numbers unique to the user not the location of the telephone set.

The central office switching facility is connected to all telephone sets initially through copper wires. Today's communications paths and iransmission media have changed in some locations. The actual type of transmission line utilized may have changed but ultimately there is still a physical connection made between the central office and the target phone. The central office sends a signal down a specific circuit, through the transmission line, which is intended to ring the device terminated on the end of the circuit. The phone on the end of that pair of wires rings. The entire concept of the existing telephone network is built on the basis of communications between two locations outfitted with telephone sets and connected by hardwire.

Personal communications networks (PCN) have introduced an entirely new concept to telephone communications. A tetherless portable telephone provides the end user the mobility to travel anywhere. The actual telephone set no longer requires a physical, electrical connection to the telephone network. A networi of wireless radio base stations are implemented to furnish the radio communications path to the portable phone. In the long term, the radio network should provide seamless coverage no matter where the end user may travel within North America. The advanced intelligent network imbedded into the PCN switching system provides the means to track the portable phone as it moves throughout the wireless system.

PCN eliminates the notion of ringing a phone located at a predetermined location. PCN will ring the phone affiliated to the individual that is being sought no matter where that individual may be geographically located in the network. The actual number dialed by the originator now will relate to the individual trying to be reached rather than the location of the phone, hoping that the party trying to be reached may be there. If that particular individual is not available to take the call at that moment the 
call could be automatically routed to a personal mail box. Then again the originator of the call can leave a message for the destination person, reaching that person indirectly. Placing a call with no answer or having the party not available, try again later scenarios would be eliminated.

In conclusion this personalized number concept inherent to PCN was well synopsized in a press release issued by Northern Telecom, a very aggressive proponent of PCN. It was stated by Mr. R. Schwantes, vice president, product / technology planning, that "Personal communications systems represent the next major advancement in the evolution of the intelligent communications network. There is a substantial demand for portarle communications services which connect people to people, instead of just places to places." [26] It has been thought that if $\mathrm{PCN}$ becomes as popular as surmised, individuals would be issued with an distinct, personal telephone number early after birth that could stay with them for their entire life.

\subsection{System Concepts}

\subsubsection{System Mobility}

As the most primary system attribute for Personal Communications Networks, the concept of personalized numbering and the ability to roam anywhere within the boundaries of the network or even beyond into other networks and automatically receive calls and have the ability to place a call is foremost regardless of location This mobility of the user will further complicate the ability of law enforcement to intercept communications on a PCN. A comment is made in an article published in the IEEE Communications magazine titled "Personal Communications - A Viewpoint".

" A vision of personal communications should embrace the integration of several communications concepts, approaches, or systems into one interconnected and interworking network. This integrated network should support ss.veral different tetherless communications devices optimized for their specific eivironments and should also include wireline communications. The vision of personal communications should include the ability for a person to initiate or receive calls (voice or other information (data, fax etc.) anywhere, at least anywhere within areas having reasonable population densities or along highways interconnecting such areas." [4] 
Bell Northern Research, in their Telesis publication, describes personal Communications:

"The Personal Communications Services environment will provide locationindependent and access-independent services across both wireless and wireline networks. Users will be reachable in all environments at a single directory number via a simple and convenient interface - whether they are at home, in transit, at work, in a public place or pursuing a leisure activity. The database capability of a home location register (HLR) function will enable the system to track the users and direct calls to them wherever they are located in the network. In addition, a PCS server, such as Northern Telecom's mobility manager (internally called the mobility control point), can contain or access the location data in the HLR to provide enhance mobility services to the end user."[12]

Most articles published outlining the inherent differences between existing telephone type communications and $\mathrm{PCN}$ dwell on the concept of personalized identification to the network or it is sometimes referred to as the Personal Telephone Number (PTN). It is eloquently described as follows:

"Simply put, everyone who wants one will have a personal number. So, instead of calling a device designated by that number - such as a telephone or fax - the unique number of an actual person will be called."[13]

The idea of having a unique number associated to an individual marks the most radical change in the concept of telephone communications that will be introduced as a result of PCN. From the beginning of telephone type communications the placing of a call through the telephone network was from a device at a fixed point to another device connected to the network located at another, different, physical location. It was impossible to guarantee that the target individual for the communications would be the person to actually answer the call. PCN will change this fundamental attribute of the telephone network with the introduction of the Advanced Intelligent Network (AIN). This new advanced network is a mandatory requirement to allow the mobility of the portable phone.

"Mobility - the freedom for people to move among locations and remain accessible by the telecommunications network - is a fundamental requirement for the realization of Personal Communications Services (PCS). In a fully deployed PCS network, users will be reached through location and accessindependent personal directory numbers, no matter where in the world they may be. "[14] 
The network has to continually query all phones on the network to maintain an up to date location register. This will allow the network to forward calls destined to tic PCN phone quickly and without undue delay. Without continuous interaction between the PCN phone and the AIN, call connection time would be affected. The radio traffic throughput would be decreased because of the necessity to transmit a paging call to locate the destination device. This situation would be similar to the current operation of the cellular call placement routine.

"The intelligent network or the intelligence connected to such an advanced intelligent network (AIN) is what will drive the future of personal communications. The wireless access is the short link between the pedestrian using the portable and picocell equipment that will connect him or her into the switch and then into the network, or in the office to another extension. "[13] The network architectures will incorporate numerous attributes so that it may provide a wide range of services to the consumer. Those services available over a wireline network are the minimum required so that $\mathrm{PCN}$ service providers can compete for a place in, what is now considered, the local loop market. This corresponds to the services a consumer can subscribe to at his place of residence.

PCN will also try to compete in the Private Branch Exchange (PBX) world. A smart private wireless telephone network can reside in business facilities which could provide an extension to the public PCN network. The PCN telephone sets could be used on the private network while located within the radio coverage of the business network and then roam back on to the public network when moving outside the confines of the work facility. This example would provide further mobility to the PCN user. The telephone set would be universal and mobility expanded to include the work location. In this situation, when the user is on the private network, routine incoming calls for the PCN subscriber could be automatically forwarded to a voice mail system. If the call is considered to be an emergency or the call originated from specific, pre-defined, source the call could be routed through to the user even at work.

The flexibility of the AIN provides countless opportunities for smart call routing. The interconnection to private wireless networks that are designed to adhere to the PCN standards for communication can cover the gaps to provide upwards of 24 hour wireless telephone service to the user any day of the week. Mobility in this sense is seamless and independent of the users' physical location. The user could use his personal PCN 
phone at home, while at work or while on private time anywhere and can provide the ultimate freedom for the future telephone user.

\subsubsection{Comparison of Competing PCN Standards}

To technically develop the ability to intercept communications it is mandatory that the format and all the details surrounding the transmission scheme of the communications be identified. There were numerous different technologies created by different companies competing for the right to be considered a standard and adopted by a service provider for their PCN offering. In some cases the communications standard could be adopted for all PCN communications within a country.

The real goal to those agencies and governing bodies that oversee the adoption of communications standards throughout the world is to overcome a stumbling block now experienced with cellular mobile communications, the non-uniformity of transmission and modulation standards and the uncommon frequency assignments for the same services. Currently, there are at least 6 different incompatible standards for cellular radio in use in different parts of the world. Canada has remained compatible to the standard adopted for the United States, Advanced Mobile Phone System (AMPS), which allows users to freely roam frem one country to the other and maintain communications. It is foreseen that the next generation of cellular phches, which will introduce digital communications to the radio network, will also remain compatible complying to the Electronic Industry Association (EIA ) interim standard IS-54. This standard only applies to North America and at this time at least two other standards have been released for digital cellular.

The first is the standard for western Europe; Groupe Special Mobile ( GSM) which is now referred to as the Global System for Mobile communications. The second is for Japan originally called JDC and now called JDP. It should be noted that the IS-54 standard is an enhancement for the North American analog cellular system. It does not dictate all the recessary details associated to digital cellular communications such that there would be only one form of this communication. North America, has up until now, enjoyed complete interoperability within the analog system and seems to be 
heading towards numerous digital advanced technologies, all of which may be incompatible.

Cordless telephones today are stand alone devices that require only the ability for the handset to communicate to the base station provided with the unit. There is no requirement for that same handset to communicate with anything else. This inherent principle provides rudimentary security for the cordless telephone as it is highly unlikely that another cordless telephone handset could mistakenly or intentionally connect to a base station from another unit. These telephone devices require hardwire connection to the Local Exchange Carrier (LEC) and the PSTN at all times to facilitate access to a telephone network. These types of phones fall into the category of conventional Cordless Telephones (CT).

Technology has improved and provided an increase in the operational usage of wireless telephone services with the introduction of the second generation of cordless telephone, CT1. Europe, specifically Britain, has moved forward $u$ ith the inplementation of telepoint services.

Telepoint or, sometimes referred to as, phone-point service is based on low power digital cordless telephone technology. Specifically, the handsets' transmit power is on average approximately 10 milliwatts. The user of this type of network has to be within the range of fixed base stations. These base stations are typically located in public places such as malls, train stations or airports. Also, there are some randomly located through the downtown core of major metropolitan cities. These telepoints do not provide a seamless radio network. The user, if in an unfamiliar place, would look for a sign or placard which is placed with high visibility and indicates that there is a base sta. 'on in close proximity.

The fundamental difference between telepoint service and the third generation of cordless phone, PCN, is the lack of the seamless network and CT1 does not provide any facility to accommodate inbound telephone calls. CT1 telepoint provides the customer with what is referred to, as a portable pay phone. The security of the CT1 service is established through registration and handshaking procedures between the handset and the remote base station. As in PCN the consumer is provided with a personal base station unit for his residence that connects to the wireline telephone network. In Britain there are now four operators offering the phone-point $\mathrm{cr}$ telepoint 
services. It has been reported, however, that the projected popularity of this service did not transpire. CT1 telepoint has not been a large success in Britain, at least not as expected. These hard limitations to the network capabilities has discouraged consumers. Reports seem to indicate that the consumer market demands services like the ones that will be offered with PCN.

The third generation of cordless telephone should improve the services to the consumer based on the facts about CTI and cellular. It is stated quite clearly in and article from the IEEE Communications magazine.

"In various organizations, a vision of third generation wireless
information networks is coming into focus. The idea is to create
a single network infrastructure that will make it possible for all
people to transfer economically any kind of information between
any desired locations. The new network will merge the separate
first and second generation cellular and cordless services, and
also encompass other means of wireless access such as paging,
dispatch, public safety, and wireless local area networks."[5]

As indicated there are competing standards for the PCN technology not only in North America but across the world. Four primary technologies have been identified for the North American market place. They are CT2Plus, CT3, DECT and CDMA. Table 2.1 , originally published by the IEEE Communications Society in their Communications Magazine, shows the technical differences between the four proposals.

There are numerous distinctions that can be seen between the attributes ot these differing technologies. The most significant can be seen in the practical number of voice channels per $10 \mathrm{MHz}$ of bandwidth. The CT2Plus can only accommodate, on average, 7 while the CDMA can theoretically have approximately 55 voice channels in $20 \mathrm{MHz}$. Practically CDMA can support 39 voice channels in the $1250 \mathrm{kHz}$ bandwidth. The three primary proposals all utilize $32 \mathrm{kbit} / \mathrm{sec}$ ADPCM but the CT2Pius has a maximum data rate of only the $32 \mathrm{kbit} / \mathrm{sec}$ while CT3 and DECT are compatible to the Basic Rate ISDN signaling of $144 \mathrm{kbit} / \mathrm{sec}$. There are many parameters, as indicated in the table, that must be weighed to provide the best choice overall. Once the standard has been chosen, more likely than not, that will be the final say for the particular country. The regulatory commissions are striving to adopt one and only one standard protocol so that a seamless network can be accomplished and no one company will have the monopoly on the technology. 
Table 2.1

Technical Comparison of Competing Standards for PCN

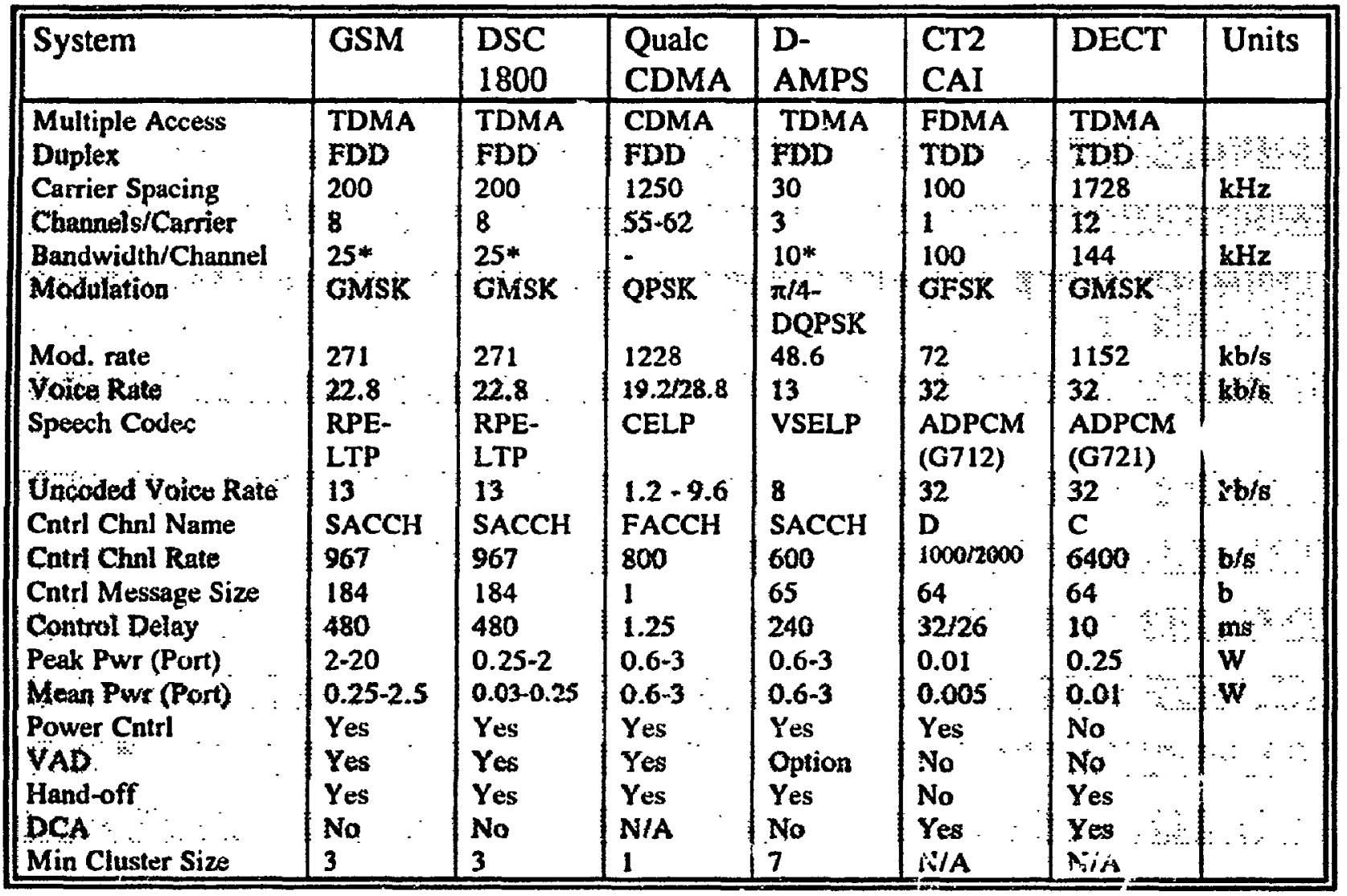

Note: * per duplex channel

VAD is Voice Activity Detection

DCA is Dynamic Channel Allocation

RPE-LTP is Regular Pulse Excited LPC c/w Long Term

Prediction

CELP is Code Excited Linear Prediction

VSELP is Vector Sum Excited Linear Prediction 


\subsubsection{CT2Plus Adoption By The Department Of Communications}

On March 14, 1992 Communications Minister Perrin Beatty announced that CT2Plus, the PCN standard developed by Northern Telecom, had been chosen for the Canadian standard for PCN. At the same point in time the United States had not chosen a standard and, therefore, Canada has set the precedent for future cordless telephone communications.

In October 1992, Draft 0.4 of the CT2Plus Class 2 Specification for the Canadian Common Air Interface for Digital Cordless Telephony, Including Public Access Services was published and is known as Annex 1 to Radio Standard Specification (RSS) 130. This document was developed from the original document identified as I-ETS $\mathbf{3 0 0}$ 131, " Common Air Interface Specification to be used for the Interworking Between Cordless Telephone Apparatus in the Frequency Band 864.1 MHz to 868.1 MHz, Including Public Access Services" dated April 1991. The actual radio standard RSS 130 is entitled "Digital Cordless Telephones in the Band $944-948 \mathrm{MHz}$ " and was published by Communications Canada. Documents also published by the Department of Communications are the following and are referenced within RSS 130:

i) Standard Radio System Plan (SRSP) 508, "Technical Requirements for Digital Cordless Telephone (DCT) Systems Operating in the Band 944 $948 \mathrm{MHz}$

ii) Appendix A to RSS 130, "Specification to the Audio Requirements for CT2Plus Class 2 Digital Cordless telephones In Canada."

iii) Radio Standards Procedure (RSP) 100, "Certification of Radio Equipment."

These standards and procedures comprise the available documentation specifically oriented to PCN in Canada. The DOC has also referenced standards and published international recommendations from CCITT, ISO and AT\&T. All together the industry will have the necessary information to develop equipment that can interact and provide a seamless network with complete roaming capabilities on a national basis. It is expected, through the strict adherence to the CT2Plus standards, equipment purchased by a consumer can work on any of the available competing PCN networks. 


\subsubsection{Cordless Telephones and PCN}

A distinction must be made between existing cordless phone technology and Personal Communications Network hand held communications devices. In appearance to the average consumer the difference probably will not be obvious. This will be especially true when the first $\mathrm{PCN}$ handsets are put onto the market with the ability to purchase it's own private base station unit that can be connected to the existing residential wireline service. As a kit they will appear the same as cordless telephones today. Yet, it has to be made clear that there are many fundamental differences in the actual technologies used in the two divices and differences in the features that both can offer the consumer.

Today's cordless phone technology, referred to as CT provides strictly a wireless hand held telephone handset to the user. This handset must communicate with a radio base station device which in turn must be physically connected to the already exiting conventional wireline telephone network. The technique used to intercept this communications, therefore, is identical to that of a standard, conventional residential telephone circuit. A bridging device is placed directly onto the target telephone line.

Besides paging between it and its base station and having hold, auto dialing features and last number redial, the cordless device does not provide any telephone service beyond what can be subscribed to by the existing wireline service that it is connected to. The range is limited to usually in the order of 200 meters, all dependent on placement of the kit's radio base station unit and it's antenna and the physical obstructions between the handset and the base. The transmission type is typically an analog technology with it's inherent problems in providing high grade audio signals through a band limited channel. It should be noted that some of the more recent cordless telephone sets reaching the consumer market are boasting "900 $\mathrm{MHz}^{\text {" and "all }}$ digital technology". These manufactures were smart in their introduction of the new cordless telephone designs exploiting technologies developed for PCN. For example the Escort 9000 boasts that it is the first consumer phone to use digital spread spectrum technology. It also transmits in the $900 \mathrm{MHz}$ spectrum and has available up to 100 channels in this band. The only drawback to these $900 \mathrm{MHz}$, digital cordless phones is that their price tag is usually 5 to 6 times that of the analog style. The Escort 9000 list price is $\$ 399.00$ US while an analog conventional cordless phone complete with a base 
station unit is typically priced around the $\$ 125.00$ Canadian range dependent on equipment features. This higher price provides no real advantage to the user but a sometimes unappreciable higher quality audio product, protection from interference and a higher level of security. These features are inherent in the digital transmission technology used within a cordless digital phone. The published advertisement for the Escort 9000 again boasts the clearest, most crisp conversations, no third party interference and absolute privacy with total security assured.

Conventional cordless telephones will never propagate into the CT2Plus PCN type market. A PCN handset will always utilize a digital technology in both modulation and transmission types. The PCN handset will, no doubt in it's infancy, be sold on the market complete with a base station unit the same as done now with conventional CT. This base station will again be connected to a conventional wireline system to provide the user with access to the PSTN. However, the fundamental difference is that this PCN phone will have a customized number associated strictly to the owner or user of the device. This number will allow the user to roam outside of the limited radio range of the home base station into the outside world never loosing touch with the telephone network. A new "personal" telephone number will be issued to the user of PCN which this device and the advanced intelligent network supporting PCN will reccgnize. The telephone will be in constant communications with the network allowing it track and route all incoming calls to the user immediately. Wireless access anywhere the user may wish to move without any loss or disruption of service is the ultimate goal of PCN.

Conventional cordless phones were never designed to provide access to a seamless advanced intelligent digital communications network. The technologies inherent in the two types of units are fundamentally differt it with PCN jumping into the fully digital communications realm. PCN is extremely complex but it will provide the consumer with access to a personalized telephone network no matter where he may travel. 


\section{Chapter 3}

\section{Wireline Network for PCN}

\subsection{Intelligent Network Concepts \& General Overview}

It is easy to surmise that there are fundamental concepts that, when put together, will create a Personal Communications Network. Developments underway at this time will be the strategic necessities for the next generation national and international telecommunications networks. As early as 1991, in the telecommunications industry journals, a link between PCN and the Advanced Intelligent Network (AIN) was noted. "It will take the Advanced Intelligent Network to make personal communications truly personal. If ever two telerom concepts were perfectly complementary, AIN and wireless technology are."[15] The AIN will create a significant complication in the ability of law enforcement agencies to perform the interception of private communications through network access.

Bellcore in the United States has identified seven strategic themes for their future development strategy. The two that apply here are their commitment to the development of personal, nomadic communications and information access. "We (Bellcore) will help position the public wireline networks to be the networks of choice for providers of PCS, through the work on interface specifications, access services, SS7 interconnection and inter working among CCS, AIN, ISDN and PCS operations systems. "[16] As a second strategic development plan Bellcore commits to "Advanced voice and messaging services to realize the full potential of the Advanced Intelligent Network (AIN). Beginning from the near term drivers such as PCS and fax services, Bellcore is developing tools and contributing to standards for interfaces that will, for instance, enable service creation by customers and by selected third parties."[16] Bellcore is not the only company or industry looking forward with the realization that IN and IIN will be the mandatory network concepts of the future and that they hold the necessary attributes to achieve the long term goal of complete personal wireless telephone communications. 
There are numerous technological hurdles to be overcome to approach the realization of an actual Advanced Intelligent Network. Many industry guidelines and standards have been drafted with the intent to provide ultimately a global ability for interconnection of wireless telephone communications. Further to this, there are new concepts being formulated with the introduction of AIN's that change the users' fundamental operation of the telephone network. Inherent in the basic conceptual attributes of an AIN is the ability to contact the target individual no matter where he or she may be located. One of the basic requirements to allow this attribute to become a realization is the concept of a unique telephone number for each individual. It will be necessary to show no geographical or physical boundaries to the communications path. Presently, people have business numbers, residential numbers, car phone numbers, voice mail numbers and possibly many more. All these numbers are for one purpose, to contact one individual. One unique number and an Intelligent Network infrastructure behind the communications can provide the ability to contact any individual, seemingly wherever they may be physically located. This fact further complicates communications intercept techniques as no longer are there telephone numbers associated to geographical locations. The ability to roam and accept calls independent of physical location introduces a technical complexity that must be overcome before any technical guarantee can be achieved in the technique for interception of the communications to and from the named target only.

Figure 3A shows a conceptual diagram for a PCS Environment. The key issue to be realized in this diagram is the ability to roam from private networks into public networks and into the residential environment. The network shows no boundaries. The consumer, in this diagram, can wander between t.seir work place to a shopping mall and to home using the same wireless handset. Once the user has gone into their vehicle their cellular phone becomes the active telephone terminal. Further to this, if the user roams out of radio coverage for their wireless handset the call management features will reroute calls to a paging system to alert the consumer.

The International Consultative Committee for Telephone and Telegraph (CCITT) developed an early standards document outlining attributes of an IN. This document provides a minimum standard on which to design by and is referred to as IN CS-1. IN CS-1 was the first standardized stage of IN development and the beginning of the evolution of IN and AIN. IN CS -1 is based on the technology base and ability at the 


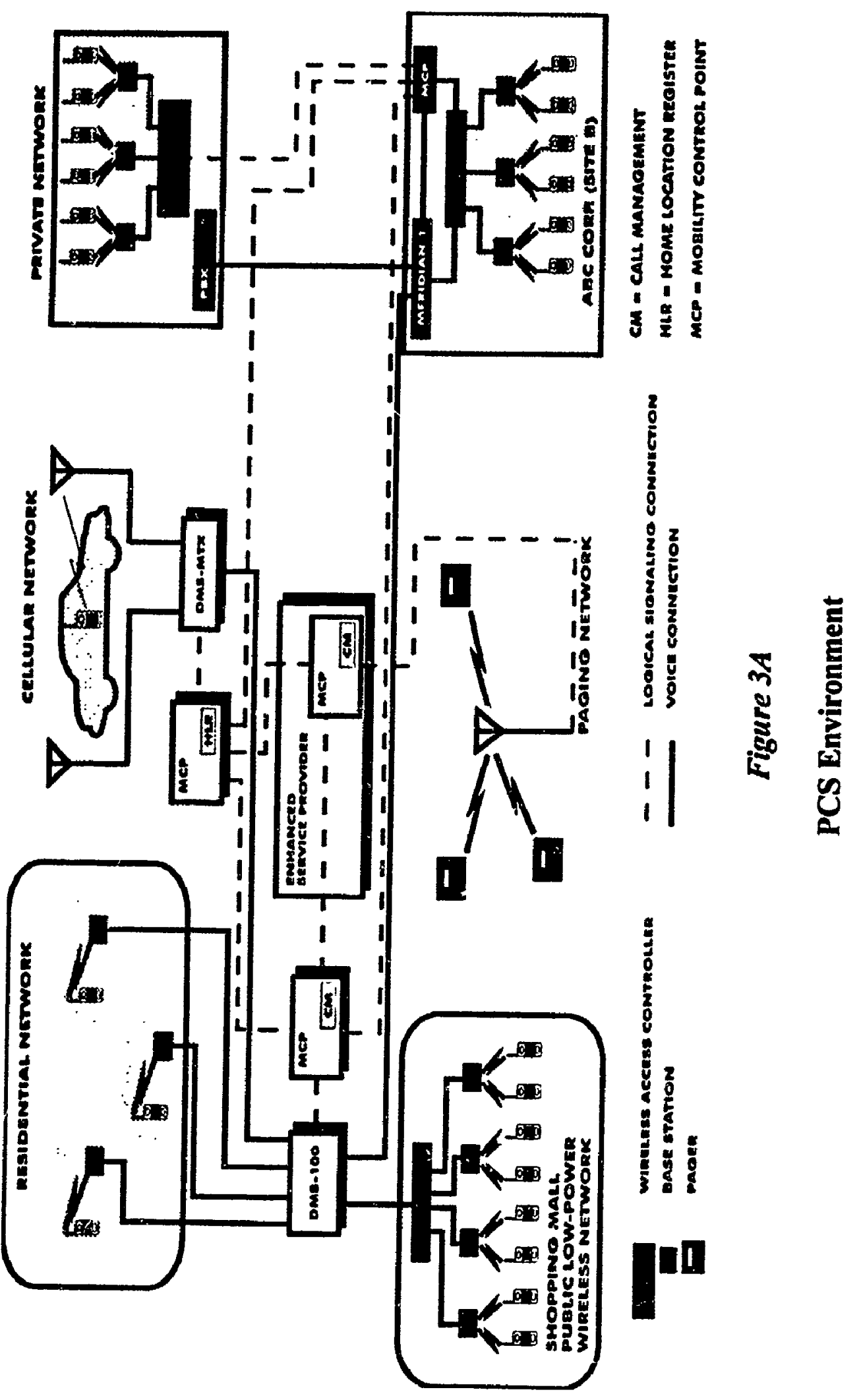


time of the publishing of the standard and the evolutionary requirements to enhance its abilities. It defines capabilities of direct use to both manufacturers and network operators in support of circuit switched voice and data services either already defined in the process of being defined by CCITT.

As far as intelligent networking is concerned, it is accepted in the telecommunications industry that the PCN is the lead IN or AIN service. It will he the first public communication system offering that will require the diversity and functionality available in an IN. Without this backbone network PCN will simply not work. The goal of fully mobile tetherless hand held telephone communications that will include both inbound and outbound call routing needs an Intelligent Network.

Figure 3B is presented in an article published in the February 1992 issue of the IEEE Communications Magazine called "Intelligent Network Requirements for Personal Communications Services".[27] This diagram is presented as the fundamental intelligent network overview. It defines two distinct layers, the service layer and the physical layer. It is further divided into two other basic subsystems, the real time service execution layer and the non-real time functionality layer. The real time layer components are those elements that have the responsibility for the real time execution and control of the PCN subscriber services.

The three real time procsssing components of this model are the Service Control Point (SCP), the Service Switching Point (SSP) and the Intelligent Peripheral (IP). The SSP capabilities are defined in terms of trigger check points (TCP) and the SCP and IP capabilities are defined in terms of functional entity actions (FEA). The "call model" for PCN is the basis for the actions of the IN. The "call model" is the link between the service layer and the user layer in the IN architecture. It will convey to the service layer from the user layer such user requests as off hook and dialed digits. The TCP's are one half of every action in the call model. The other half is called the Points In Call (PIC). The PIC's are the active operations performed by the switch for every call and the TCP's are the completion of these operations. For example some TCP's are disconnect, answer and feature requested.

In the progress of the definitions of the AIN feature architecture Table 3.1 shows the progress f.um Bellcore's AIN specification release 0.1 to the CCITT CS-1 specification to the Bellcore AIN release 1. In the original release from Bellcore there were 5 


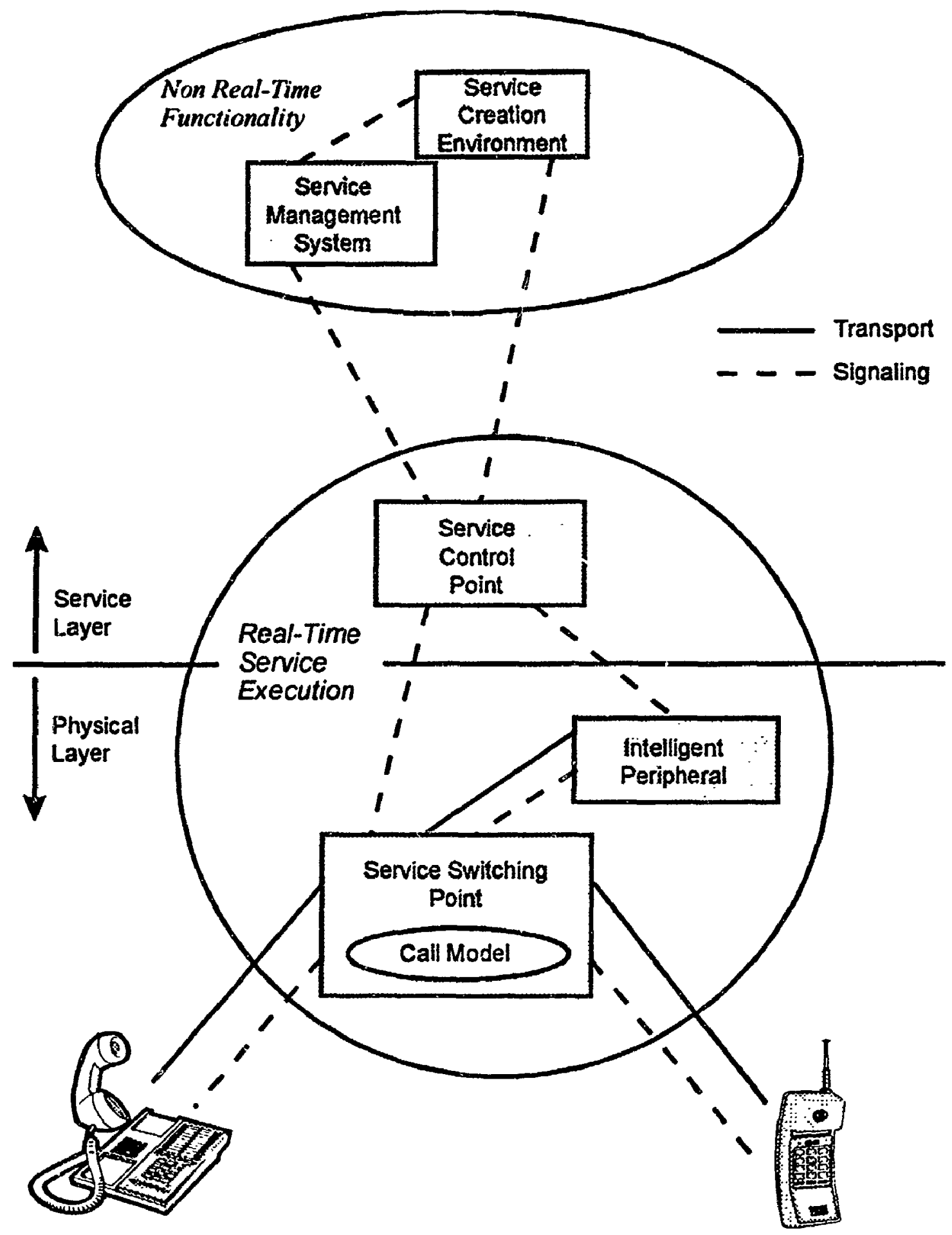

Figure $3 B$

Intelligent Network Overview 


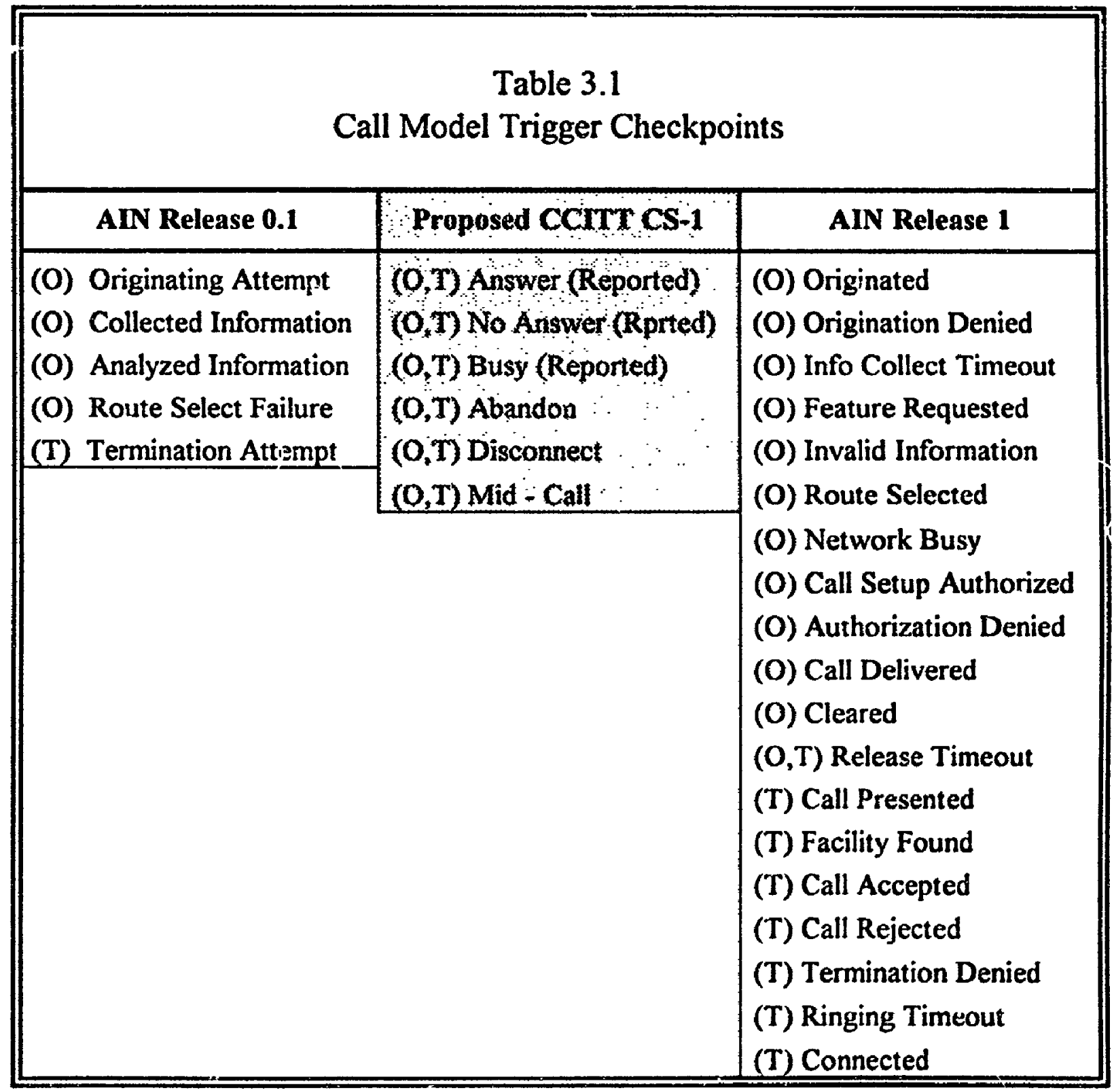

Note : (0) - Originating Call Model

(T) - Terminating Call Model 
simple trigger control points defined. Four of the TCP's were associated to the originating call model and one was for the terminating call model. In hindsight it was obvious that this set of functional controls were too few to handle all the complicated calling scenarios envisioned in an AIN.

The CCITT furthered the list to six. Each of the six trigger control points applies to both the originating call model and the terminating call model. In essence there are twelve control functions defined by the CCITT. With the CCITT model developed in the in the early 1990's and with this provision of an initial set of IN capabilities Bellcore carried on and released their AIN Release 1, Generic Requirements in May 1991.

The future will no doubt see many iterations and changes in the development of IN and AIN standards. Hopefully, the expected demand for PCN services will drive the developers of the networks to further enhance and provide features and benefits to the consumers that cannot be realized today with the conventional telephone infrastructure. Nevertheless, each and every iteraiion of IN development could possibly introduce further technical hurdles for law enforcement to overcome to maintain their ability to intercept communications through the network

\subsection{Service Features With the Introduction of AIN}

The deployment of the Advanced Intelligent Network will offer great versatility and promise to both the providers and the users of switched circuit voice and data networks. Users will have access to a broad range of features including some that were unavailable untii the introduction of the new networking. Some of these features will be enhanced 800 service, credit card billing and, the primary one, intelligent call routing. Providers will receive one fundamental benefit. They will have the ability to provide different features from their competition allowing them to draw a larger market share to them. AIN's basic architectural design provides for the ability to add services to the network easily and, therefore, provide new products for the customer base. However, this same basic architectural design does not accommodate any functionality for the interception of communications on the network. 
It has been stated that PCN will be the market driver for the implementation of AIN. In that context Table 3.2 shows a list of end user feature requirements for PCN and, therefore, the AIN. A description of each feature listed in the tabic follows.

When a subscriber would request to the service provider for an additional feature the provider would have to depend on their own implementation and provisioning of their AIN. If the AIN has not been installed with full functionality it may be extremely difficult to manage or provide for the management of a network that was ultimately designed to be extremely dynamic. In some cases the user would actually be able to program a feature on or off by use of their own phone and signaling their request when they desire the change in their service profile.

When a subscriber's request is received a carrier would have to modify the user's personal service profile in a service control point (SCP). They would then activate the appropriate triggers within the switch and possibly provision for ani intelligent peripheral. For the carriers to provide a reasonable level of customer service they would have to be able to query these profile records and interact with the customer when information is requested.

To be able to keep up to market demand for new features and their competition the AIN service providers must be able to add and support new and increasingly complex services and features quickly and effectively. The AIN has provisioned for Service Control Points specifically for the purpose of providing the carriers with the ability to add new services without waiting for the actual switch manufacturer to implement them. The fact that both the main network designers and the carrier can introduce new features in the AIN indicates that there may not be a single, fundamental intercept solution for AIN. Depending on the features in the AIN and, therefore, the possible unique network operational software, the intercept feature may have to be versatile enough to take into account a differing subscriber feature ability. 


\begin{tabular}{|c|c|c|c|c|}
\hline \multicolumn{5}{|c|}{$\begin{array}{c}\text { Table } 3.2 \\
\text { PCN End User Feature Requirements }\end{array}$} \\
\hline Clesses & Number & End User Requirement & New & Exist \\
\hline \multirow{10}{*}{$\begin{array}{l}\text { Incoming } \\
\text { Call } \\
\text { Handling }\end{array}$} & 1 & Network Access (Terminal) Registration & $\bullet$ & \\
\hline & 2 & Enhanced Telephony Features Portability & $\bullet$ & $\bullet$ \\
\hline & 3 & Call Direction - Pre specified Parameters & & $\bullet$ \\
\hline & 4 & Call Direction - Calling Party Interaction & & $\bullet$ \\
\hline & 5 & Call Direction - Called Party Interaction & & $\bullet$ \\
\hline & 6 & Remote Call Answer (pre specified terminal) & $\bullet$ & \\
\hline & 7 & Remote Call Pickup (dynamic) & $\bullet$ & \\
\hline & 8 & Billing For Relocation Leg & $\bullet$ & \\
\hline & 9 & Distinct Ringing for Temporary PN & $\bullet$ & \\
\hline & 10 & PN to PN Call Transfer & $\bullet$ & \\
\hline \multirow{3}{*}{$\begin{array}{l}\text { Outgoing } \\
\text { Call } \\
\text { Handling } \\
\end{array}$} & 11 & Network Access (Terminal) Registration & $\bullet$ & \\
\hline & 12 & Enhanced Telephony Features Portability & - & $\bullet$ \\
\hline & 13 & Call Importance Marking & & $\bullet$ \\
\hline \multirow{2}{*}{$\begin{array}{l}\text { Mid-Call } \\
\text { Handling } \\
\end{array}$} & 14 & Inter Domain Hand-off & - & \\
\hline & 15 & Billing Negotiation \& Changes & & $\bullet$ \\
\hline \multirow{2}{*}{$\begin{array}{l}\text { Profile } \\
\text { Control }\end{array}$} & 16 & Profile Status Interrogation & & $\bullet$ \\
\hline & 17 & Profile Modification & & $\bullet$ \\
\hline
\end{tabular}

Description of Features:

1. Register the location of a PN to receive calls. This will usually be to a specific terminal with a known physical address or to the domain of an access network.

2. Within the limitations of the subtending access network and terminal device, maintain the use of a common set of enhanced telephony features on incoming calls.

3. Route the call according to parameters such as calling number and time of day previously set by the PCN subscriber. 
4. Route the call according to pre specified parameters working in conjunction with a PCN user's Personal Communications Agent interacting with the calling party.

5. Alert and refer the call to the called party via signaling connection to obtain routing instructions. In its simplest form this may just involve calling number delivery.

6. Separation of alerting and connection. Alerting is to one physical device such as a pager and connection is to another device such as a portable handset.

7. As in number 6 but the user dynamically specifies the physical connection device usually via dial in programmability. This may require the "please wait" message to the calling party.

8. As a default the called party is billed for the addition'al connection leg from a base location. An enhanced version may involve negotiation with either party.

9. Delivery of a distinctive alerting pattern for a call routed to a PCN user registered at a terminal which is shared or owned by another PCN subscriber.

10. Several scenarios and uses exist within this feature. One is for every user owning several PN's to map a profile (directives) associated with one to another.

11. Register the location of a PN, usually against a specific terminal whose physical address is known to the network, to originate calls. This is necessary for billing purposes.

12. Within the limitations of the subtending access network and terminal device, maintain use of a common set of enhanced telephony features on outgoing calls.

13. Mark a call with the attributes such as "urgent" so that the called party's call direction routines have more information on which to make routing and alerting decisions.

14. Dynamic hand-off of an in progress call as the user moves from one mobility island to another. Intra-island hand-offs are assumed to be transparent to the core network.

15. Called and/or calling party intervention and negotiation during the course of a call to modify default billing arrangements. 
16. Ability of a PCN user to query the settings and status of his PCN personal profile. (e.g. number of times a specific feature was used)

17. Ability of a PCN user to modify the settings of his ow'u PCN profile including such settings as call direction routines for certain PN's.

\subsection{CCITT IN Concepts}

The International Consultative Committee for Telephone and Telegraph (CCITT) has proposed objectives for the standardization for the framework for In elligent Network (IN) technology worldwide and a set of recommendations towards the development and future evolution of IN. In the period ending in 1992 the CCITT Study Groups XI and XVIII completed the first stage of IN standardization research. This research led to formal recommendations on IN referred to as CS - 1 where CS stands for capability set. The recommendations were to provide target objectives, guidelines and concepts in the design, development and evolution of Intelligent Networks throughout the world but, again, do not address the international requirement for law enforcement to intercept communications being routed through an Intelligent Network.

The CCITT work and research into IN technology had the goal to define a new architectural concept that meets the needs of telecommunications service providers to "rapidly, cost effectively, and differentially satisfy their existing and potential market needs for services" and to "improve the quality and reduce the cost of network service operations and management."

The CCITT provided the following objectives for the new IN architectural concept:

- IN should be applicable to all telecommunications networks e.g. public switched telephone networks, including ISDN networks both narrowband and broadband, packet switched public data networks and mobile networks,

- IN should enable service providers to define their own services, independent of service specific developments by equipment suppliers, 
- IN should enable network operators to allocate functionality and resources within their networks and efficiently manage their networks, independent of network specific developments by equipment suppliers,

- IN should be introduced starting from the existing networks and current CCITT Recommendations,

- In should evolve to reflect the implementation experiences, new technological opportunities, and market evolution.

The CCITT has structured their recommendations with a phased implementation method with each phase leading to the goal of the target IN architecture and functionality. Within each of the structured implementation phases the CCITT intends to provide a set of IN capabilities. Each of these capability sets (CS) is intended to address requirements within on: or more of the following areas:

- service creation

- service management

- service processing

- network interworking.

The CCITT developed as the principle reference model, the IN Conceptual Model. This is shown in Figure 3C. This conceptual model is divided into four distinct areas, the service plane, the global functional plane, the distributed functional plane and the physical plane.

The service plane primarily defines service features from a user perspective independent of how they are technically implemented within the IN. This layer is of interest to the service providers and users.

The global plane describes what is termed as, service independent building blocks (SIBs) which are units of the service functionality. SIBs are technically independent of how the functionality is distributed through the network. However, SIBs can be combined with global service logic on the global functional plane to realize services and service features on the previous level, the service plane. There are 14 SIB's defined for IN CS-1. They are algorithm, charge, compare, distribution, limit, log call information, queue, screen, service data management, status notification, translate, user inieraction, verify and basic call process. 
The distributed functional plane describes the functional architecture of an IN structured network in terms of units of network functionality defined as "functional entities". This layer is of primary interest to network designers and providers. The functional entities on this plane interact with information flo'ving between them in "relationships". The functional entities and relationships are described independently of how the functionality is physically implemented or deployed in the IN. SIBs on the global functional plane are realized on the distributed functional plane by a sequence of functional entity actions and resulting information flows.

Finally, the physical plane of the IN conceptual model describes the physical architecture alternatives for an IN structured network in terms of potential physical systems in a network and interfaces between physical entities. This plane is of interest to the network operators and the equipment providers for the IN. One or more functional entities from the distributed functional plane may be realized in a physical entity on the physical plane, and one or more relationships from the distributed functional plane may map into an interface on the physical plane.

The CCITT IN conceptual model was defined in such a manner so that it could theoretically be implementou in a top down approach or bottom up approach. The bottom up method would focus on the capabilities of an existing network and how the functionality could be brought forward and evolve into an IN architecture. The top down would lead the network designer from the defined IN CS-1 services and service features, continue to a set of IN requirements and capabilities and then confirm that the functional and physical layers of the network could support these features.

The CCITT have defined, as part of their CS-1 publication, a target set of service drivers including Freephone, universal personal telecommunications (UPT) and virtual private network (VPT). The definition emphasizes capabilities that provide for flexible routing, charging and user interaction. However, the CS-1 specification basically addressed a target set of services that apply only during the set up or release phases of is connected through the network.

These type of services are referred to as "single ended" as they apply to only the beginning or the end of a cali transaction. It has been stated that the CCITT defined only the "single ended" services through the CS-1 specification to limit the operational, implementation and control complexity of the network at this point of the IN evolution. 
IN CS-1 focuses on the service processing requirements for the network. It also takes into account a minimal set of network interworking requirements in support of the service features defined by the specification. It does not address requirements for service creation, service or network management. It is expected that the network designers will create solutions to these requirements as part of their IN design process. Yet, the design will be based on the fundamental layers and service functionality that the CCITT has put forth in the CS-1 specification. The specification does not apply to the active phase of the call while the call.

This leads to the physical plane architecture design that the CCITT has defined as the basis for IN design. Figure 3D shows the CCITT CS-1 physical plane architecture. The emphasis in this architecture is based on call modeling in the service switching function and call control function and on the relationships and interactions between the service control function and the service switching function, the service data function and the special resource function.

The IN CS-1 physical architecture shown in Figure 3D describes how the functional entities and relationships in the functional archilecture translate into physi: al entities and interfaces. The physical entities in the architecture model are set forth in such a manner as to allow equipment designers freedom in their development based on the mapping of functional entities and the standard interfaces for IN CS-1. There was not intent to preclude any physical entity alternative. For example an early implementation of an intelligent network may only include a service switching point and a service conirol point or adjunct. This may be further extended with the use of an intelligent peripheral or service node. The interfaces for IN CS-1 use already existing lower layer prutocols such as SS7, ISDN basic rate or primary rate to carry the application layer protocol messages needed to support the goa! IN services. Therefore, the CCITT has continued the basic principal of standardization through to the application layer protocol. This layer protocol is referred to as the IN Application Protocol (INAP). The INAP is based on the Open Systems Interconnection (OSI) model Application Layer Structure. This again shows the principal of adhering to recognized standards and utilizing the OSI model into the INAP will maximize the flexibility in mapping the functional entities to physical entities on the physical plane of the IN conceptual model. 

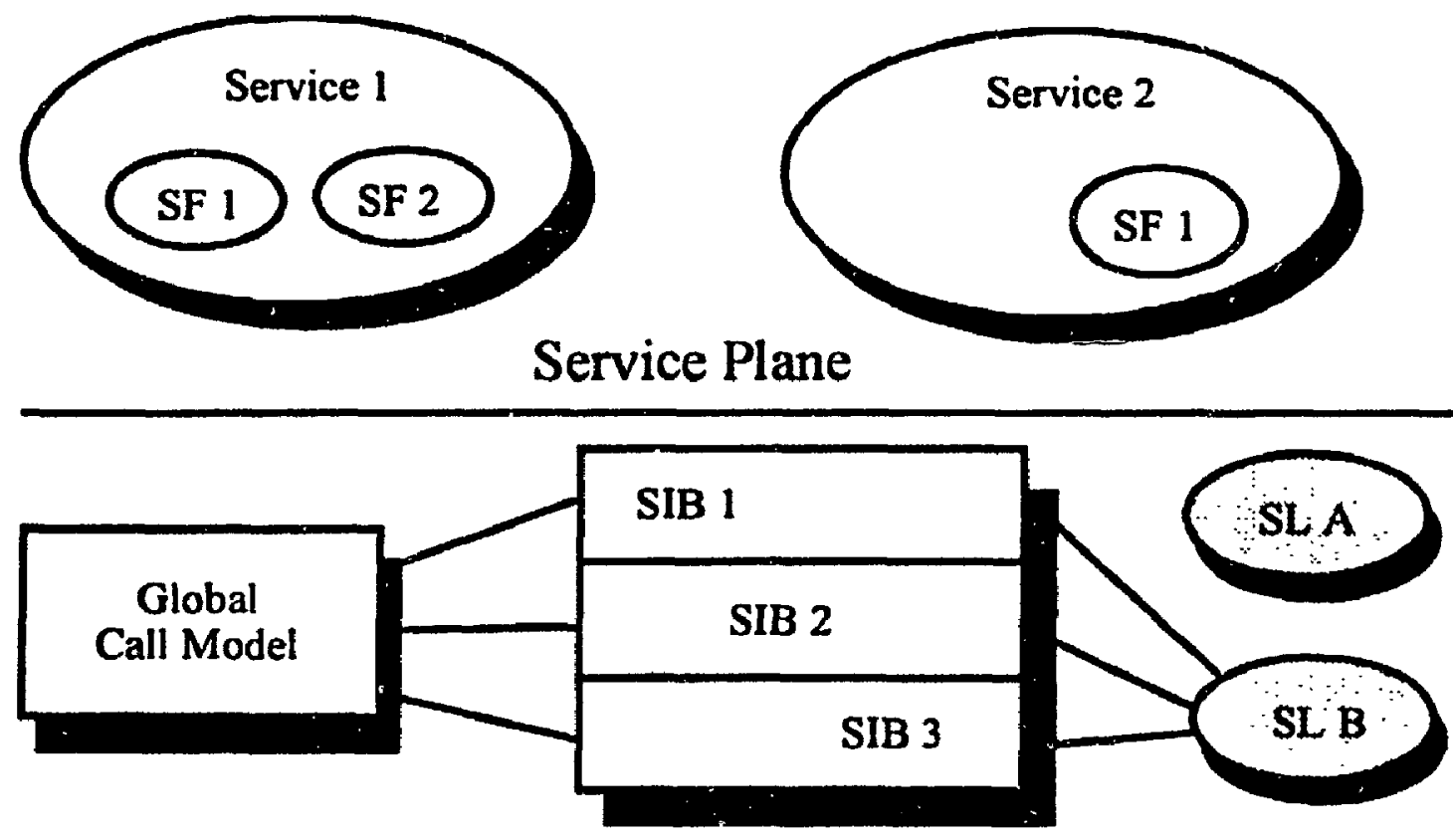

Global Functional Plane
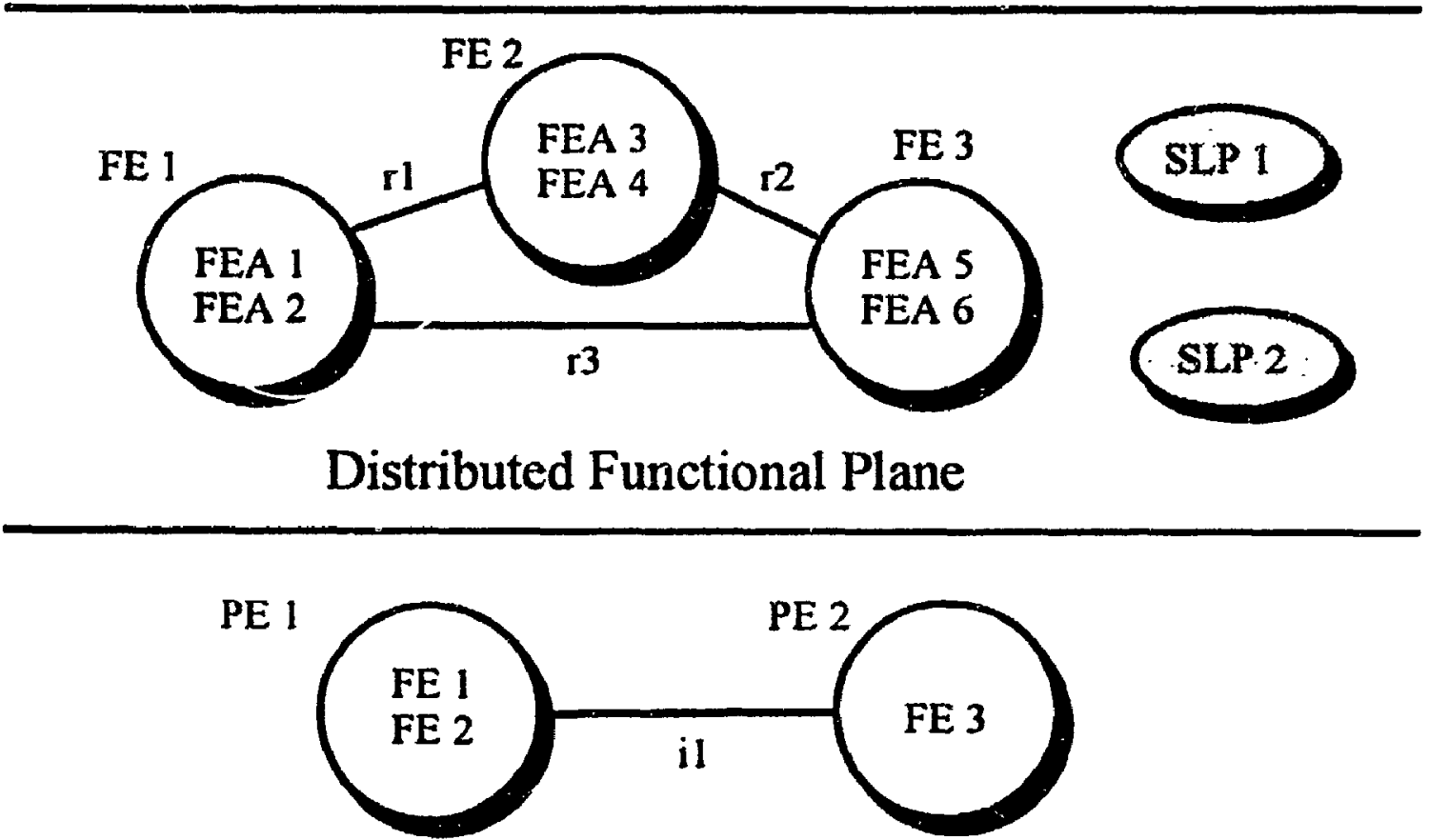

Physical Plane

SF Service Feature

SIB Service Independent Building Block

SL Service Logic

SLP Service Logic Program

FE Functional Entity

FEA EE Action

PE Physical Entity
iN Interface $N$

r $N$ Relationship $N$

\section{Figure $3 C$ \\ IN Conceptual Model}




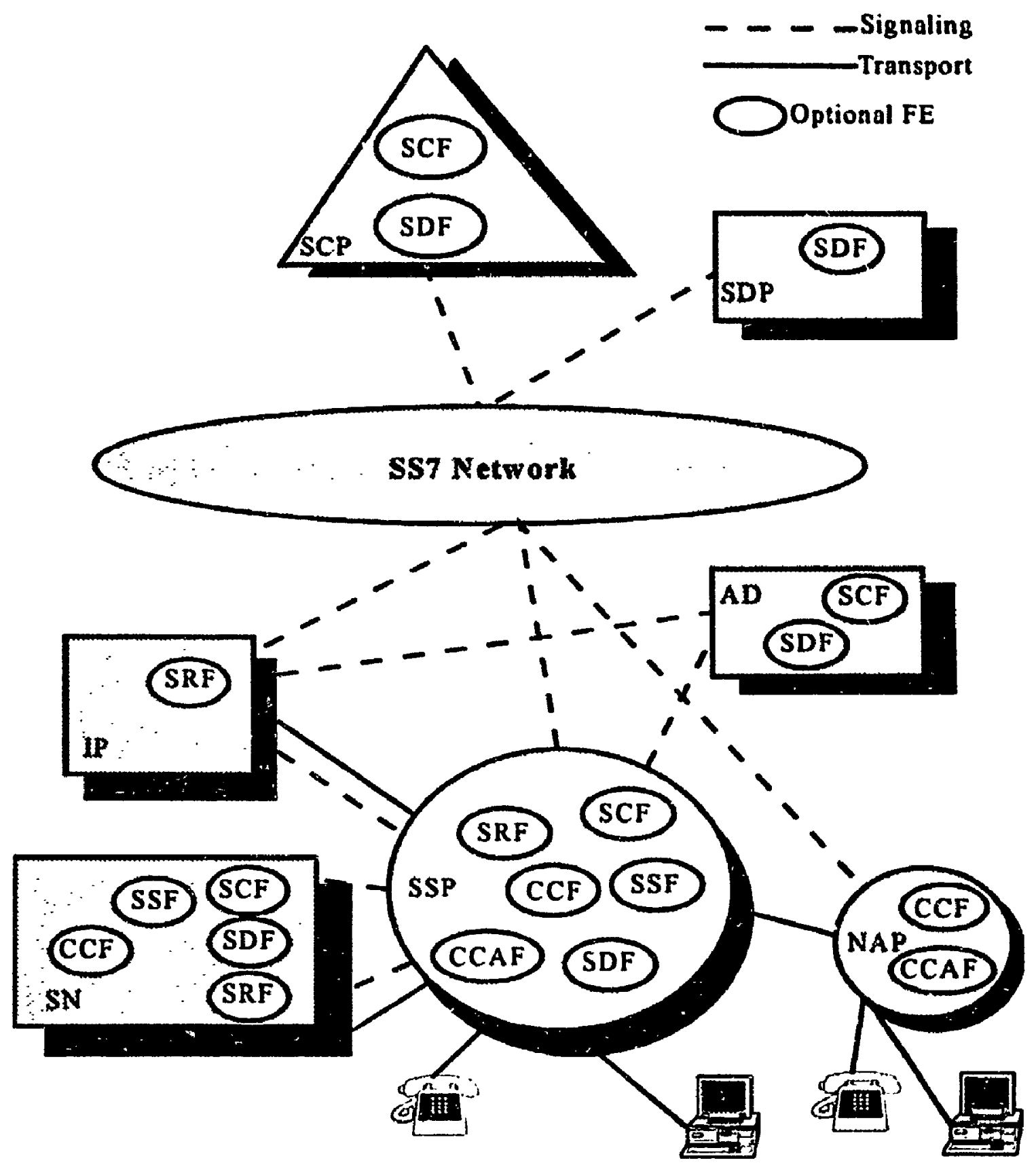

Figure 3D

IN CS-1 Physical Plane Architecture

\begin{tabular}{llll}
\multicolumn{5}{c}{ Glossary for Figure 3D } \\
Physical Entities (PE's) & Functional Entities (FE's) \\
AD & adjunct & CCF & call control function \\
IP & intelligent peripheral & CCAF & call control agent function \\
NAP & network access point & SCF & service control fi rction \\
SCP & service control point & SDF & service dus. . \\
SDP & service data point & SRF & special resource function \\
SN & services node & SSF & service switching function \\
SSP & service switching point & &
\end{tabular}


The CCITT has shown a proactive, aggressive effort to provide enough detail in their IN framework standards to ensure a fundamental similarity amongst all Intelligent Networks throughout the world. Yet, they have not been so strict as to hamper the imaginative, creative minds of the network designers allowing them many freedoms in their design work. Adhering to the CCITT IN CS-1 building block as a standard for an IN design will guarantee adherence to numerous other internation:ally recognized communications standards such as the OSI model and SS7. The attempt, at this early stage of this advancing technology may ensure that there are not islands of sophisticated, state of the art telecommunications iut an international ability to roam free from the burden of the inability to interoperate. This could provide a benefit to law enforcement as the fundamental building blocks to the network may be universal. However, no matter how common the elements of the IN are, there has been no consideration for the provision for intercept of communications. This functionality block would have to be added to an existing architecture and, because there has been no initial provision for it, impletientation will probably be very difficult.

\subsection{Bellcore Standards for AIN}

One of the leaders in the development of new, innovative telephone communications technologies has always been Bellcore. This statement holds true in the development of Advanced Intelligent Networks and associated technologies. Bellcore has an ongoing program to develop standards addressing the introduction and evolution of Intelligent Networks and Advanced Intelligent Networks in local exchange carrier networks throughout the United States and within any of their international client networks. The goals and objectives of Bellcore within their AIN strategies are in line with those strategies defined by the CCITT in CS-1 IN standard. Bellcore has adopted a phased approach to the release of AIN functional standards. In each subsequent release of AIN standard Bellcore hopes to introduce additional marketable features to the network in a realistic time frame. Yet, as in the international CS-1 set of standards, the ability to get the communications out of the network for a legally authorized intercept has not been considered. Hopefully the phased approach of the Bellcore standard does not preclude the introduction of an intercept feature. 
It is reported that AIN release $1 \mathrm{i}$ - - iewed as Bellcore's target AIN architecture for the delivery of circuit switched voice and data services. Bellcore is apparently concurrently working on the definition of AIN specification releases leading towards the goal of release 1 . They are also developing refinements to release 1 . the integration of other technologies and platforms for future release beyond release 1 and on the long term architectural principals for the ultimate evolution of AIN. Bellcore released AIN 0.1 which is a subset of release 1 and builds on existing IN implementations and represents the AIN release that should be available in the 1993 - 1994 time frame. Bellcore is preparing another release of generic requirements, release 0.2 , which represents to Bellcore the AIN release expected to be available in the 1995 - 1996 time frame.

AIN release 0.1 and 0.2 are both apparently closely aligned with the CCITT IN CS-1 standard document. Both 0.1 and 0.2 support circuit switched voice and data services emphasizing the flexibility of routing through the network, the ability to have differing call charging schemes and providing user interaction on two party alls. However, Bellcore's goal with both the 0.1 and 0.2 releases are to be able to support these networking features through existing switch based network infrastructures. It is obvious that the intent of releases 0.1 and 0.2 is not to introduce all the AIN features at once but to logically and methodically introduce added features that can be effectively realized in the given time frames. AIN release 1 will introduce service capabilities during active calls and extend the network abilities beyond 0.1 and 0.2 . AIN release 0.1 focuses on the service processing requirements of the overall concept and $h_{2}$ s minimal network interworking requirements for the identified services. However, release 0.1 does sumass IN CS-1 in that it also addresses service management and network management requirements in support of the features that are introduced. Release 0.2 adds to this in all aspects of the AIN but, as with CS-1, does not address the requirements associated to service creation.

The "Initial Release of AIN Release 1, Generic 'zequirements" was puolished in May 1991. It was preceded by Bellcore document "Advanced Intelligent Network Release 1 Baseline Architecture" (NPL-001555) published in March 1990 and "Advanced Intelligent Network Release 1 Network and Operations Plan" (SR-NPL-001623) published in June 1990. Within AIN Release 1 are the following set of generic requirements documents: 
1) Advanced Intelligent Network (AIN) Release 1 Switching Systems Generic Requirements (TA-NWT-001123)

2) Advanceu Intelligeat Network (AIN) Release 1 Service Logic Execution Environment Generic Requirements (TA-NWT-001124)

3) Advanced Intelligent Network (AIN) Release 1 Service Control Point (SCP) Generic Requirements (TA-NWT-00125)

4) Advanced Intelligent Network (AIN) Release 1 Switch - Service Control Point (SCP)/Adjunct Application Protocol Interface Generic Requirenents (TA-NWT-001126)

5) Advanced Intelligent Network (AIN) Release 1 Logical Data Model (LDM) Generic Requirements (TA-NWT-001182)

6) Advanced Intelligent Network (AIN) Release 1 Service Logic Program Framework Generic Requirements (FA-NWT-001132)

Quoted directly from the introductory text of the Release 1 document is that "AIN is an evolving, service independent architecture that will allow telecommunications services to be expeditiously created of modified. AIN Release 1, which Bellcore understands is targeted for deployment in the 1993 time frame, supports the delivery of circuitswitched voice and circuit-switched data services to network subscribers." The Bellcore AIN Release I Architecture is shown in Figure 3E.

Further to this Bellcore initially indicates their assumptions. It is necessary for the imbedded switching network that will support the AIN to use Common Channel Signaling (CCS) adhering to the Signaling System Number 7 (SS7) protocol form. The AIN Release $i$ will add to the existing infrastructure a service control architecture that is engaged during call processing when a designated condition is encountered where a certain, pre-defined event occurs and the conditions associated to this event are satisfied.

The two issues addressed within the Bellcore specification that are of interest here are the definitions of Service Control Points (SCP), the service layer control logic model that interacts with the physical layer portions of the AIN. Also, the AIN Release 1 physical architecture concept is defined. Included in the overall specification is the cross reference to TA-NWT-001125, AIN Release 1 Service Control Point Generic requirements. An SCP in this Bellcore document is defined as a "network system that executes customized service logic to furnish an AIN Switch Capable Switch with 


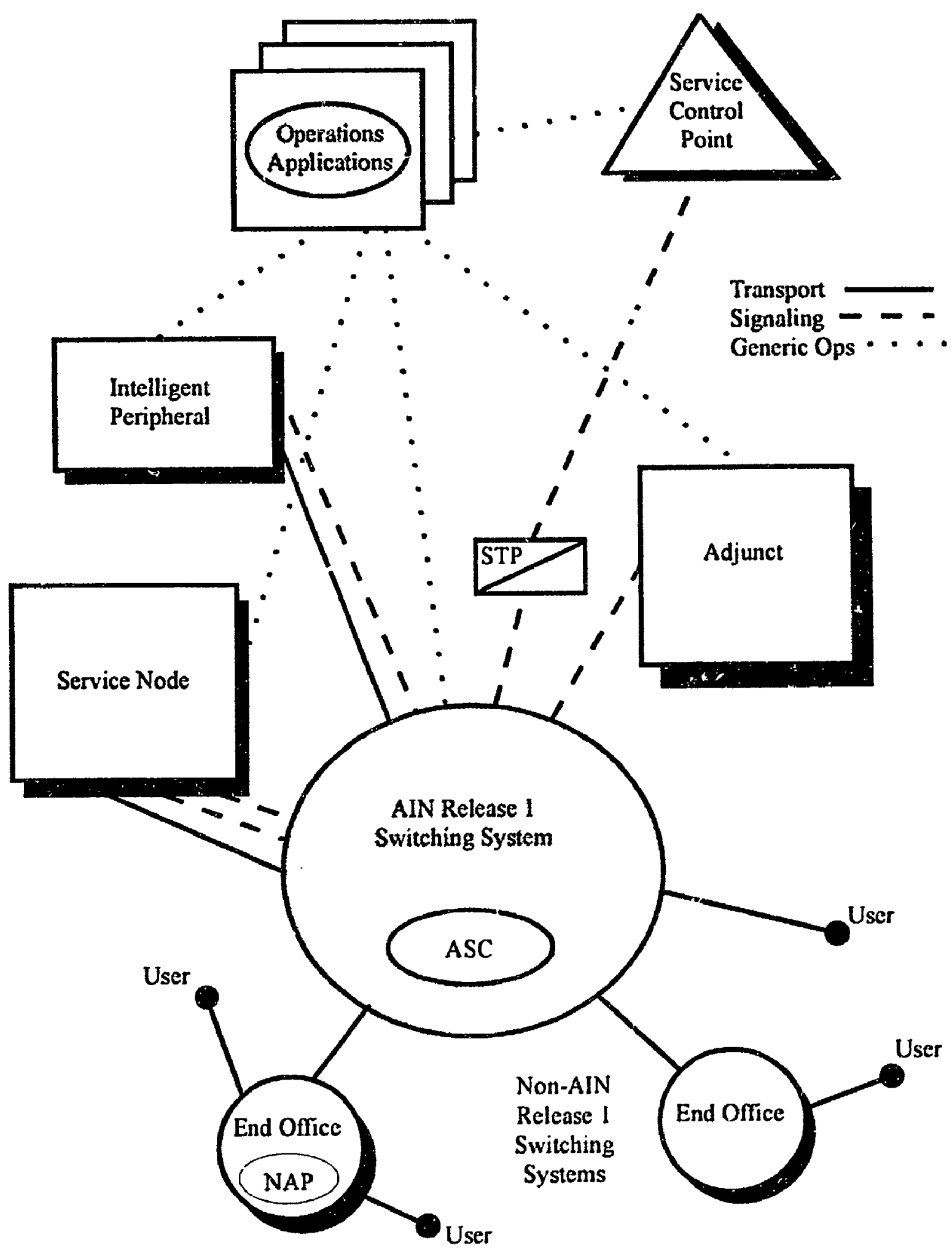

ASC $=$ AIN Switch Capabilities

NAP $=$ Network Access Point

STP $=$ Signal Transfer Point

Figure $3 E$

Bellcore AIN

Release 1 Architecture 
service information to provide AIN Release 1 services." In this definition an SCP is comprised of an SCP Platform and service logic programs. The sub-specification describes characteristics to be met by an AIN Release $1 \mathrm{SCP}$, such as performance, reliability and environmental requirements. Bellcore also provided a diagram outlining their generic concept of an AIN architecture. Figure 3E shows this conceptual architecture. This AIN Release 1 physical architecture is identical to the definition in the IN CS-1 physical architecture with the following exceptions:

- AIN Release 1 does not support direct interfaces between the service control point and the intelligent peripheral of between the adjunct and the intelligent peripheral

- AIN Release 1 treats the intelligent peripheral and the services node identically in terms of the interface to the service switching point - AIN Release 1 supports generic interfaces between operations systems and each physical entity

As in the IN CS-1 definition, the Bellcore AIN Release 1 focuses the majority of their AIN interface standardization on the application layer protocol. It defines the set of conventions to manage the communications between applications to provide services in the AIN architecture. The functional architecture is well aligned with IN CS-1.

Bellcore has taken a progressive move towards the development of standards for the development of AIN's. Historically, Bellcore has set the standard for telephone communications within the United States. These standards have then been adopted by Canada in an attempt to keep the communication flow between the two countries free from technological barriers due to incompatibility. Hopefully as the technology and design of the AIN matures a methodology to intercept the communications can be developed. If the U.S. law enforcement agencies pressure the carriers and the network designers for the intercept facility it should also be exported and remain universal so that Canadian law enforcement can benefit. 


\subsection{Probable PCN Architectures With AIN}

The Advanced Intelligent Network has been identified as a key component to the overall Personal Communications Networks. However, it is expected that, to expedite the introduction of $\mathrm{PCN}$, carriers and service providers will introduce pockets or islands of PCN. PCN has been further described as the basis on which islands of telecommunications networks are linked. Figure 3F shows PCN as the core network functionality for numerous other service islands. PCN, utilizing an AIN network infrastructure, will be able to bring all these conventional communications nodes together into one offering for the consumer. These dynamic linkings between islands of communications will pose a problem for law enforcement in their attempt to locate a single point on the network where all communications to and from the target appears and can, therefore, be easily routed back to a monitoring facility.

Figure 3G shows a more explicit functional architecture for PCN. in this diagram more defined islands of communications are identified.

Large and small business centrex systems are shown with the ability for wireless communications to that node through locally placed radio base stations. These would be private or business PCN networks that the user could freely roam into maintaining their communications path through to the backbone infrastructure.

The Service Transfer Point (STP) shows the point in the target network architecture where the switching is transferred from the local switching infrastructure to the networkwide switching level. This architecture adheres to the principles outlined in both the CCITT IN CS-1 and the Bellcore AIN Release 1. This figure was originally published in the December 23, 1991 issue of Telephony Magazine showing a PCS / PCN Functional Diagram. It may not of been completely apparent to the readership unless they looked into the diagram that defined points of an AIN are incorporated. Again, the PCN functional infrastructure is defined by the abilities and control point definitions of an AIN. To be able to provide the AIN and the interconnection of the islands of telecommunications services the service provider must have an AIN as the foundation. 


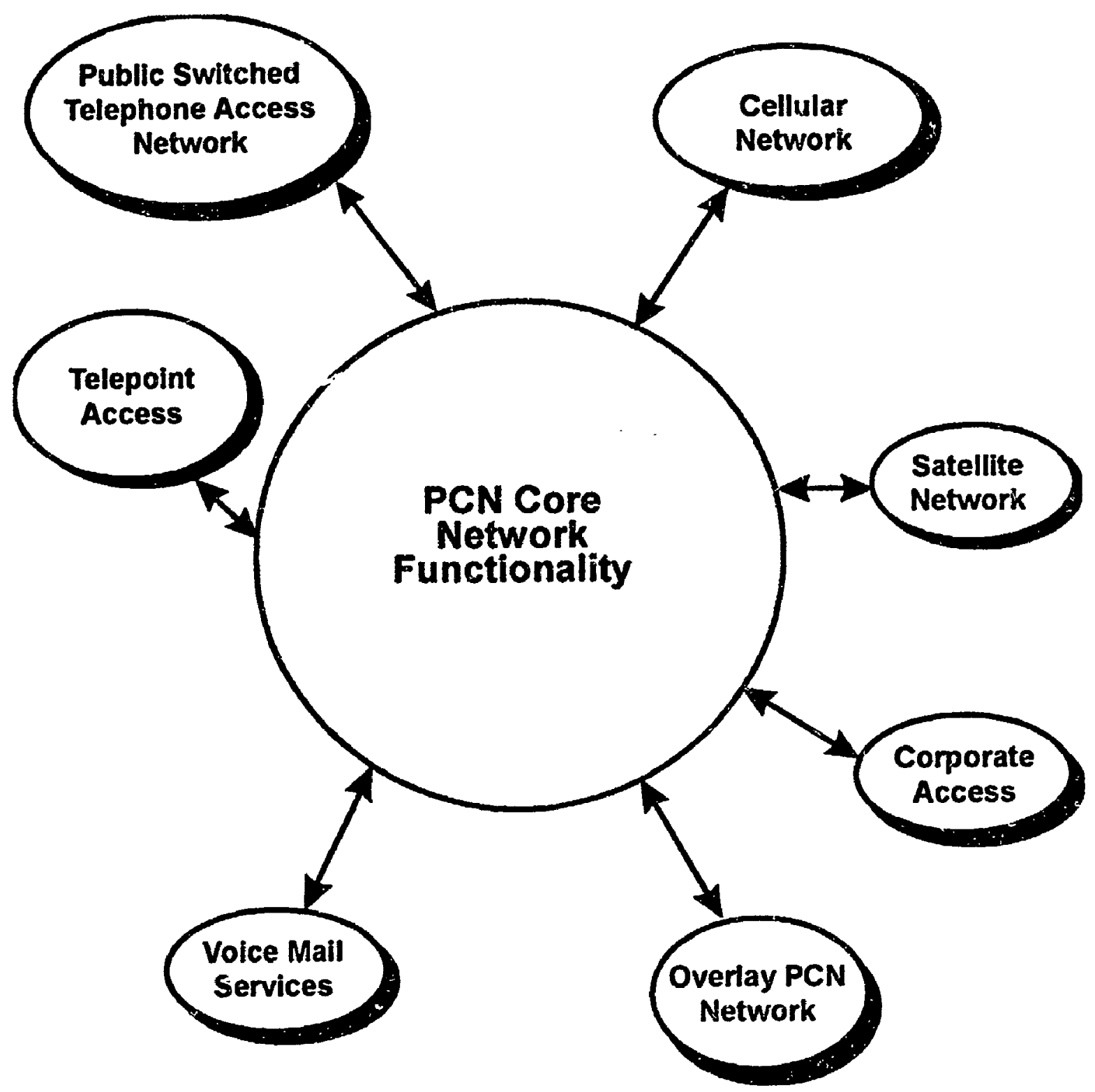

Figure $3 F$

PCN Core Network as an

Integrator of Islands

of Mobility 

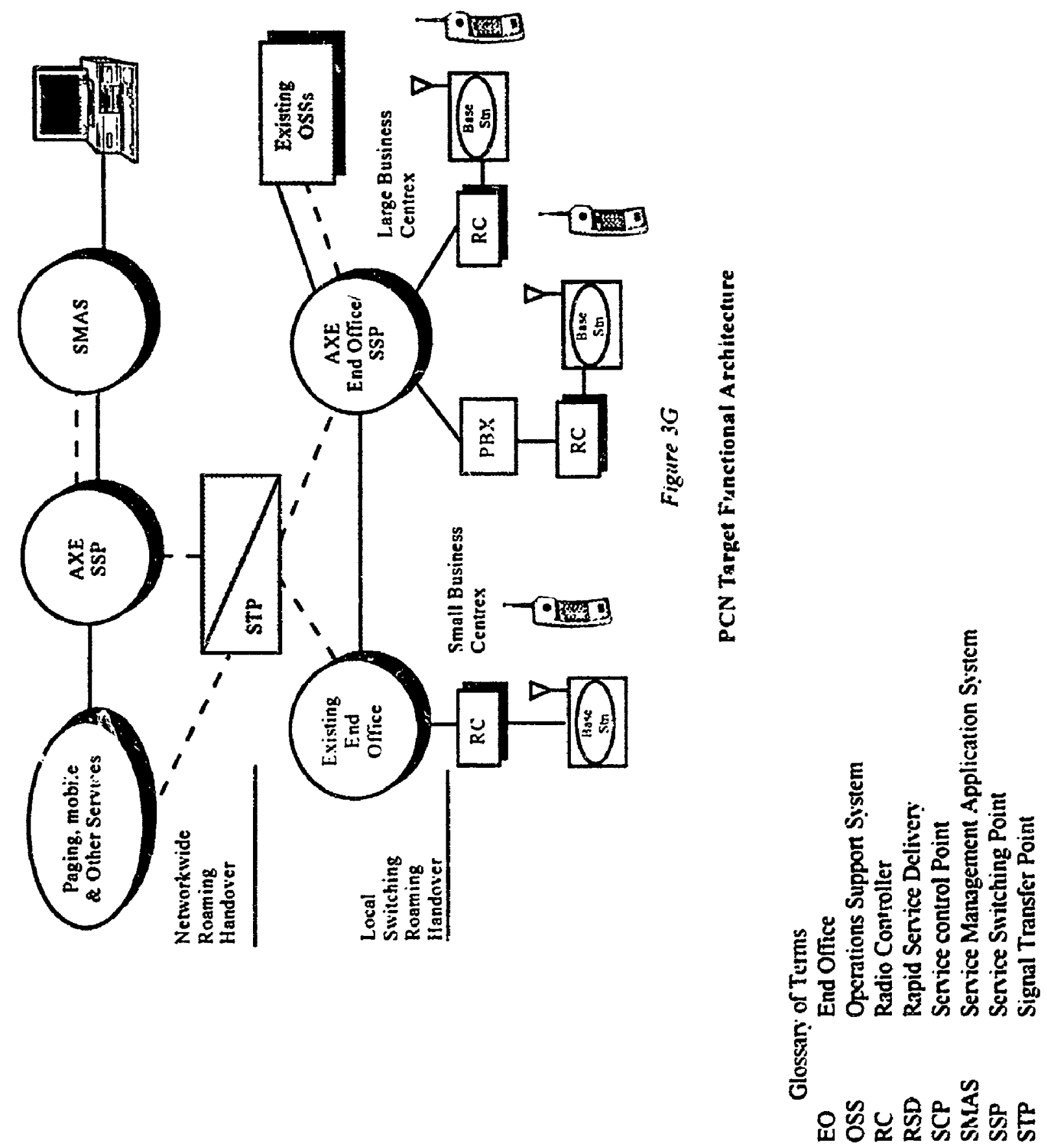
A more generic, but comprehensive network architecture for PCN is shown in Figure 3H. The control points and more generic AIN architecture elements are not depicted but, rather, physical components to the network are shown.

The central point within Figure 34 is the element labeled the Group Switch (GS). This, in comparison to a cellular network, would be comparable to the Mobile Telephone Switching Office (MTSO). However, a unique component to the network has been added referred to as the Mobile Distributed Switching System (MDSS). This component of the network architecture adds the ability for more diversified processing within the network, taking some of the rudimentary tasks away from the GS. Each of these MDSS's in the network could be representative of private networks or switching devices in the public network located close to a high number of radio base stations. This comparison shows the fundamental similarity between the PCS Environment diagram in Figure 3A and this more basic diagram, Figure 3H.

Each group switch in the network infrastructure will be conrietied to numerous MDSS's. Each MDSS has the ability to connect to local dial tone on the PSTN directly, again, taking some of the switching and connectivity responsibilities away from the group switch. In this architecture local calls wills be connected quickly and will not be affected by how busy the main network would be. This applies strictly to when a user still remains in their hoine location register (HLR) and is not roaming.

If the user roams outside their home location register into the visitor location register (VLR) the calls that they place would have to be routed through the GS. Also, the only access to the toll network for long distance calling is through the GS even if the user is located within their own HL R. This switching procedure is to simplify the billing for long distance calling as, typically, the long distance carrier would not necessarily be directly affiliated with the PCN service provider except for a user agreement. This scenario should also reduce a significant amount of long distance telephone fraud on the PCN network as further checks are m.de during call setup procedures to confirm the validity of the phone and approval to actually place long distance toll charges. The billing data will be retained as part of the GS functionality. 


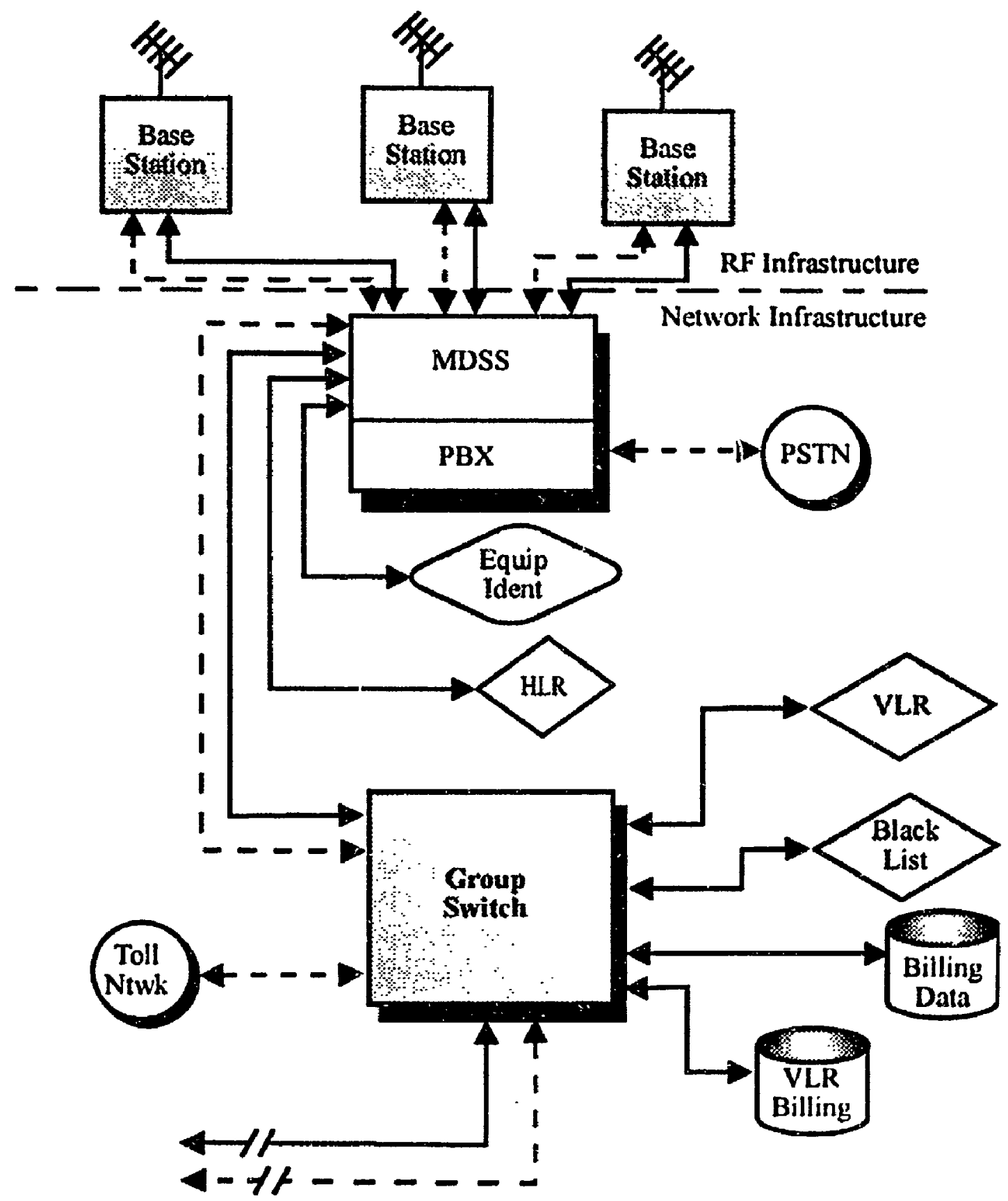

To Other MDSS's

On This Group Switch

Figure $3 \mathrm{H}$

Basic Personal Communications

Network Architecture

Glossary of Terms for Figure $3 \mathrm{H}$

MDSS Mobile Distributed Switching System

PSTN Public Switched telephone Network

VLR Visitor Location Register

HLR Home Location Register 
Figure 3H does depict the basic elements of an AIN supporting a Personal Communications Network. The names of the elements may change from one network manufacturer to another. Yet, the fundamental concepts will remain. Their will be a central, master type switch which will have the overall control over many sub-switches, MDSS's in this case. Therefore, this switch should have overall control over all communications within it's service area. A second, lower luvel of connectivity has been provided through local access to the PSTN through the remote switches. This scenario holds only if the user is in their home location register. Visitors will always be handled through the central, master switch to expedite validity checking, then effectively minimizing fraudulent use of the network. Also, having the central switch handie visitors, billing for system use can be expedited back to the visitor's service provider. The user will be able to roam freely between numerous base stations, depending how fast and over what distance, possibly staying within the control of one MDSS. Yet, they may and very well could roam between numerous MDSS's connected to the same central gioup switch. Further, the user could continue to roam from one GS to the next as lor.g as the group switch does not simply provide the network support to an "island" of PCN but is actually interconnected to a yet larger network affording the user a wide geographical area in which to freely roam.

The introduction of multi-layered switching as a fundamental element to the PCN architecture imposes a significant complication for law enforcement. Ideally, in the curreni telephone network philosophy, a telephone number is related to a telephone set located at a physical location and connected through a physical transmission media back to a specific telephone network switch. Interception of communications to and from an identified telephone number can be accomplished by simple bridging at a single point in the network where there is an appearance of the telephone line and can be accomplished usually at more than one place in the network architecture. All these concepts vanish with the introduction of AIN. The target PCN handset could be connected through a multitude of radio base stations to various MDSS's dependent strictly on the handset's physical location. Therefore, there is no one single MDSS that can be targeted to obtain all communications to and from the target. Further, the communications could be routed to numerous Group Switches depending on there location again and whether or not they are roaming at the time of the call connection. Realistically, there is no one single location in this multi-layered, dynamic network where all the desired 
communications to be intercepted will be routed as a result of standard operating procedures in the network. 


\section{CHAPTER 4}

\section{PCN RE Communications}

\subsection{General}

One of the opportunities available to technical investigations and law enforcement agents is the ability to intercept transmitted communications. If the communications is transmitted in a format that can be easily captured and recognizahle law enforcement agents could use a method of radio based interception to afford them a means to perform a lawful coinmunications intercept. A portion of the architecture for communications on a Personal Communications Network will have the communications transmitted over the air between the handset and the radio base station. At this point the communications would be vulnerable to eavesdropping through the use of a radio receiver. The following sections will describe the frequencies to be used, transmission schemes and technical details associated to the radio frequency (RF) communications for PCN. This information will be used as the basis for the evaluation of using an RF based intercent technique for the lawful interception of communications on a PCN.

As background information one of the most important concern to all governments and radio regulatory bodies is to use the limited radio spectrum more efficiently. It seems that all frequencies between the lowest in the $\mathrm{MHz}$ range to the extremely high $\mathbf{G H z}$ range have all been spoken for. To add another system operation into that already extremely cluttered spectrunī becomes very difficult especially if it demands a significant amount of bandwidth. When new services are introduced that cou!d have an impact on radio spectrum assignments in this limited and already over crowded domain many considerations are to be taken into account. For example one aspect that has to be taken into account is whether the transmission will cross international boundaries and what affect they may have on other existing systems in those other countries. Further to this is whether the transmissions are actually to be intentionally designed to provide interoperability across the international border. Each country has the responsibility to maintain and regulate radio spectrum within their own territorial borders. However, there is no strict necessity for bordering countries to allocate any 
part of the radio spectrum for common purposes. PCN, like cellular mobile communications, will ideally see no geographical boundaries or international borders. Due to the nature of the borders between the United States and Canada, it seems likely that the two countries should adopt the same PCN communication standard within the same assigned radio frequenc $y$ spectrum.

An internationally recognized body was created to better regulate the radio spectrum throughout the world. The intent of this advisory board is to assure the minimization of radio interference and to promo.e cross border interoperability. It applies to Canada and our border with the US but this advisory group has the most impact in Europe. There are so many geographically small countries bordered by so many others in Europe that there must be some unique group overseeing specirum allocations and usage otherwise there may be so many interfering communication transmissions nothing would get through. In today's communication age this would be devastating.

The International Telecommunications Union (ITU) was created as a specialized agency of the United Nations and is stationed in Geneva Switzerland. The ITU is comprised of 150 government representatives and their mission is to regulate all policies associated to radio, telegraph and telephone on an international scope. The ITU divides the world into three regions. Region 1 is comprised of Europe including the former Soviet Union, Outer Mongolia, Africa and the Middle East, west of Iran. Region 2 has the Americas and Greenland. Region 3 is Asia excluding those areas defined as part of region 1 as well as Australia and Oceania.

In 1992 the World Administrative Radio Conference (WARC) of the ITU was held in Torremolinos, Spain enaing March 3, 1992. With international representation from throughout the world this meeting resulted in a world wide allocation of the $1.7 \mathrm{GHz}$ to $2.69 \mathrm{GHz}$ as a band for mobile communications. This was - precedent setting decision as it brought all three ITU defined regions into conformity for a specific piece of radio spectrum. The auspices of this world wide allocation was part of Future Public Land Mobile Telecommunications Systems (FPLMTS). The ITU defined FPLMTS as "systems capable of providing a wide range of services (voice and non-voice) including personal communications with regiona' or international roaming." The FPLMTS does combine both terrestrial based and sateilite delivered personal communications services. The WARC 92 conference identified the sub-bands $1.885 \mathrm{GHz}$ to $2.025 \mathrm{GHz}$ and 2.11 $\mathrm{GHz}$ to $2.2 \mathrm{GHz}$ for terrestrial based PCS communications on a world wide basis. 
Industry analysts saw the heavy support from the European delegation on behalf of this spectrum allocation as support for European based product manufacturers, opening the world market to them. Further to this WARC 92 allocated spectrum to Low Earth Orbit (LEO) satellite services that could provide PCN type services to more remote areas of the earth where terrestrial based services would not be cost effective or practical. For LEO systems operating below $1 \mathrm{GHz}$ a primary allocation was provided world wide at $149.9 \mathrm{MHz}$ to $150.5 \mathrm{MHz}$ and secundary allocations at $312 \mathrm{MHz}$ to 315 $\mathrm{MHz}$ and $387 \mathrm{MHz}$ to $3: 0 \mathrm{MHz}$. Above $1 \mathrm{GHz}$ the primary allocation earth to space is at $1.610 \mathrm{GHz}$ to $1.6255 \mathrm{GHz}$ and $2.4835 \mathrm{GHz}$ to $2.52 \mathrm{GHz}$ for space to earth communications.

The ITU has taken steps to proactively address emerging technologies that would have an impact on radio spectrum world wide. In this realization and specifically at WARC 92 the ITU has designated a specific segment of radio spectrum to both terrestrial based and satellite based PCN type systems. However, they did fall short in not providing any direction to communications standards or directing the adherence to a common air interface. Their intent is to promote international roaming of PCN type communications yet with their decision limited tr only frequency allocations this goal may never be achieved.

In conclusion, the international trends show a momentum converging upon a series of substantial global spectrum allocations for Personal Communications. These international allocations are substantially within the $1.8 \mathrm{GHz}$ to $2.2 \mathrm{GHz}$ band. If Canada adheres to this internationally designated band the target band to be intercepted will be identified and law enforcement's equipment can be designed accordingly. An article in the IEEE Communications magazine also indicates arother substantial benefit to the introduction of this revolutionary cordless telephone communications concept. The author, Kurt Wimmer, an attorney in the communications field in Washington D.C., states that "PCS presents an opportunity for developed countries to move toward a new standard for portable telephony and for undeveloped countries to move directly from obsoleie wired infrastructures to state-of-the-art digital networks. "[17] With a global direction to freguency assignments for PCN all countries, indeperdent of the state of their current wireline communications, could go forward with the next generation cordless telephone communications. 


\subsection{Telepoint Services}

One of the earlier predecessors to full Personal Communications Networks is a service called "Telepoint". Telepoint services can best be equated to a wireless pay phone system. Initial telepoint systems offered strictly outbound calling from the portable handset. The network infrastructure behind telepoint is unable to track the subscriber as they move. Therefore, no inbound calls to the telepoint phone can be accomplished. The following information is provided to show the reasoning for the trend to a fully featured Personal Communications Network and winy this type of communications network will not be a required system to be intercepted.

The radio network is relatively trivial for this type of cordless telephone system. Base stations are located strategically, typically in public locations and have coverage radii in the order of 100 to 200 meters depending on the physical location. Each of these base stations has a direct connection to the wireline telephone network. None of the base stations are interconnected as the design criteria does not permit mobility of the subscriber once the call is set up and established. When the subscriber in a telepoint system desires to place a call they look for indicators, small signs posted in the area to indicate to them that they are within range of a radio base station. The user would then turn on their handset and attempt to place the outbound call. Once the call is established the user cannot move a any significant distance as, cnce the signal is lost from the base station, the call is terminated and the user would have to reinitiate the procedure. To enhance the overall capability of telepoint services some companies have offered, as an integral part of the system, a pager. This allows the subscriber to obtain inbound requests for telephone cails and can answer the page through the use of the telepoint system when he gets within the proximity of a telepoint base station. Pager nexworks typically have a much gieater range than the telepoint system and can contact the subscriber in more locations.

CT-1 is the principal standard for telepoint systems which incorporates a fully digital, frequency division multiple access scheme on the radio link. CT-1 system installations have had frequencies aiocated and have been typically operated in the $800 \mathrm{MHz}$ area of the radio spectrum. The United Kingdom was the country to take major steps towards universal portable cordlese telephony utilizing the $\mathrm{C}^{2}-1$ concept. However, there were 
significant technological drawbacks to the way that these services were offered to the public. Four companies were licensed to provide telepoint services and only $4 \mathrm{MHz}$, $864 \mathrm{MHz}$ to $868 \mathrm{MHz}$, was allotted for these four companies to provide competitive services. This was done through the British Department of Trade and Industry in 1989. There was a provision for another $4 \mathrm{MHz}$ in case of the necessity for expansion. All of these companies incorporated a proprietary signaling scheme, none of them aunering to any standard. Also, none of the four provided any interoperability between service providers. This meant that all four companies vying for the, what was imagined, lucrative market would have to install radio base stations everywhere they wished to provide the service. To date three out of the four companies have folded. Mercury "Callpoint" and Ferranti "Creditphone" closed onerations in August 1991. Phionepoint, the only active carrier, terminated operation in November 1991. This left only one, "Rabbit" operated by H.tchison Personal Communications Inc. based in London England, which is competition with the cellular companies.

Nevertheless, even with the notable failure of the telepoint services in the United Kingdom other countries have chosen to go ahead and set up these type of systems. The IEEE Spectrum reports that" in Hong Kong, another Hutchison affiliate attracted 50,000 telepoint subscribers in the first month. Singape e Telecom obtained more than 24,000 subscribers to its telepoint service in the first year. Both of these countries have chosen to assign the $864 \mathrm{MHz}$ io $868 \mathrm{MHz}$ band for CT-1 services. In Brisbane, Australia, 600 base stations have been installed to serve users of "walkabout". A telepoint service launched by Telecom Australia, Melbourne, on March 17 (1993). The service will be expanded to other Australian cities over the next three years." $[18]$

The collapse of the British telepoint type cordless telephone communications has demonstrated to all other countries looking towards wireless personal telephone services that telepoint is not the solution. The public highly desi-es those features which are commensurate with PCN. In Canada CT - 1 Telepoint services are not expected to be offered and, therefore, there will not be a requirement for law enforcement agencies to create a technique to intercept this specific form of communications. The consumer market research for all of North America has indicated that wireless pay phones are not what the consumer market wants. The consumers desire a fully automatic portable telephone system with no limitations especially radio coverage. They also demand two way communications, not outbound communications only. The only possibility of the introduction of telepoint type systems would be as a predecessor to the full PCN system 
because the AIN required to provide inbound call routing would not yet be fully functional and companies would want to put their phones on the market.

\subsection{Microcelı Technology}

One of the radio frequency system architecture plans being considered for public access PCN is what is termed as "microcell" technology. Therefore, if law enforcement cor siders a radio based intercept system for PCN, the designer of the intercept equipment must understand the basics of microcell technology. A microcell is defined as " a region served by a radio base unit, just as in current cellular systems, only smaller in area by one to two orders of magititude."[19] The current design for analog cellular base station coverage typically extends outwards over a $1 \mathrm{~km}$ radius. Microcell technology is designed to have a radio coverage range of less than 150 meters.

In the overall expectations of system capacity for $\mathrm{PCN}$, the design goal is to provide an RF infrastructure that could accommodate a capacity two orders of magnitude greater than that of the existing analog cellular system. Some of the PCN communications design strategies takes this goal into account. Yet, through digitization of voice and multiple access schemes the design goal of 100 times the capacity of analog cellular cannot be achieved. Through the adoption of the IS-54 digital cellular standard triple the capacity can be accomplished. Frequency reuse plans will also increase radio network capacity but there will be no great increase in allocated spectrum to provide further gains in capacity. Yet, again, the two orders of magnitude is not reached. One simple way to achieve the design goal is to reduce the cell radius. Reducing a ce!l radius from $1 \mathrm{~km}$ to $100 \mathrm{~m}$ corresponds to a factor of 100 reduction in cell area. With this area reduction the capacity design goal can theoretically now be achieved by the same factor, two orders of magnitude.

Research has taken place at the Communications Systems Research Laboratory at AT\&T Bell Laboratories in Holmdel New Jersey delving into many aspects of microcell technology and its use in PCN appiications. The fundamental aspert of their research was based on the fact that using microcells for PCN, the design goal for radio network capacity could be achieved. To further investigate the applicability of 
microcell technology other aspects were also investigated inherent in the fact that using microcells would require a large increase in the actual of numbers of base stations required so provide the seamless radio coverage, a design goal is now to make the interconnecting infrastructure simple as well as the entire radio network cost effective and economical. Another aspect that Bell Labs is louking into is developing new radio propagation models for microcells and the ability to predict radio link performances. They are also considering the added complexity of channel assignments, hand-offs from one cell to another, the architecture of the radio network itself combining microcells with macrocells. As well, with all these difficulties introduced with the use of microcells, they also must consider the limited radio spectrum available. All these design criteria and difficulties in the PCN radio system architecture must be defined prior to any attempt at the interception of communications on a microcell type system.

\subsection{Comparison of Competing Standards}

The fundamental transmission scheme for the common air interface between the PCN radio handset and the base station must be completely understood before a radio based intercept system could ever be considered. Precluding the adoption of a Canadian standard, there were numerous cesign proposals reviewed for the over the air transmission protocol. Nevertheless, the major proposals are presented here because the Canadian standard is only one of the possible protocols to be seen internationally. The possibility may warrant, in the future, for other international law enforcement agencies to attempt the same radio based intercept approach. Also, in years to come if Communications Canada ever chcoses to adopt another transmission protocol so that Canadian PCN subscribers can roan internationally, more specifically into the United States, Canadian law enforcement may still have the problem of interception of one of the other proposed common air protocols.

There has been many discussions regarding what standard to adopt for $\mathrm{PCN}$ radio communications. As specified in a previsus section the CT2Plus Class 2 specification has been adopted in Cartada as the standard for the second generation wireless telephone system. This specification goe's into great depth describing the radio signaling, communications control and, most importantly, the methodology to have the handset autumatically interchange through radio base stations. This will ultimately 
provide the user with the ability to move freely maintaining radio coverage and corcless telephone communications. Personal Communications equipment adhering to the CT2Plus standard should be able to communicate with any other similar network adhering to this strict standard when operating in the same assigned frequency band. When roaming outside the radio coverage of a particular service provider, if another exists and is operating in the same radio banci the handset should be able to roam into the second system. The user would then have a further enhancement to their operating region and would not be strictly limited to those areas that were covered by their own service provider.

The goal of all the research into the various components of the radio transmission scheme for the second generation cordless telephone system was centered around the optimal use of limited available radio spectrum. It was also to aftord the uset the highest quality voice communimations and provide, in the long term, a seamless network of radio base stativi.. which would provide the users uninterrupted telephone communications no matter where they may be.

Since the next generation cordless telephone system was to be fully digital this afforded the designers with a multitude of options. Initially the algorithm to do the analog to digital conversion of the voice information had to be chosen. With that the voice coding rate in kilobits per second had to be chosen taking into account the consumer demand of equal, if not perceivably better, voice quality at the handset. The next choice was the modulation scheme for the RF channel and, based on the voice coding rate, the modulation data rate. Inherent in this choice would be the channel bandwidth requirements. The next, which seems to be one of the most controversial design choices to be resolved would be the $\mathrm{n}$. 'tiple access scheme. Throlighout the literature on PCN and dating back to the introduction of the concept of digital cellular telephone the choice of the multiple access scheme has been an issue that seems to have no clear cut, logical basis for favoring one over another. Once the decision is made, ho'vever, the designer has to choose the duplexing method to fulfil the full duplex requirement of the data transmission to allow for identical operation of the cordless phone compared to today's operating norm. Once all these choices have been finalized the overall bandwidth requirements can be determined and, furthermore, the number of simultaneous voice conversions in an allotted bandwidth can be determined. Hopefully ail the design criteria leading to the choices of the various aspects of the digital transmission scheme has led to the cptimum bandwidth usage and spectral efficiency. 
However, it should be noted that there were many competing standards put forth regarding the radio communications specifications for the next generation of digital cordless telephone. Table 4.1 shows some of the differing standards for second generation cordless telephone as well as cellular communications. In November 1993 when this table was published as part of an article in the IEEE Communications Magazine, the FCC in the United States still had not adopted a standard for the radio side of their next generation cordless telephone. As menticned previously, Canada had by this time adopted CT2Plus (iass II complete with a standard for the Common Air Interface (CAI). The CAI is based on the European Standard I-ETS 300 131, "Common Air Interface Specification to be used for the Interworking Between Cordless Telephone Apparatus in Frequency Band 864.1 MHz to 868.1 MHz Including Public Access Services". Communications Canada published another CAI document based on this European standard with certain items redefined for Canadian use.

The first standard ever adopted for use in a PCN system is the DCS 1800 system. It has been deployed in the United Kingdom. This standard has many similarities to the GSM standard, however, the DCS 1800 system operates in the $1800 \mathrm{MHz}$ band and it uses lower transmission power to accommodate smaller RF coverage cells.

CT-3 developed by Ericsson was an earlier contender in the competition for standards in the next generation cordless telephone. However, as time went by this system for PCN has all but disappeared in North American publications and periodicals. CT-3 was a standard that competed for the Canadian market against CT2Plus but did not survive. The basis was a TDMA multiple access scheme using time domain duplexing, $32 \mathrm{kbit}$ ADPCM for voice coding and GMSK as the modulation type. The CT-3 specification is quite close to DECT. However, the CT-3 RF channel bandwidth is less and the data transmission rate on the RF channel is slower.

In table 4.1 a number of differing radio transmission standards are described. Canada has notably adopted a form of CT2 CAI as described in the table. However, further to the details provicled in the table the "Hand-off" variable in the table has changed to "Yes" in the CT2Plus Class II functional specification. This fact is critical to the overall comparison to the competing standards. With the ability to provide full mobility to the user, the CT2Plus Class II standard can compete with the other standards vying for domınance in the PCN market. 
Table 4.1

Comparison of Competing Radio Standards

Second Generation Digital Cordless Telephone

\begin{tabular}{|c|c|c|c|c|c|c|c|}
\hline System & GSM & $\begin{array}{l}\text { DSC } \\
1800\end{array}$ & $\begin{array}{l}\text { Qualc } \\
\text { CDMA }\end{array}$ & $\begin{array}{l}\text { D- } \\
\text { AMPS }\end{array}$ & $\begin{array}{l}\text { CT2 } \\
\text { CAI }\end{array}$ & DECT & Units \\
\hline 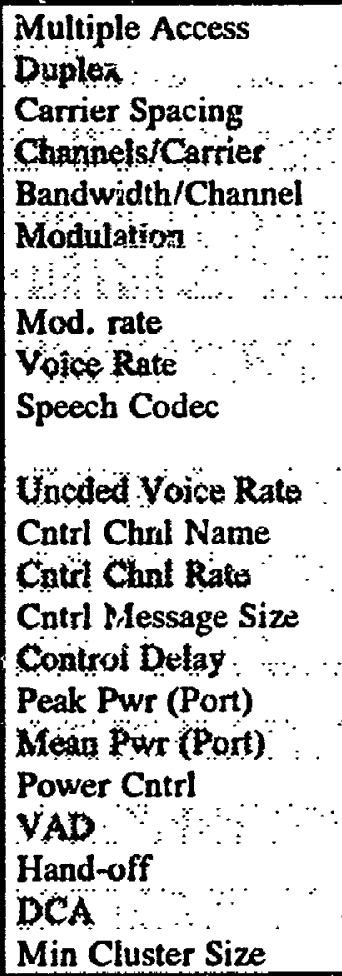 & $\begin{array}{l}\text { TDMA } \\
\text { FDD } \\
200 \\
8 \\
25 * \\
\text { GMSK } \\
271 \\
22.8 \\
\text { PPE- } \\
\text { LTP } \\
13 \\
\text { SACCH } \\
967 \\
184 \\
480 \\
2-20 \\
0.25-2.5 \\
\text { Yes } \\
\text { Yes } \\
\text { Yes } \\
\text { No } \\
3 \\
\end{array}$ & $\begin{array}{l}\text { TDMA } \\
\text { FDD } \\
200 \\
8 \\
25 * \\
\text { GMSK } \\
271 \\
22.8 \\
\text { RPE- } \\
\text { LTP } \\
13 \\
\text { SACCH } \\
967 \\
184 \\
480 \\
0.25-2 \\
0.03-125 \\
\text { Yes } \\
\text { Yes } \\
\text { Yes } \\
\text { No } \\
3 \\
\end{array}$ & $\begin{array}{l}\text { CDMA } \\
\text { FDD } \\
1250 \\
55-62 \\
\text { QFSK } \\
\\
1228 \\
19.2 / 28.8 \\
\text { CELP } \\
1.2 \cdot 9.6 \\
\text { FACCH } \\
800 \\
1 \\
1.25 \\
0.6-3 \\
0.6-3 \\
\text { Yes } \\
\text { Yes } \\
\text { Yes } \\
\text { N/A } \\
1\end{array}$ & $\begin{array}{l}\text { TDMA } \\
\text { FDD } \\
30 \\
3 \\
10 * \\
\pi / 4- \\
\text { DQPSK } \\
48.6 \\
13 \\
\text { VSELP } \\
8 \\
8 \\
\text { SACCH } \\
600 \\
65 \\
240 \\
0.6-3 \\
0.6-3 \\
\text { Yes } \\
\text { Option } \\
\text { Yes } \\
\text { No } \\
7 \\
\end{array}$ & $\begin{array}{l}\text { FDMA } \\
\text { TDD } \\
100 \\
1 \\
100 \\
\text { GFSK } \\
72 \\
32 \\
\text { ADPCM } \\
\text { (G712) } \\
32 \\
\text { D } \\
100012000 \\
64 \\
32 / 26 \\
0.01 \\
0.005 \\
\text { Yes } \\
\text { No } \\
\text { No } \\
\text { Yes } \\
\text { N/A } \\
\end{array}$ & $\begin{array}{l}\text { TDMA } \\
\text { TDD } \\
1728 \\
12 \\
146 \\
\text { GMSK } \\
\\
1152 \\
32 \\
\text { ADPCM } \\
(G 721) \\
32 \\
C \\
6400 \\
64 \\
10 \\
0.25 \\
0.01 \\
\text { No } \\
\text { No } \\
\text { Yes } \\
\text { Yess } \\
\text { N/A } \\
\end{array}$ & $\begin{array}{l}\mathrm{kb} / \mathrm{s} \\
\mathrm{b} / \mathrm{s} \\
\mathrm{b} \\
\mathrm{ms} \\
W \\
W\end{array}$ \\
\hline
\end{tabular}

Note: * per duplex channel

VAD is Voice Activity Detection

DCA is Dynamic Channel Allocation

RPE-LTP is Regular Pulse Excited LPC c/w Long Term Prediction

CELP is Code Excited Linear Prediction

VSELP is Vector Sum Excited Linear Prediction

FACCH is Fast Associated Control Channel

SACCH is Slow Associated Control Channe! 
In periodicals and publications associated to the implementation of digital cellular and then digital PCN communications, one of the most contentious issues was the multiple access scheme. Even in early 1994 the Federal Communications Commission in the United States has not yet defined a standard for PCN due to heavy lobbying from numerous sources, all with differing positions on the RF standard. The largest issue still remains to be multiple access scheme. Once this one topic is strictly defined the rest of the specifications for the radio transmission fall into place. Ironically, as indicated in table 4.1, the only standard that has adopted Frequency Division Multiple Access (FDMA) is CT2 CAI. The other singularly different proposal was the Qualcomm CDMA specification. The Code Division Multiple Access (CDMA) scheme is the primary technology marketed by Qualcomm Corp. of California. They have succeeded in persuading numerous equipment manufacturers to adopt this technology in their equipment as well as service providers to utilize CDMA as the access scheme. This fact does not affect PCN in Canada but creates a level of indecision within the United States as far as setting a defined, universal standard for PCN services. Time Domain Multiple Access (TDMA) is the third, and seemingly, most popular choice for $\mathrm{PCN}$ and digital system designers. Out of the 6 competing standards 4 chose TDMA for their multiple access scheme. TDMA was chosen for the multiple access scheme for digital cellular by the Cellular Telecommunications Industry Association (CTIA) for the United States. This fact may put some pressure on the U.S. regulatory bodies to keep with a previously adopted technological standard but the competition continues for PCN. Since there may be differing standards between the United States and Canada, the Canadian governing body may choose to somehow develop another standard so that roaming into the United States could be accomplished in PCN. This may dictate the development of another intercept system to accommodate a different transmission protocol.

\subsection{Global System for Mobile Communications (GSM)}

The Global System for Mobile communications (GSM) has been described in some telecommunicatiors trade periodicals as the framework for the next generation cordless telephone communications and is, therefore, presented here as background technical 
material on international PCN communications. Currently it is the standard on which the digital cellular systems of Europe are based. GSM comprises numerous specifications and worldwide standards developed by the CCITT and CCIR for panEuropean digital land mobile communications. GSM is now considered the prevailing world standard for the next generation cordless telephone communications. The primary use is for mobile communications but the new, innovative concepts incorporated into this communications scheme can be brought forward as primary requirements for PCN. These new concepts introduced by GSM create further technical issues with the lawful interception of PCN communications.

Table 4.2 shcws a comparison of the available features between GSM and the U.S. cellular IS-41 standard mobility management protocol. It is quite apparent that even the new cellular mobility standard cannot compete with the flexibility and feature rich GSM standard. GSM uses the Mobile Applications Part (MAP) which is currently being adapted to the U.S. signaling system 7 network by the Telecommunications Industry Association TR-46 committee.

The fundamental concept implemented in GSM that will be taken into PCN and must be examined when considering a technical means to the interception of PCN communications is the powerful message signaling capabilities that will facilitate enhanced, seamless roaming potentiality. GSM can, through automatic network location and registration features, keep track of the users throughout the whole expanse of the network more efficiently compared to the simple methodology incorporated into the existing analog cellular systems. Many of the network capabilities such as mobility management, user security protection and resource allocation are basic features of GSM and the network design building blocks for the next generation cordless phone systems.

GSM defines a number of network databases that are designed to enhance the ability to better control all the mobile users on the network. The databases include three spccific registers. They are the Home Location Register (HLR), Visiting Location Register (VLR) and the Equipment Identity Register (EIR). The fourth database is called the Authentication Center (AC). 
Table 4.2

Telephony Features; GSM vs. IS-41

\begin{tabular}{|c|c|c|}
\hline Feature & IS-4I & GSM \\
\hline 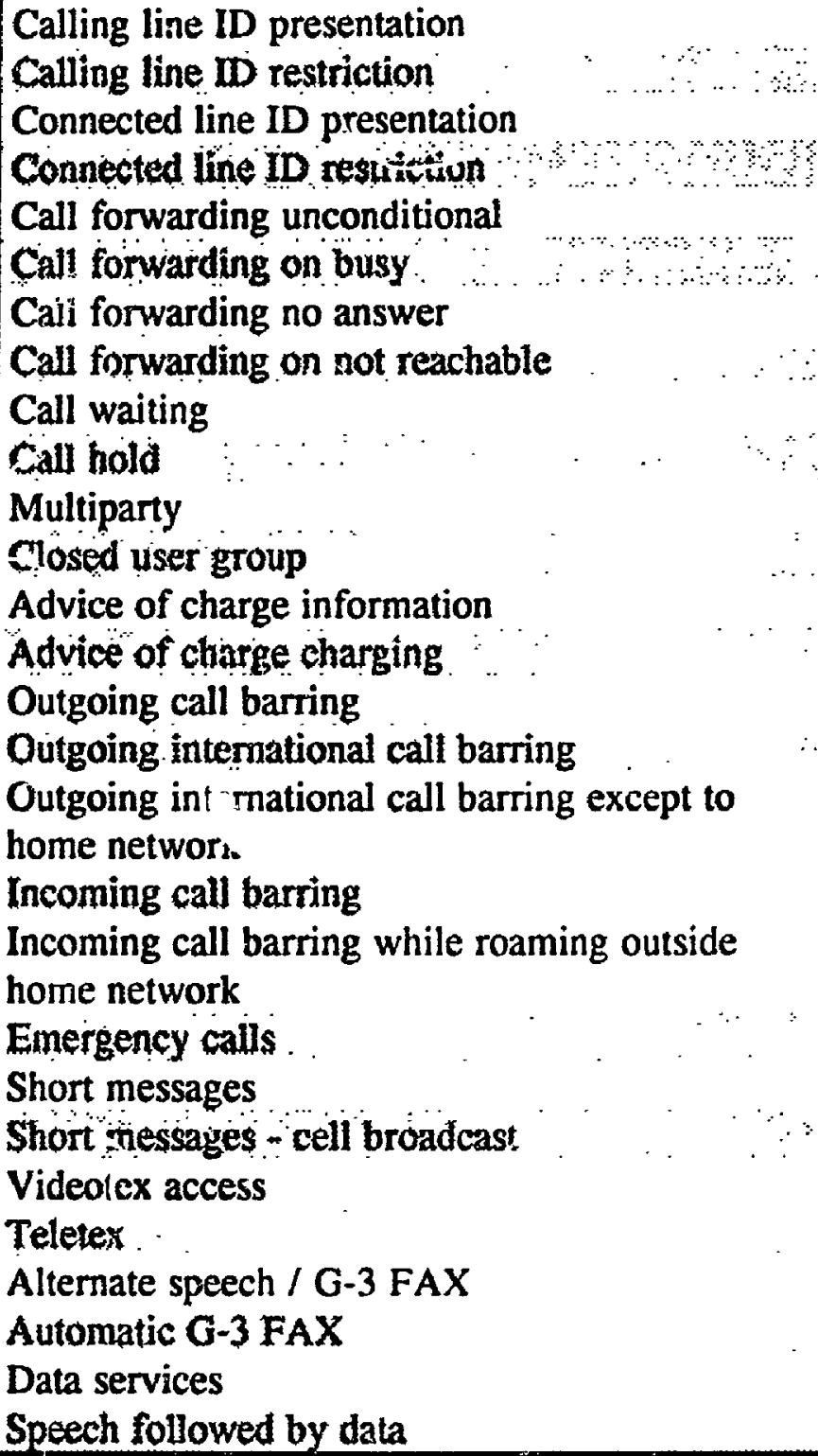 & $\bullet$ & 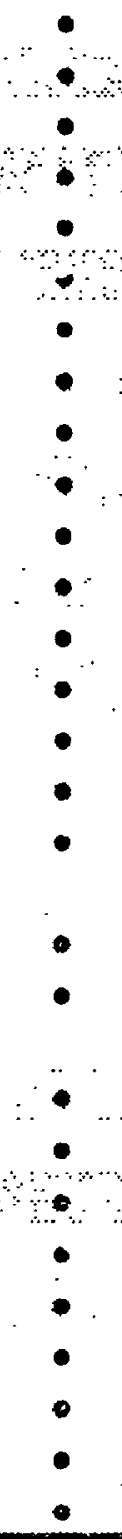 \\
\hline
\end{tabular}


The HLR maintains and updates the mobile subscriber's location and service profile information including any added or special service features that might be subscribed to. The VLR maintains the same information as the HLR when the subscriber is roaming outside their home service coverage area. It is understood that the VLR is a database maintained within the mobile switching centers. In the terminology of Intelligent Networks, these two registers would be considered the service control points.

The EIR is used to exactly determine the mobile equipment identity. This information is used as part of the authorization procedure in GSM. The EIR is used to confirm that the use of the particular piece of equipm-nt is sanctioned and, in turn, will block illegitimate use on the system. The security precautions were developed to combat one of the largest problems within the existing analog cellular systems. Fraudulent use of cellular communications adds up to millions of lost revenues for service providers yearly. The authentication center is another element of the security infrastructure designed in the GSM architecture. The AC provides the key material and algorithm for maintaining the security of the subscriber's identity and for the encryption of the digital information that will be transmitted over the radio link.

With all these critical components introduced as mandatory requirements for a GSM network, GSM is considered an IN application and the GSM providers are considering the GSM implementation as an experience in intelligent networking. Figure 4.1, GSM Network Architecture, shows the fundamental network concept for a GSM system. IN or AIN (Advanced Intelligent Networks) is the key component to the basic requirements for the network functionality in PCN.

Mobility management is the other major enharicement introduced through the GSM standard. GSM allows, for example, hand-offs between channels in the cell, channels in different cells under the control of the same base station subsystem, between cells under the coverage of different base stations and beiween cells controlled by different mobile switching centers. Hand-offs are handled at two different levels. Switching between cells handled by the same base station or between channels of the same cell are handled by the base station controller itself. The other two types of hand-offs are controlled by the mobile switching center. These diversified control ievels shows yet another example of intelligence in the network and the ability to relinquish some control responsibilities from the singular control point and assign a level of the controlling logic responsibility to the outer most point of the network. The mobile 


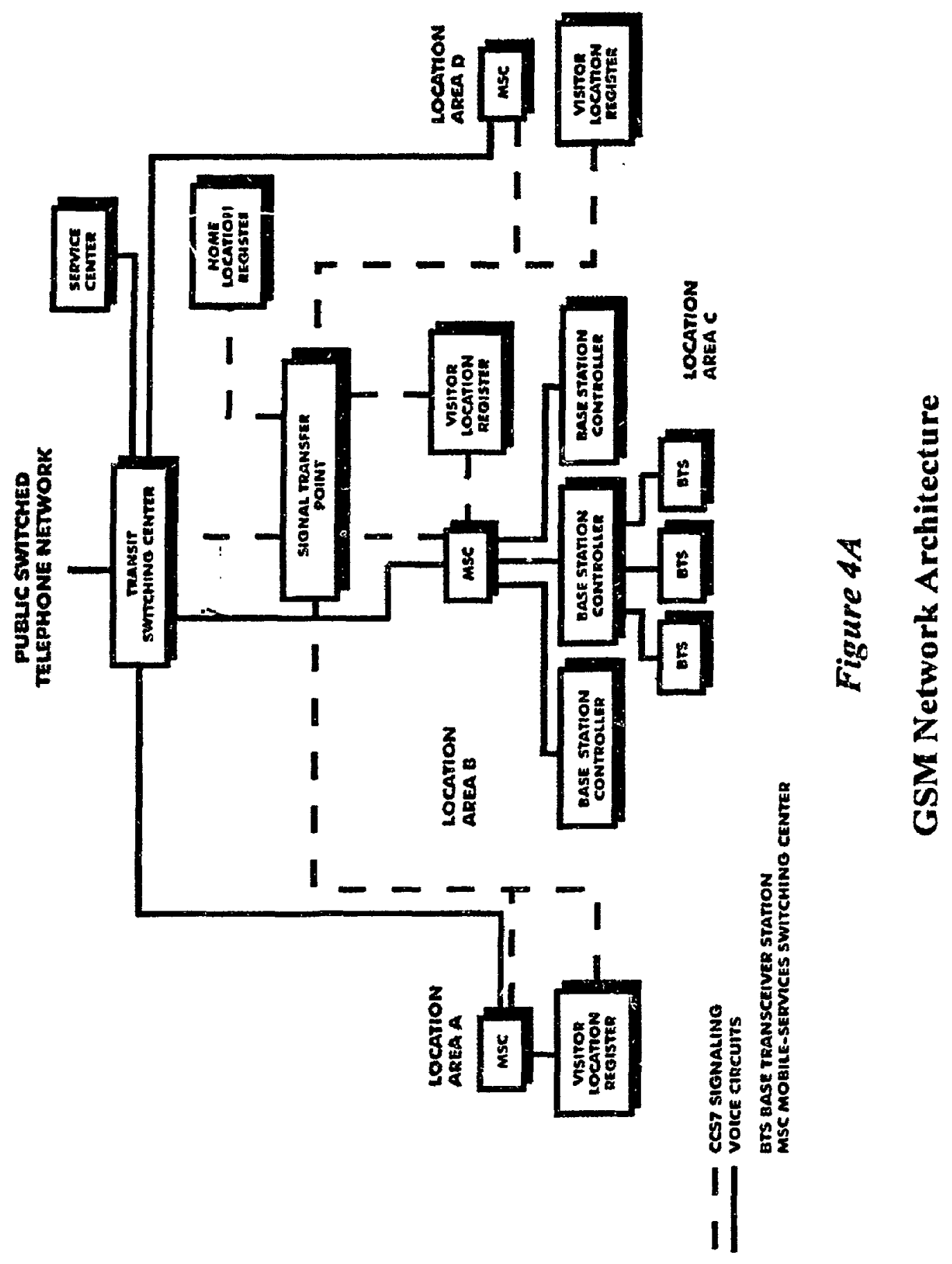


switching center is afforded some information back based on functions performed at the base station so that it may keep track of the users on the network and, as a whole, the continued updating of the location of the subscribers. The fundamental aspect that provides for the mobility of the users is the concept of the Subscriber Identity Module (SIM) introduced by GSM. The SIM carries the personal number assigned to the mobile user and in some specific situations can be coded on a removable "smart card" again to enhance the security of the terminal device and reduce fraudulent use of the communications services.

Many European countries have adopted GSM for their digital cellular communications standard. Also, a major deployment is destined for Australia and among non-European countries looking at GSM are Brazil, China, India, New Zealand, Thailand, Saudi Arabia, Kuwait and a number of other Gulf States. Currently, GSM is being adopted in 52 countries throughout the world. A stumbling block was found when trying to export GSM technology to central and eastern European nations. The technology used in the encryption algorithm in GSM, namely the A5 algorithm, is controlled under strict export laws and cannot be released to these nations. Another, less robust security algorithm is being developed for these destinations that will be endorsed by the British government for export purposes. This is only one of the early problems with the roll out of GSM systems. Early, as the systems were just going operational, there was a definite short coming in the amount of consumer equipment available which absolutely limited the popularity of the services.

In the United States there are several proponents of GSM for the standard for PCN services. One of the biggest supporters of GSM is MCI Communications Corp. of Washington D.C. It was reported in the January 1994 issue of the IEEE Spectrum Newslog that $\mathrm{MCI}$ had signed agreements with four wireless technology companies and Lincoln Laboratories of Cambridge Mass. to develop novel wireless phone devices. MCI stated that the group will develop specifications for U.S. PCN systems that would be compatible with the European GSM standard. This is yet another possibility for another set of standards for PCN communications in the United States.

The concept of home and visitor location registers and detailed mobility inanagement over the radio network are concepts that are brought forward into the basic architecture and radio network functionality of PCN. These concepts may provide a technical 
means to intercept the communications through a radio based solution or may make $i$. so complicated that this alternative may be impossible.

\subsection{CT2Plus Channel Frequency Specification}

The CT2Plus Class II standard, RSS 130 Annex 1 Draft 0.4, was prepared by the Department of Communications in Canada and adopted as the national standard for the common air interface for all radio communications for PCN. The details provided here identify the specific frequencies that must be targeted for a radio based intercept system.

Section 6.2 of the CT2Plus specification indicates the center frequency of operation with offset associated to the actual channel number of operation for the communication session. The equation used is as follows:

$$
f_{\mathrm{c}}=943.95+0.1 \cdot \mathrm{n} \quad \mathrm{MHz}
$$

The parameter " $n$ " in this equation is defined as the charnel number. The peak frequency deviation under all possible data transmission patterns shall be limited to the range of $14.4 \mathrm{kHz}$ to $25.2 \mathrm{kHz}$ with a modulation index between 0.4 and 0.7 respectively. The modulation scheme to be used is a 2 level Frequency Shift Keying (FSK) shaped by an approximately Guassian filter. The filter shall maintain the adjacent channel power transmission specification parameter to not exceed $10 \mu \mathrm{W}$. The carrier spacing is $100 \mathrm{kHz}$ and the transmitter center frequency must be within ${ }_{-} 10$ kHz. In the specification " $n$ " can vary from 1 to $\mathbf{4 0}$ with an option to increase to $\mathbf{8 0 .}$ This corresponds to a frequency range of $944.05 \mathrm{MHz}$ to $947.95 \mathrm{MHz}$. With the expansion to 80 channels the frequency assignment would increase to 951 . $5 \mathrm{MHz}$. One of the mandatory technical design criteria for FDMA type CT2Plus PCN equipment is the efficient use of radio transmission bandwidth with a minimum specification for out of band or cochannel interference. All aspects of today's radio transmission technology centers arolnd clean, band limited transmitters with efficient modulation schemes. 
The RSS 130 Annex 1 Draft 0.4 specification clearly states that all portable PCN randsets inust be capable of operating on all 80 channels. The fixes equipment must initially only operate over the first $\mathbf{4 0}$ channels assigned but have the technical capability to easily expand to accommodate the 40 higher channels. Yet, the supplier of the fixed equipment must provide a means to strictly block the use of the higher channels and only operate on the lower 40 . The equipment shall be designed in such a manner that it is nut possible to defeat the restriction to the lower 40 channels through the use of the normally accessible controls of the equipment.

From the release of the CT2Plus Class II, RSS 130 Draft 0.4, specification in August of 1992 some minor changes have been instituted by the DOC. In the Draft specification only 35 channels, 1 through 35 , were assigned for traffic channels.

\begin{tabular}{||c|c|cc|cc|cc||}
\hline \multicolumn{8}{|c||}{ Table 4.3 } \\
Carrier Frequencies (MHz) For \\
Radio Traffic Channels For \\
CT2Plus Cordless Telephone Systems \\
\hline \multicolumn{8}{|c||}{ Reference Coni...unications Canada SRSP-508 Issue 2 } \\
\hline 1 & 944.0500 & 11 & 945.0500 & 21 & 946.0500 & 31 & 947.0500 \\
2 & $944.15 C j$ & 12 & 945.1500 & 22 & 946.1500 & 32 & 947.1500 \\
3 & 944.2500 & 13 & 945.2500 & 23 & 946.2500 & 33 & 947.2500 \\
4 & 944.3500 & 14 & 945.3500 & 24 & 946.3500 & 34 & 947.3500 \\
5 & 944.4500 & 15 & $945.450 C$ & 25 & 946.4500 & 35 & 947.4500 \\
6 & $944.550^{\circ}$ & 16 & 945.5500 & 26 & 946.5500 & 36 & 947.5500 \\
7 & 944.6500 & 17 & 945.6500 & 27 & 946.6500 & 37 & 947.6500 \\
8 & 944.7500 & 18 & 945.7500 & 28 & 946.7500 & 33 & 947.7500 \\
9 & 944.8500 & 19 & 945.8500 & 29 & 946.8500 & 39 & 947.8500 \\
10 & 944.9500 & 20 & 945.9500 & 30 & 946.9500 & 40 & 947.9500 \\
\hline
\end{tabular}

Channels 36 through 40 were the five common signaling channels. With the release of the standard radio system plan, SRSP 508 Issue 2 entitled "Technical Requirements for Digital Cordless Telephone (DCT) Systems Operating in the Band $944-948.5 \mathrm{MHz}$ on January 23rd, 1993 these assignments were changed. In the SRSP-508 Issue 2 specification channels 1 isrough 40 are reserved as regular voice traffic channels. Table 4.2 shows the assigned voice channel frequencie, as set fot th by the DOC. Channels 41 through 45 are reserved for common signaling channels (CSC's). A CSC is used for data traffic such as link initialization, handi-off control signaling and, most 

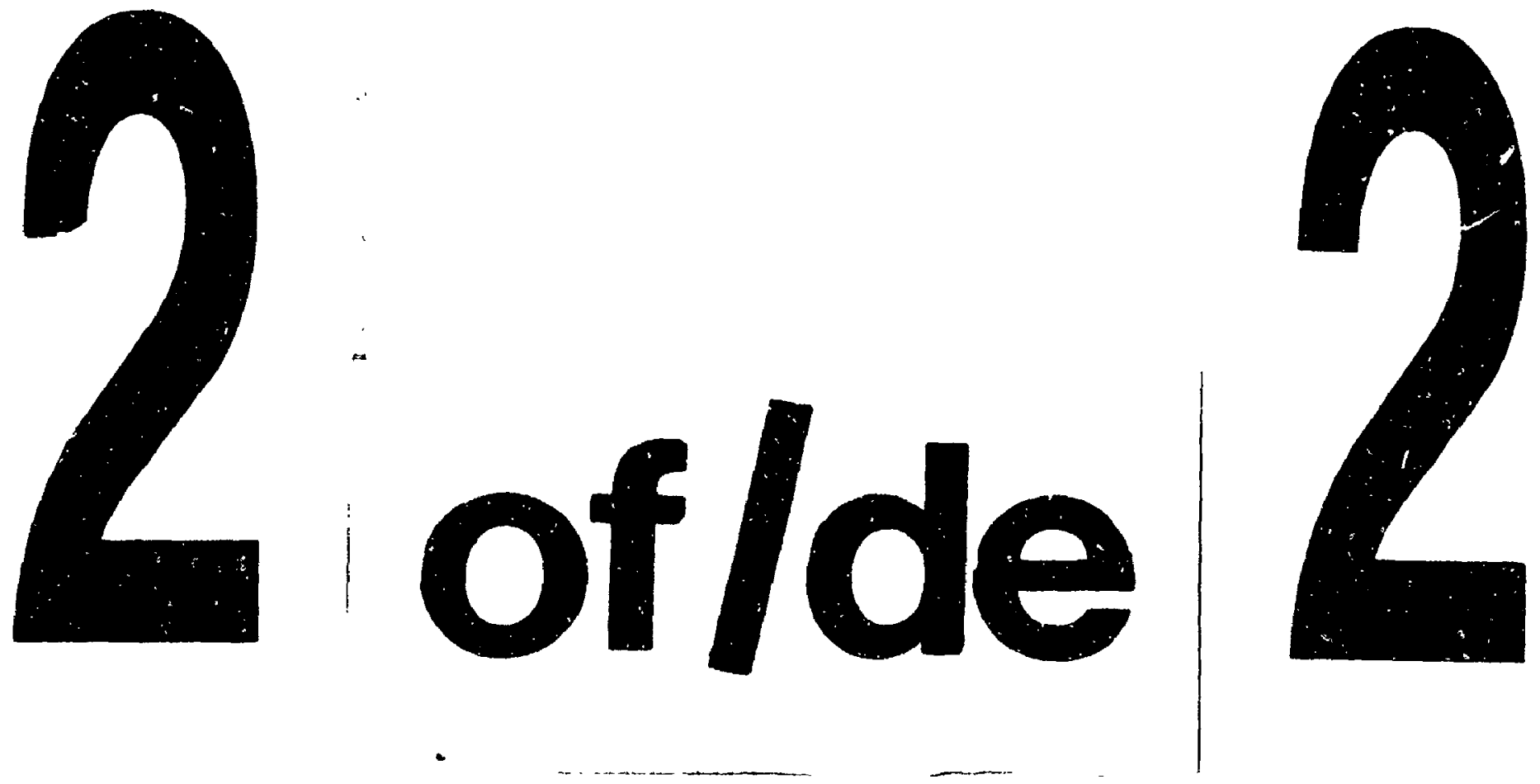

PM-1 31/2"X4" PHOTOGRAPHIC MICROCOPY TARGET NBS 1010a ANSI/ISO \#2 EQUIVALENT

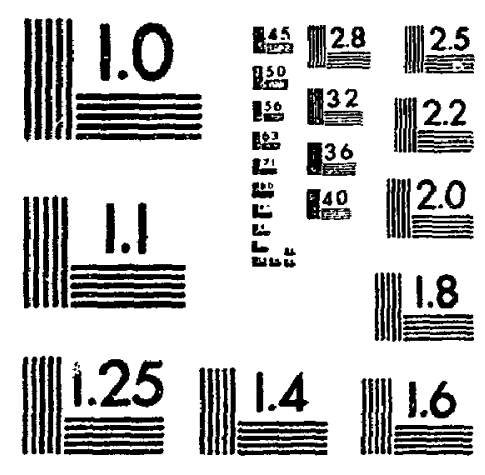

PRECISIONSM RESOLUTION TARGETS 
importantly, location tracking on the PCN RF network. Table 4.3 shows the frequencies assigned to CSC's by the DOC in SRSP-508.

\begin{tabular}{|c|}
\hline Täle 4.4 \\
Carrier Frequencies for \\
Common Signaling Channels \\
For CT2Plus Cordless Telephone Systems \\
Reference Communications Canada SRSP-508 Issue 2 \\
\hline $41.948 .0500 \mathrm{MHz}$ \\
$42.948 .1500 \mathrm{MHz}$ \\
$43.948 .2500 \mathrm{MHr}$ \\
$44.948 .3500 \mathrm{MHz}$ \\
$45.948 .4500 \mathrm{MHz}$ \\
\hline
\end{tabular}

The frequencies listed in the previous two tables define exactly what frequencies must be accommodated by a radio based intercept system for CT2Plus in Canada.

In recognition of the world wide spectrum allocation within the $1.8 \mathrm{GHz}$ to $1.9 \mathrm{GHz}$ band for PCN as outlined by WARC 92, the Industry Advisory Committee (IAC) of the Department of Communications has recommended a PCN allocation conforming to this direction. It is for this reason that in the future there may be two bands identified for PCN services. One as specified in SRSP 508 Issue 2 and another conforming to the US and world wide allocation in the $1850 \mathrm{MHz}$ to $1990 \mathrm{MHz}$ band. This dual allocation would lead to an inefficient use of limited radio spectrum. It is highly unlikely that $\mathrm{PCN}$ phones working in the $948 \mathrm{MHz}$ range would have the versatility to have the frequency agility to operate in the two bands. Therefore, there eventually may be two PCN systems in Cinada. The higher frequency systems may, however, provide for the interoperability for Canadian users to roam into the US.

\subsection{Description of CT2Plus RF Data Transmission}

Within the C12Plus Class II standard there are specific guidelines for all types of digital transmissions associated to the communications. The details of the data transmissions are described to provide insight into the complication of another individual not directly involved in the communications intercepting the digital off air 
transmissions between the PCN handset device and the radio base station. Simply, the digital messages can be divided into two broad categories, digital voice and control data transmissions. The control signaling is done via the Common Signaling Channel (CSC).

The CSC uses a multiplex structure called Multiplex 4 or MUX4. Each of the radio channels assigned for a CSC can support 12 CSCs through the use of time multiplexing. Each CSC data frame is divided into 12 six millisecond slots. Within each slot 2 data words are alternated three times each. Each word, CFP Tx and CPP $\mathrm{Tx}$, is one millisecond in duration. This corresponds to a total frame duration of 72 milliseconds.

The CFP Tx message is comprised of 66 bits. The first 16 bits as well as the last 16 bits of the message are part of the D-channel signaling. The D-channel throughput is $1.333 \mathrm{kbits} / \mathrm{second}$ and is used for layer 2 and 3 signaling and to indicate the status of the channel. The center 34 bits of the message is subdivided into 10 bits of preamble and 24 bits of either channel marker bit pattern sent by the fixed base station (CHMF) or the synchronization word from the fixed base station (SYNCF). The CPP Tx message is subdivided by the identical scheme as the CFP Tx message. The first and last 16 bits of the message is D-channel information. The center 34 bits of the message is 10 bits of preamble and then 24 bits of synchronization word from the portable (SYNCP). When transmitting on a CSC, the portable device synchronizes its timing to the base station transmissions which is considered the master.

The traffic channels in the CT2Plus Class II specification outlines the transmission of signaling information as well as transmission of the voice packets. Compared to the CSC, the traffic channel handles data in three different burst structures, MUX3, MUX2, and MUX1.4. The standard supports the transmission of 68 bits of data at an instantaneous rate of $72 \mathrm{kbits} / \mathrm{second}$. The fundamental data being transmitted on the traffic channel is the data corresponding to the encoded speech information. The speech channel occupies 64 of the 68 data bits available in every burst on the traffic channel. These words, in the context of the fixed side of the communications, are CFP transmit and CFP receive messages. The entire frame is 144 bits long and has a 2 millisecond duration. This incorporates 8 bits for guard band, 4 bits between each alternating CFP transmit and CFP receive messages. This coincides with the 72 kbits/second throughput requirements as outlined previously. By alternating between 
transmit and receive packets on the same RF channel, the CT2Plus standard has adopted a term called time division duplexing (TDD). TDD using the 144 bit frame and two 68 bit packets within the frame and corresponding guard bands is the normal operational state of transmission on the RF link.

Finally, it is important in the overall details of the CT2Plus Class II RF transmission plan, to describe the digital speech coding algorithm. The standard identifies the CCITT G.721 specification for the basis of the voice coding. This is the speech coding algorithm defined in Section 8 of the European I-ETS 300 131, 1992 standard for cordless telephone apparatus. This portion of the specification outlines all the details associated to a codec using a Adaptive Differential Pulse Code Modulation (ADPCM) at a rate of $32 \mathrm{kbits} / \mathrm{second}$ for the analog to digital conversion of the speech information. Voice transmissions over the traffic channel take place at $72 \mathrm{kbits} / \mathrm{sec}, 2$ times the single ADPCM rate which corresponds to the TDD duplexing scheme.

Without strict adhurence to the digitization scheme for the voice transmission, the interoperability of PCN equipment would be lost. In an effort to regulate this extremely important element of the overall interworking of the various PCN equipment, it was determined that it was necessary to regulate many facets of the analog portion of the speech coding as well as the digital. The performance of the analog information transmitted via the digital channel has to remain a constant throughout the network. Such analog variables as frequency sensitivities and response and reference speech levels to define loudness are defined to maintain the optimal quality to the end user in the interoperation of the PCN equipment. Further to this more complicated parameters are outlined in the specification. Detectable aspects of the user's audio are strictly defined so that the user is provided with the highest quality audio product available. Distortion, both harmoric and quantizing, levels are strictly limited. Also, one of the required analog aspects of telephone that all user's have come to expect is listener sidetone. In a digital application it is somewhat difficult to produce this analog affect. However it would be noticed if missing. Therefore, section 8.7.2.2 defines that the listener sidetone level shall not be less than $35 \mathrm{~dB}$.

Network considerations must also be taken into account when designing a speech $\because$ iented system. The I-ETS 300131 standard outlines the limits of network delays. These delays could be a combination of conventional analog delays such as delays created by transducers and filters. It also takes into account digital delay caused by the 
burst structure of the transmission. Network echo affects are also limited for both a two wire interface and a four wire interface.

Many exacting details are outlined in the digital transmission portions of all the applicable standards and specifications. Without strict adherence to these details guaranteed high quality communications for PCN could not be achieved. Compared to technologies, that only a few years ago were at the forefront of the radio communications and telephone communications domain, this method of digitai radio transmissions is yet again leading edge technology. Some of it may be publishred in 1992 which is a couple of years old but it takes time for definitions to become reality with the appropriate hardware. These new, innovative concepts introduced in the digital transmission scheme for CT2Plus in Canada creates a serious technical complication to the off air interception of PCN communications. No longer will a simple scanner afford a method to eavesdrop on radio telephone communications. Also, no longer will any analog radio receiving device allow for the technical means for the lawful interception of radio telephone communications as it applies to CT2: lus.

\subsection{Canadian CT2Plus Common Air Interface}

Communications Canada has adopted as the national standard the CT2Plus Class II standard for the next generation cordless telephone communications. The fundamental basis for this specification adopted by Communications Canada is the European common air interface for second generation, CT2, digital cordless telephones, I-ETS 300 131. This European specification was published in April 1992 and provides full technical details for the radio component of CT2 cordless telephone communications including such items as transmission standards, data communications handling and specific data word structures for all communication transactions. These technical details, presented here, will be used to create the ability to decode radio transmissions for the purpose of off air interception of communications on a CT2Plus PCN network.

Communications Canada, subsequently, has published a Radio Standards Specification (RSS) number 130, Issue 2 which outlines the specifications for the Canadian set of standards ove: and above the European set. RSS 130, Issue 2 is entitled "Digital 
Cordless telephones in the Band 944 to $948.5 \mathrm{MHz}$. RSS 130, Issue 2. Annex 1 is entitled "CT2Plus Class 2: Specification for the Canadian Common Air Interface for Digital Cordless Telephony, Including Public Access Services". The effective date of these documents was January 23,1993. RSS 130, combined with the European document, defines the technical standards for CT2Plus Class II cordless telephone communications in Canada. The RSS 130 publications provide a superset of technical instructions and details that supersedes the specifications in the ETS 300131 document. All equipment manufacturert for use in Canada must adhere to the details of RSS 130, Issue 2 as well as ETS 130131 , RSS 130 taking priority where applicable.

There are fundamental differences that RSS 130 outlines. In the area of RF specifications the ETS 300131 applies to cordless telephones operating in the band 864.1 to 868.1 MHz. Both the CT2Plus standard and the European standard outline the use of 40 traffic channels and 5 common signaling channels (CSC). The CT2Plus standard, however, assigns the frequency band of 944 to $948.5 \mathrm{MHz}$ for the operational band. However, the RSS 130 specification takes into account the out of band emissions for an $8 \mathrm{MHz}$ wide band rather than the $4 \mathrm{MHz}$ band as in ETS 300131 . This is due to the planned expansion of 4 more $\mathrm{MHz}$ in bandwidth for cordless telephone communications in Canada. This would push the upper bound of the operating frequencies to $952.5 \mathrm{MHz}$. It is stipulated in section 1.3 of the RSS 130 , Issue 2 document that all portable equipment must be capable of operating over the entire band, 944 to $952 \mathrm{MHz}$. This shows, outside of the original release of 40 traffic channels, Industry Canada is anticipating a high usage for this bandwidth and has already allotted a second $4 \mathrm{MHz}$ portion of the radio spectrum for future use. Somie minor differences associated to the Canadian CT2Plus specification are associated to spurious emissions in operational television transmission bands. Also, there are less stringent spurious emission requirements in the microwave bands in Canada.

In the operation of the CSC signaling, the portable handset is responsible for local registration. Thus the network will only page the handset in the zone where it has registered. Location registration is defined as a background task for the handset. Normal call set-up procedures use the CSC's. Since there is always a transmitting signal transmitted from the fixed base station all transmissions from both parts of the radio communications are always synchronized. In this scenario there is no MUX 3 type transmissions. However, as a fall back procedure, call set-up can be executed over the traffic channel using MUX 3 type transmissions from the portable or MUX 2 
from the base station. The signaling rate, MUX 1.4 which is optional in ti.e ETS standard is the mandatory MUX 1 signaling rate in the CT2Plus standard.

The other area that differs from the European specification are the details outlining the hand-off procedures for the class 2 cordless telephone. In the Canadian CT2Plus handoff is synchronous. The base station always will transmit first using the MUX 2 signaling scheme. There is no MUX 3 mode for this operation in the standard hand-off procedure. Further, the traffic channel selected to hand-off to will be negotiated between the base station and the handset prior to the hand-off via "Candidate Channels" and "Channel Confirm" message exchanges. If the hand-off procedure fails the handset will try to reestablish the hand-off via a CSC. If this again fails then the hand:et tries to reestablish the hand-off using a MUX 3 signaling scheme as a fall back procedure. The message used in the Class 2 hard-off message has the ability to specify more than 40 basic traffic channels, allowing for the future traffic channel expansion, and when the message is sent by the base station, has the ability to reduce the portable's transmit power. The "Link Re-establish on a Given Channel" message as specified in the ETS 300131 specification is never used.

There are some further specific messaging difference between the ETS 300131 specification and RSS 130 Annex 1, Issue 2. For example in RSS 130 the portable device always presets the "ZAP" field to " $F$ " hex upon successful manual eniry of the registration data. There are some other layer 3 messages and their usage is mandatory in CT2Plus rather than optional as in the European specification.

The common air interface is one of the most if not the most important aspect of the communication standard in Canada and must be fully understood to successfully develop equipment to lawfully intercept PCN radio transmissions. Looking back at the attempt to provide second generation cordless communications in Britain, one of the key aspects that led this endeavor to failure was the lack of strict criteria for the RF interface amongst all the service providers. With this well defined Common Air Interface the interoperability amongst service providers will be inherent in the equipment. The user should, therefore, have the ability to roam freely over a great range without the loss of communications. Also, with the ability to hand-off during an active call and the system having the ability to track the portable because of the stressed registration technique in the Canadian specification, the user has what he demands. The user will be able to receive a call directed to him wherever he has radio base 
station coverage. Once that call is established the user can move freely and maintain that call with a high level of probability with the constraints inherent in cordless telephone applications such as the user can only move at a walking rate. The communications coverage will not extend into mobile applications. This will have to be covered off by cellular telephones.

\subsection{Scrambling and Encryption}

One of the most significant technical threats to law enforcement that is introduced as the result of digital transmission schemes being adopted by the private sector and available to the public is the ease for that digital traffic to be scrambled or encrypted. Scrambling has been given the definition related to an analog method used to manipulate an analog signal into an unrecognizable form. All transformations of the original signal are perfurmed in the analog realm. Encryption, on the other hand, is interpreted as the format that manipulates a signal utilizing a digital means. It is considered the most robust and the one that can provide the highest amount of signal security. The level of security given to the digital signal through use of encryption does not depend on the method in which it is transmitted. The encryption operation akes place prior to transmission of the signal. Public encryption of digital transmissions will completely protect the communications from any form of eavesdropping or interception regardless if it is a law enforcement agency attempting the intercept.

PCN will utilize a digital bit stream to represent voice information. This digital bit stream is then encoded into the correct radio transmission format and then transmitted. hit this simplistic voice transmission architecture it is obvious that a device can be incorporated in series with this digital bit stream to encrypt the signal prior to encoding and transmission. Also, there is no limitation to how far the encrypted signal can pass into the network. The PCN voice network infrastructurc is fully digital and would transparently transmit a signal encrypted or clear. The signal could, therefore, possibly be encrypted end to end. 
Currently, single integrated circuits are available that perform digital encryption to a serial bit stream. Security levels are mainly based on the sophistication of the IC but it is realized that an encryption scheme as robust as the Digital Encryption Standard (DES) is available on a single chip. DES, up until recently, has been certified to protect very sensitive information including inter-bank transfers and classified law enforcement radio transmissions. With a 64 bit key word DES provides the possibility of 13 million different permutations to the transmitted signal.

There is no possible way to anticipate if or how encryption will be utilized in PCN. There are so many variables associated to this application that there are infinite possibilities and examples of encrypted voice signals in PCN. The only savin grace is the fact that if a user who is in roam mode, outside of their personal base station range, has to use a predefined or agreed encryption key that the network has knowledge of so that the user can communicate through the roaming network. If the network base station has this information it can forward it to law enforcement, if necessary, during the setup procedure of every call and, therefore, provide the information necessary for law enforcement to decrypt the signal. However, there is a possibility that when the user is within range of their private base station there will be no simple way to obtain the encryption key and, therefore, the signal could become unobtainable and secure from eavesdropping.

The availability of digital encryption schemes and the ease in which it can be incorporated into PCN communications is a serious threat to law enforcement and their ability to intercept these signals. Currently, there is no industry accepted encryption scheme or method to provide a level of security beyond what is inherent in the PCN communication standard. Yet, it can be incorporated quite simply into the PCN hardware and network.

\subsubsection{Northern Telecom Security for PCN}

The Canadian Department of Communications has adopted CT2Plus class 2 as the national standard for PCN within Canada. Also, since Northern Telecom and Bell Northern Research developed this standard, it is wise to investigate the security measures that these companies have developed within CT2Plus because it will directly 
affect the ability to implement a radio based interception technique by law enforcement. These will be the technological security measures that must be over-ome to allow for the authorized interception of PCN communications. In BNR's own publication, Telesis issue 94, telecommunications security issues are brought to the forefront.

BNR states that even more of an issue to be considered within the subject of security in PCN is the fact that the telephone conversation is transmitted via radio. The issues that they identify are as follows:

"1. eavesdropping or intercepting voice and data

2. fraudulent access to telephony services

3. privacy o: iucation

4. unauthorized call suditing and

5. unauthorized use of a personal handset. "[12]

Item 1 on this list is the one most applicable to this research. This security risk is best described in the same publication as follows:

"The most obvious security risk is the radio link's vulnerability to eavesdropping. Using commercially available scanners, eavesdroppers can easily scan radio waves to intercept con'rersations; in conventional wireline systems, they would have to physically tap the telephone lines. The consequences can be much more damaging than merely listening in on ordinary conversations. Eavesdroppers, for example, could gain access to a subscriber's calling-card or credit card numbers - information that the network operator may be legally liable to protect. "[20]

The article also describes the other items associated to security issues including telephone fraud. An estimate is provided indicating that the US cellular industry loses anywhere from $\$ 100$ million to $\$ 700$ million dollars a year in telephone fraud. The article follows with a statement that BNR designess of the PCS product line for Northern Telecom are designing in technical capabilities that will thwart the security threat in PCN. Some of these methods are being introduced into the Global System for Mobile Cornmunications (GSM) digital cellular radio products. While GSM standards are specific to the digital cellular networks, GSM represents the most sophisticated technology for mobile and personal wireless telephone communications available. It is fundamentally the basis for PCN. 
Northern Telecom describes the rudimentary expectation of security for PCN as the level commensurate with the security inherent within wireline networks today. As the result of this requirement, Northern Telecom has introduced within their DMS series "SuperNode" central telephone switching platform an authentication center. This center, which is part of the home location register, governs the administration of the immediate verification and authorization of users on the network. It also provides the source information for the encryption of the transmitted portion of the communications link. This functionality within the switch is also designed under the constraints that all the processing necessary to perform these functions will not unduly affect the subscribers service during call setup.

In an effort to overcome these security threats to future technologies in wireless telephone communications basic security standards have been adopted for GSM. In turn these standards will be the fundamental requirements within PCN. These security features are:

1. subscriber confidentiality

2. personal identification numbers

3. encryption of subscriber data, voice, and signaling information 4. subscriber identity authentication

To provide the user with total anonymity over the radio link portion of the communications the user is issued a temporary mobile subscriber identity (TMSI). This identification scheme replaces the permanent international mobile subscriber identity (IMSI) when the user logs onto the system. The transmitted identity information from the PCN handset would be, from that point on, the TMSI which is a random number, changed frequently by the system control logic and does not actually provide enough information to uniquely identify the user. This is unless the TMSI transaction, during initial system setup procedures, is also intercepted and tracked from that time forward.

To furnish a level of security to the actual hardware which is physically controllable by the user and can provide protection against unauthorized use of the handset the GSM standard has adopted an architecture for the handset. which divides it into two fundamental parts. The first part is the actual radio portion and the second is a subseriber identity module (SIM). This SIM is a new technology "smart card" which is 
the approximate size of a credit card with imbedded integrated circuitry which holds subscriber specific information and network specific authentication information. Without this "smart card" inserted into the handset the unit will not be able to place a call or obtain network authorization to use ant services. All the user has to do is remove the "smart card" from their PCN handset and that unit is protected from unauthorized "se even if the phone is stolen.

Further f-otection is afforded to the handset utilizing the SIM with a user configurable 4 digit personal identification number (PIN). Similar to the process accepted for validation of banking industry automatic teller machine transactions, a four digit PIN can be programmed into the "smart card" so, even if the phone is lost, unauthorized use of the unit is prohibited until the correct PIN is entered into the handset. This only provides 10,000 combinations for the security code but, hopefully, in the time it takes to acquire the correct code the phone can be reported stolen and entered on the "black list". If it is on the "black list" and attempts to make a call the phone will be "zapped" and the memory cleared disallowing any further use or telephone fraud.

Cryptography and encryption are attributes that are designed directly into the GSM mobile telecommunications standard. Specifically, in the BNR implementation, the $\mathrm{A} 5, \mathrm{~A} 3$ and $\mathrm{A} 8$ algorithms are incorporated. These 3 schemes provide the basis for the encryption of the subscriber's transmitted voice, data and control signaling. Specifically, the A3 algorithm is utilized in the subscriber identification authorization process during initial call setup procedures.

The A5 algorithm is used in the over the air encryption of transmitted data to and from the handset. This A5 scheme is currently a fixed GSM standard to be used by all operators to conform to a common over the air transmission standard. This will ensure the interoperability of PCN handsets and the ability to maintain digital security of the transmission link as they roam outside their respective home service areas.

The A8 algorithm is used in the generation of a ciphering key, $\mathrm{K}_{\mathrm{c}}$. This ciphering key is generated for each individual call and is forwarded from the home location area authentication center to the visitor location area for further use in the A5 algorithm by the handset and the radio base station. This means that every distinct call made by a handset will use a different cryptographic key for the encryption of its transmitted 
information. The possibilities are endless based on the increased number of bits used in the ciphering key word.

The GSM security measures also introduce a robust method of subscriber authentication prior to any call being connected. In comparison the cellular network actually does the authentication process after the initial call has already been connected and, with respect to security measures, the fraudulent call already in existence with no way for the cellular system to force a disconnect. The Figure 4B, GSM Authentication Procedure, shows the complicated transactions between the handset, the visitor location network equipment and the home location equipment to produce a valid user confirmation prioi to call connection.

The procedure for authentication in a GSM neiwork is as follows. Critical information to the process is programmed into the telephone handset and is not only the international mobile subscriber identity information but the subscriber's secret authentication key, $\mathrm{K}_{\mathbf{j}}$. When the handset requests a call the home location authentication center receives the IMSI and, through a look up table, gets the $\mathrm{K}_{\mathbf{j}}$. A pseudo-random number generator creates a number, processes it using the A3 algorithm to create an expected subscriber resfonse (SRES) number. Both the random number and the SRES are forwarded to the visitor location register. The random number is broadcast to the handset which in turn, using the known A3 algorithm programmed into the internal handset smart card, creates its subscriber response (SRES'). The SRES' is transmitted back to the visitor location register and if the SRES equals the SRES' the authentication has been successful and the call will be connected.

BNR and Northern Telecom have placed significant emphasis into the design of robust GSM security procerses that will either provide them with the basis for security in PCN or actually be transferred into their PCN design. The GSM standards relate to digital cellular networks and do not officially correspond to PCN. Huwever, in the current state of digital wireless telephony development GSM standards are the most sophisticated and could be easily considered to be the closest possible relative to the upcoming PCN digital wireless telephony systems. Subsequently, a product line has been introduced by Northern Telecom for business wireless communications. The Northern Telecom "Companion" portable wireless telephone system utilizes the model C3020 portable telephone. In the design summary sheets for this product line Northern Telecom boasts a digital system that is not prone to interference or eavesdropping. 

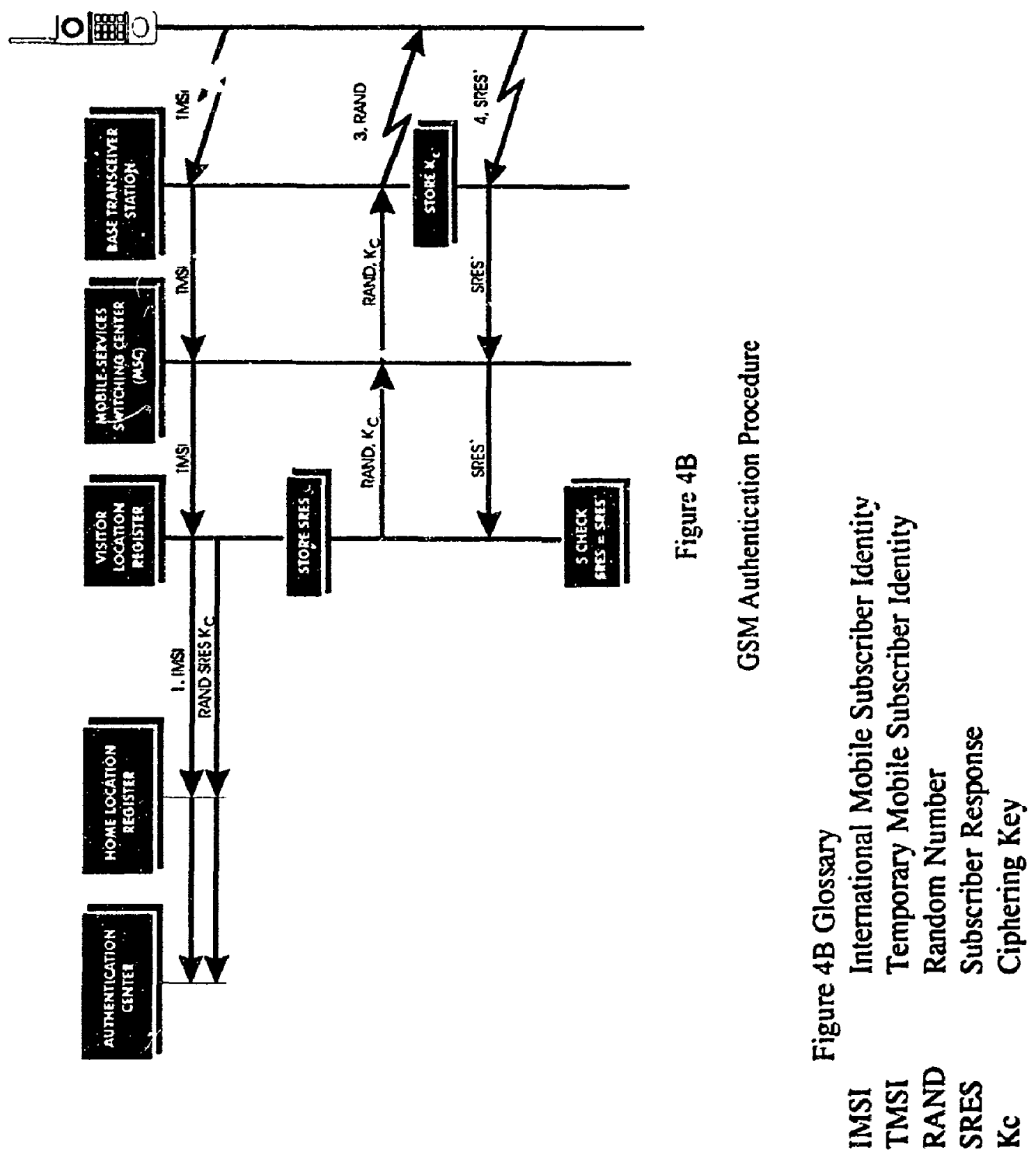
It also uses a personal password system within the handset that deters unauthorized uses and that can lock the phone. This phone also is compatible to CT2Plus public cordless telephone networks where available. All these features are directly related to the GSM security features proposed.

High level digital security will be inherent in PCN and this will cause extreme difficulties in obtaining wire tap information especially now knowing that Communications Canada has adopted the Northern Telecom CT2Plus proposal for the national standard for PCN and wireless phone systems conforming to this national standard are currently available.

\subsection{Comparison of Multiple Access Schemes}

As mentioned in a previous section, the most controversial aspect of choosing a standard for the RF transmission properties for PCN has dealt with the choice of multiple access scheme. The three alternatives available are FDMA, Frequency Division Multiple Access, TDMA, Time Domain Multiple Access and CDMA, Code Division Multiple Access. Technical iaformation is presented to offer an understanding of the three technologies and how they may complicate attempts in successfully obtaining information by intercepting communications off the air in a PCN system.

FDMA has been adopted in Canada as the multiple access scheme for PCN communications. At least for this release as information to follow indicates that the U.S. regulatory bodies are not considering techniques for $\mathrm{PCN}$ transmission that incorporate FDMA. Therefore, when the U.S. comes on board with PCN it is highly likely that the two systems will not be able to interact. Thus, this will provide a block to the ability to provide mobility and communications coverage between the two countries.

FDMA utilizes a multitude of narrow band, unique radio channels. each of these channels is associated to one two way conversation only. Therefore, in the Canadian channel allocation design there are 40 defined traffic charnels to carry voice 
conversations for PCN. The transmission on the channel is digital in format and combines, in a time domain duplexing arrangement, both the forward half and the reverse half of the conversation. Yet, fundamentally different compared to the other multiple access schemes, FDMA can only carry information associated to strictly one conversation per radio channel. Undoubtedly, this is the underlying limitation to this mode making it relatively spectrum inefficient.

In the United States the controversy continues. Initially, the CTIA chose TDMA as the multiple access scheme for digital cellular communications in tire United States. IS 54 was published by the U.S. Electronic Industries Association in cooperation with the CTIA which outlined the next generation dual mode cellular equipment compatibility standard. The specification outlined the operation of combination analog and digital cellular equipment. Each device could operate in dual modes depending on the communications infrastructure available. The CTIA recognized by the sheer volume of analog equipment in the market place they could not force cellular service suppliers to drop the analog service and switch directly into digital. Therefore, dual mode equipment was conceived. The digital portion of this cellular specification uses TDMA as its riultiple access technique.

This sarly desision by the CTIA did not impede a company based in California, Qualcomm Ltd., from continuing its development of CDMA technology for both digital cellular and PCN applications. Qualcomm first introduced their perceived advantages to CDMA technology in November 1989. Since that time Qualcomm has pushed forward with cooperation of many equipment manufacturers to put trial CDMA systems in operation. To date the comparative values of TDMA versus CDMA is still the underlying indecision regarding adopting a standard for PCN in the U.S.. Table 4.4 shows a technological comparison of the two multiple access methodologies compared to a third, AMPS, which the analog standard currently being utilized in North America for cellular communications. After extensive field testing of CDMA based conmunications the TIA, Telecommunications Industry Association, adopted IS 95 in July 1993 as the CDMA digital standard. Now there are two published and recognized digital standards for the next generation cordless telephone communications. 
Table 4.5

Capacity Comparison of TDMA \& CDMA vs. Cellular AMPS

\begin{tabular}{|c|c|c|c|}
\hline & AMPS & TDMA & CDMA \\
\hline Cellular Bandwidth & $12.5 \mathrm{MHz}$ & $12.5 \mathrm{MHz}$ & $12.5 \mathrm{MHz}$ \\
\hline Factor & $4 k=12$ & ४ $<\mathrm{k}=7$ & $x=1 \%$ ? \\
\hline RF Channel Bandwidth & $0.03 \mathrm{MHz}$ & $0.03 \mathrm{MHz}$ & $1.25 \mathrm{MHz}$ \\
\hline $\mathrm{els}$ & 12.510 .0 & $12.510 .03=416$ & $12.5 / 25=10$ \\
\hline$\#$ of $\mathrm{R}$ & $416 / 7=59$ & $416 / 7=59$ & $12.5 / 1.25=10$ \\
\hline $\mathrm{is} / \mathrm{Cell}$ & $\% 5 \%$ & से 57, & अम 10 २े \\
\hline Voice Call / RF Channel & 1 & 3 & 38 \\
\hline of Voice Channels / cell & $57 \cdot 1=57$ & $57.3=171$ & $0.38=$ \\
\hline Sectors / Cel & 3 & 3 & 3 \\
\hline Wlls / Sector & $57 / 3=19$ & $17 / / 3=5 ?$ & 380 . \\
\hline Capacity vs. AMPS & N/A & $3 x$ & $20 x$ \\
\hline
\end{tabular}

An article in the January 10, 1994 pubiication of Telephony compares the two competing digital multiple access schemes.[21] The comparison basically touts the benefits of CDMA over TDMA. For example CDMA has a higher quality inherent transmit and receive capability with the ability to accept multipath signals, coherently combine them to increase the signal to noise ratio and hold onto the signal longer than TDMA. Further, the one benefit that is quite important in the U.S. market is the system capacity because of the limited radio spectrum available. CDMA claims to have 20 times the capacity of analog AMPS and seven times the capacity of TDMA.

Many companies in the U.S. have decided to side with Qualcomm and adopt CDMA as their digital technology for PCN services. Specifically, Time Warner Communications is using CDMA on its cable system in Florida. American Personal Communications had a trial system in Washington D.C. and Cox Enterprises Inc. is testing a CDMA PCN system over their cable network in San Diego California. Moreover, other major players in the telephone industry in the United States are looking at CDMA. Bell Atlantic Mobile Systems will be testing a CDMA network in Washington D.C. as well as deployment of CDMA systems in their northeastern market including Connecticut, Rhode Island and Massachusetts. US Wesı signed an agreement with Qualcomm to supply a minimum of 36,000 CDMA phones for their systems. US West has a digital 
CDMA based network in Seattle scheduled for commercial service availability in late 1994. PacTel Cellular was the first telephone carrier to field test a CDMA based network in 1989. They announced their intent to deploy CDMA in their Los Angeles market as early as 1995 with further expansion to their markets in Sacramento and San Diego, California as well as Atlanta Georgia. Internationally, CDMA technology has been adopted by Taihan Electric Wire Co. of South Korea for their PCN type digital cordless telephone system. Teknekron Communications Systems of Berkeley California will supply the system. The CDMA phones were scheduled to be marketed by mid 1993. In complete contrast Teknekron has also joined with AT\&T, Mitsui \& Co. Ltd. and Mitsui Comtek Corp. to provide integrated chip sets for low powered digital cellular phones utilizing the TDMA standard in accordance with IS 54.

Another consideration that must be observed is the available equipment for the technology. Primarily the consumer market demands a wide range of choices in equipment that they can purchase. Competition in this lucrative market for personal handset equipment is the one issue that industry sees as a high probability of significant profits. Qualcomm, developer of the CDMA technology, has signed agreements with Alps Electric, AT\&T, Goldstar, Hyundai, Maxon, Motorola, Nokia Mobile, Northern Telecom, OKI and Samsung for the manufacture of personal handset equipment. Therefore, there is yet another reason for service providers to choose CDMA technology. The consumers will have a large choice of portable equipment that will communicate with a CDMA network.

The article in the January 10, 1994 issue of Telephony concludes stating that CDMA has gathered international recognition because it is a technology that "provides superior performance in quality, capacity and network flexibility"[21]. The author also predicts that CDMA technology will find many international and domestic applications including cellular, wireless locel loops and PCN. It should be noted that the author of this article, Thomas R. Crawford, is the Director of Marketing for Qualcomm's CDMA technology business unit based in San Diego, California.

An article in the IEEE Communications Magazine, November 1993, has a differing opinion of CDMA for PCN applications. The discussion in the article compares numerous second generation cordless telephone and digital cellular methodologies. It was concluded that CDMA has significant advantages in cellular utilization but may not be the best solution for PCN applications. In this regard it is stated that high capacity 
nodes that convey very high bit rates to users within a microcell would probably be more efficient using a FDMA scheme. The author does state his preference to CDMA yet a further issue is brought forward. In cordless telephone applications, compared to microcellular applications, cochannel interference problems are quite different. However, TDMA with dynamic channel allocation may not be out-performed by CDMA when operating in the same spectrum bandwidth. In conclusion of the quite detailed comparison of numerous technologies, CDMA is not the clear cut choice. Simple issues such as using a non-standard voice coder algorithm Code Excited Linear Prediction (CELP) is a drawback compared to CT2Plus which uses G721 ADPCM. Finally, as mentioned previously, TDMA has been adopted by the CTIA for the standard for digital cellular communications in the United States. Also, Europe's global system for mobile communications (GSM), using TDMA as the multiple access scheme, has shown a very large penetration into all the European markets.

As far as the interception of CT2Plus communications, the common air interface dictates the use of a FDMA scheme. This would seem to be the least technically complicated for interception. Unique, defined frequencies are established and there is only one conversation active on any one of the channels at a time. A system to intercept FDMA type communications has to only track the channels used as they are assigned to the user via a control signaling scheme.

\subsection{FCC Issues on PCN}

Communications stardards in Canada have historically followed those adopted in the United States. Doing this interoperability between the two countries can be simply guaranteed. However, the Federal Communications Commission (FCC), to date, has not set a definitive communications standard specification for U.S. based PCN nor does it seem inevitable. They have, although, spent the majority of their time developing a method to auction the PCN licenses and in defining the radio spectrum for these new services.

Trade journals, as early as 1992, have reported some skepticism in the proceedings of the FCC regarding new PCN offerings and possible delays due to Federal bureaucracy. 
Early in the development of PCN the FCC awarded three "pioneer's preference" vouchers to companies that will be later traded for full operational licenses. The three companies awarded were American Personal Communications Inc. of Washington D.C., Cox Enterprises Inc. of Atlanta Georgia and Omnipoint Corp. of Colorado Springs Colorado. This was the beginning of the controversy as these three companies will nave an advantage in the upcoming competitive bidding for lucrative markets.

In June 1993 the FCC took the first steps in formal PCN rulings and allotted 3 one MHz bands for narrow band PCN services. They are 901 to $902 \mathrm{MHz}, 930$ to 931 $\mathrm{MHz}$ and 940 to $941 \mathrm{MHz}$. Consequently the FCC, in late September 1993, finally releasec their framework for wideband PCN implementation in the United States. One of the leading reporters on PCN for Telephony magazine does have some doubts. "The way the commission fashioned those rules amid ferocious lobbying by industry groups is causing some question whether the type of service most frequently envisioned and written about - voice services for the average consumer - will ever develop as promised."[22]

What transpired in the FCC ruling seems to be a result of lobbying, Federal government pressure and an attempt to please all parties concerned. It came down to a decision where 2 out of the three commissioners voted for the ruling, the third opposed it. It was reported that this decision will severely hamper the goal of the FCC to have new wireless innovations available to the public in 1994. Critics expected a more definitive plan from the FCC considering they have been formally studying the issue for over a year.

The key elements of the September FCC ruling are as follows:

- a total of $160 \mathrm{MHz}$ has been allocated within the 1850 to $1970 \mathrm{MHz}$ band, 2130 to $2150 \mathrm{MHz}$ band and 2180 to $2200 \mathrm{MHz}$ band

- licenses will be awarded under competitive bidding procedures

- licensed users may aggregate up to $40 \mathrm{MHz}$ in any one service area and aggregate service areas without restriction

- the United States has been divided up into over 500 separate PCN markets

- each market can be served by up to seven different service providers

- no more than $30 \mathrm{MHz}$ can be assigned on a per license basis. 
More specifically, the FCC plans to award 2500 licerses, three times the number awarded for cellular with up to seven different licenses awarded in every U.S. city. Two $30 \mathrm{MHz}$ blocks of spectrum has been allotted in each of the 49 large regions as well as a $20 \mathrm{MHz}$ block. Four $10 \mathrm{MHz}$ blocks have been allocated for the 492 subregions. The value of the licenses is estimated at $\$ 10$ billion.

Certain critics of the decision stated that the cellular industry and local exchange carriers, who were heavily lobbying the FCC, wanted small markets and spectrum blocks to sabotage likely PCN competitors.

Steve Zacola, vice president of PCS at MCI, is opposing the FCC ruling. MCI has formed a consortium of over 200 companies interested in offering regional wireless services and has planned to offer national interconnection capabilities. Mr. Zacola stated "The FCC is talking about [thousands of] licenses. If you think that is economically viable, then you're dead wrong. The only way you are going to make a major business out of PCS is through a seamless national network." He continued "It remains to be seen just how fragmented this is going to become but we still plan to be at the table when the bidding begins."

FCC Commissioner Andrew Barret was quoted, discussing the decision, that "In an attempt to make everyone happy, the majority has created a consensus decision that involves a complicated labyrinth of a few large allocations and numerous small market allocations. The record developed over four years supported a much better decision." FCC Commissioner Barret was the individual who voted against the regulation.

The assignment of spectrum in the $2 \mathrm{GHz}$ region seems to be another controversial issue and was heavily lobbied against. PCN assignments in this particular area of the spectrum will be problematic because users already exist in this band. This band currently supports such services as microwave communications for railroads, electric utilities and public safety organizations. Those users must be justly compensated to adjust their existing equipment off this band to a new assignment. This will not only cost the FCC money and in turn the PCN industry but it will delay PCN use in this band because it will take time to move all the existing communications systems to new frequency assignments. 
There may be many opponents to the controversial decision made by the FCC yet all have 0 live with it. Auctions for PCN licenses were scheduled to begin in May 1994. How'ever, industry sources have already surmised that the suctions for wideband voice band personal communications will be delayed as late as August 1994. It seems that the FCC needs further time to prepare. Auctions for narrow band PCN continue to be on schedule for May 1994. Again, this reaffirms the impossibility of having commercial PCN in the United States within the 1994 time frame.

As PCN communications licenses are awarded in the United States new, different communications standards may be adopted not complying with CT2Plus. This will eliminate any chance at the interoperability of PCN radio communications between the two countries. It may also force the governing bodies in Canada to review their choice of CT2Plus. In this light there may be more than one PCN type communication scheme that law enforcement agencies in Canada may have to intercept. 


\section{CWAPTER 5}

\section{Call Processing}

\subsection{General}

It is necessary to detail numerous processes associated to a PCN call to define the scope and magnitude of the intercept problem. This section presents the uverall concept of call routing for a PCN call through the RF and wireline networks already described in previous chapters. Also, the specific details and standards for the Advanced Intelligent Network which is the backbone infrastructure for PCN are described in an earlier chapter. The PCN architecture used for this section's discussion is Figure 5A "Basic Personal Communications Network Architecture". The assumption used is that the access to the PSTN is only as depicted.

The call routing for all possible PCN call setup possibilities must be reviewed and are presented here. Once all these possibilities are identified one can localize a point in the network where law enforcement can obtain all communications to and from the target's handset. Specifically, for the CT2Plus case, the hand-off procedures and details of the signaling between the handset and the base station are described to show the overall complication to the command and control signaling for an active PCN call. Maintaining the connection through all hand-offs is a mandatory requirement for the intercept technology. Ideally, the law enforcement agency would like to only require one appearance of the target line, tap on at this point and route all the intercepted communications back to their monitoring facility.

If, after review, it is determined that the call routing scenarios do not switch the comrnunications through a single point in the network, the most opportune location could be identified to maximize the number of calls intercepted. Also, since there is an Advanced Intelligent Network providing for the supervisory command and control of the call processing, rerouting techniques could be developed to ensure that a calls to and from the target appear at a single point of reference for the intercept. 


\subsection{PCN Call Routing}

The multitude of call routing scenarios are depicted in Figure 5B; " PCN Network Call Routing Flow Diagram". The diagram is divided into two basic sections, home and roaming. The complication to the possible network call routing originates at this changeover point. Within the user's home MDSS area there are two fundamental call scenarios available, inbound and outbound calls.

The inbound call to the user or subscriber then has to be broken down into two basic groups, calls originating from a landline circuit or calls originating from another PCN subscriber. This landline circuit call can be derived from two routing scenarios, originating from the local PSTN or from the long distance toll network. On the half of the :sbound routing flow diagram, a call originating from another PCN subscriber can arise from three different locations. The PCN call can come from the actual subscriber's home MDSS (Mobile Distributed Switching System), anuther MDSS but the same GS (Group Switch) or from another MDSS on any other GS.

It is evident from the diagram that the home MDSS call routing scenario has the least number of cail routing possibilities. Yet, it does define the beginning of tite problem with network interception of a PCN call. The inbound call routing from a call originating from another PCN subscriber on the same MDSS has the audio switched through only that particular MDSS. The audio would not appear anywhere else within the complex network. The PCN network has the capability to accommodate this call setup within the MDSS and would require no interaction with the GS except for billing purposes and this interaction does not necessarily have to occur immediately after the call. The billing information could routinely be transmitted from the MDSS to the GS at a predetermined time of day knowing that this administrative data transfer would have the least affect on the network throughput if transmitted at a known low usage period.

The most complicated of the call routing possibilities is affiliated to the case when the target PCN phone is roaming outside the subscriber's home MDSS and there is an 
inbound call from a different PCN phone. This call routing could have originated from one of six different points within the $\mathrm{PCN}$ network infrastructure. One of these six routing alternatives has the audio of the call appearing on only on MDSS and it happens that it is not the subscriber's home MDSS. In this case the subscriber could be anywhere in the proposed PCN network actively communicating to another PCN user. His call information and audio would appear only and would be strictly limited to a very small subsection of the network. The fact of that this call occurred is not transmitted back to the target's home register until the billing records are updated. Theoretically, a PCN phone registered in Toronto, Ontario Canada could be actively in use in Miami Florida U.S.A. and if the law enforcement agency was not aware of the actual movement of the suspect or the target PCN phone, the fact that calls have taken place would not be evident until some time later and the audio information would be lost forever.

To further complicate this diagram the PCN target phone could, theoretically, be located within the home MDSS service area and the call be switched to a different MDSS because the home switch is currently busied out with active calls. The diagram does not show this call routing possibility as it would provide almost infinite call setup and routing possibilities for the case when the standard routing procedure has to be lypassed due to network activity. In general within the concept of AIN, network switching is intelligent enough to route a call past any possible blocking and the audio path connected with no perceivable delay to the user. Tracking calls through the network with, fundamentally, random appearance is close if not completely impossible from ortside the network intelligence.

Roaming will be the most difficult situation to find a technical solution to the intercept problem in PCN. The target phone could appear anywhere in the network and be given access to local dial tone and make a call. Not only can the user place a call, but with the advent of AIN, and one of the most publicized features, is the ability to receive a call as well. 


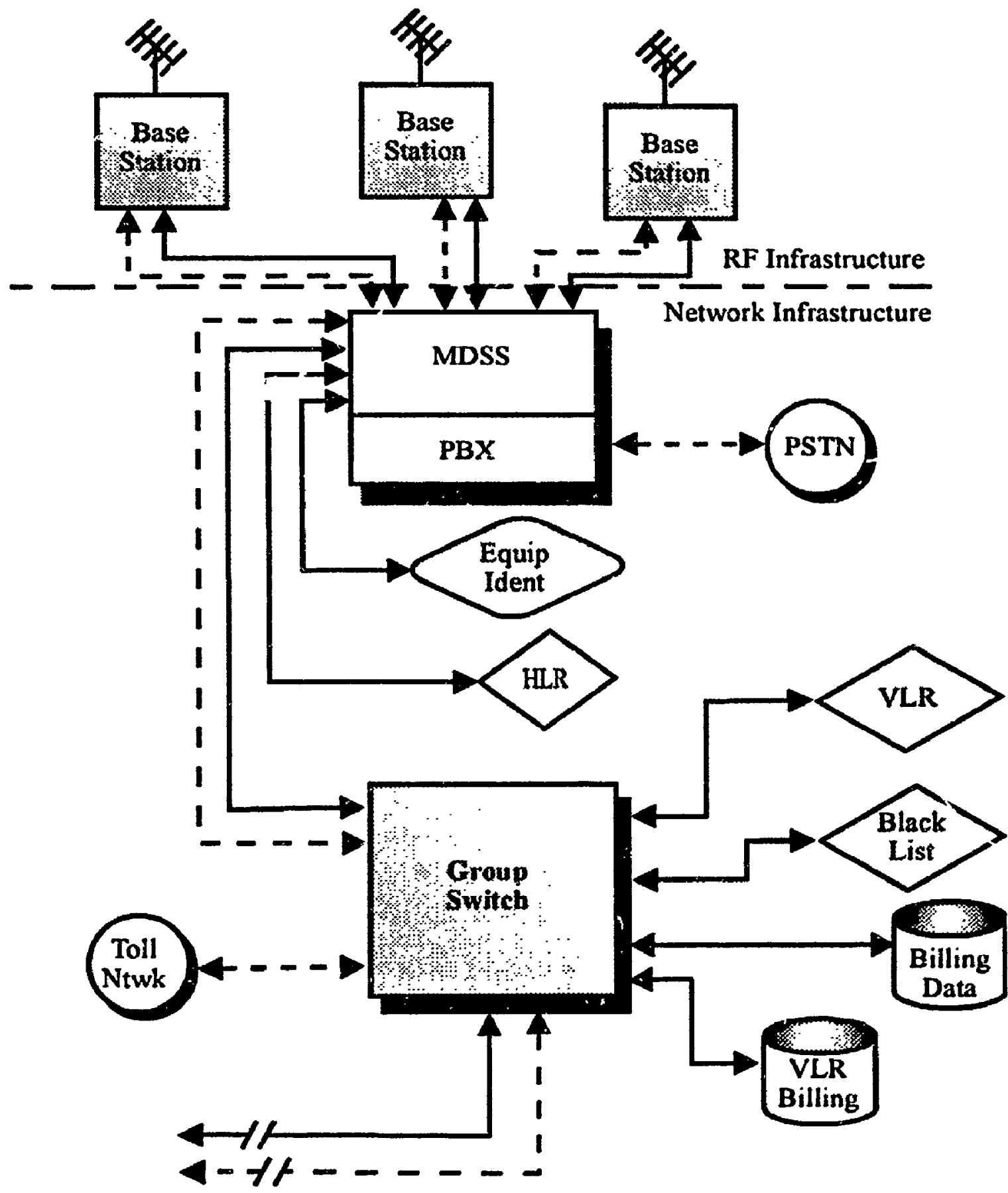

To Other MDSS's On This Group Switch

Figure $5 A$

Basic Personal Communications Network Architecture 

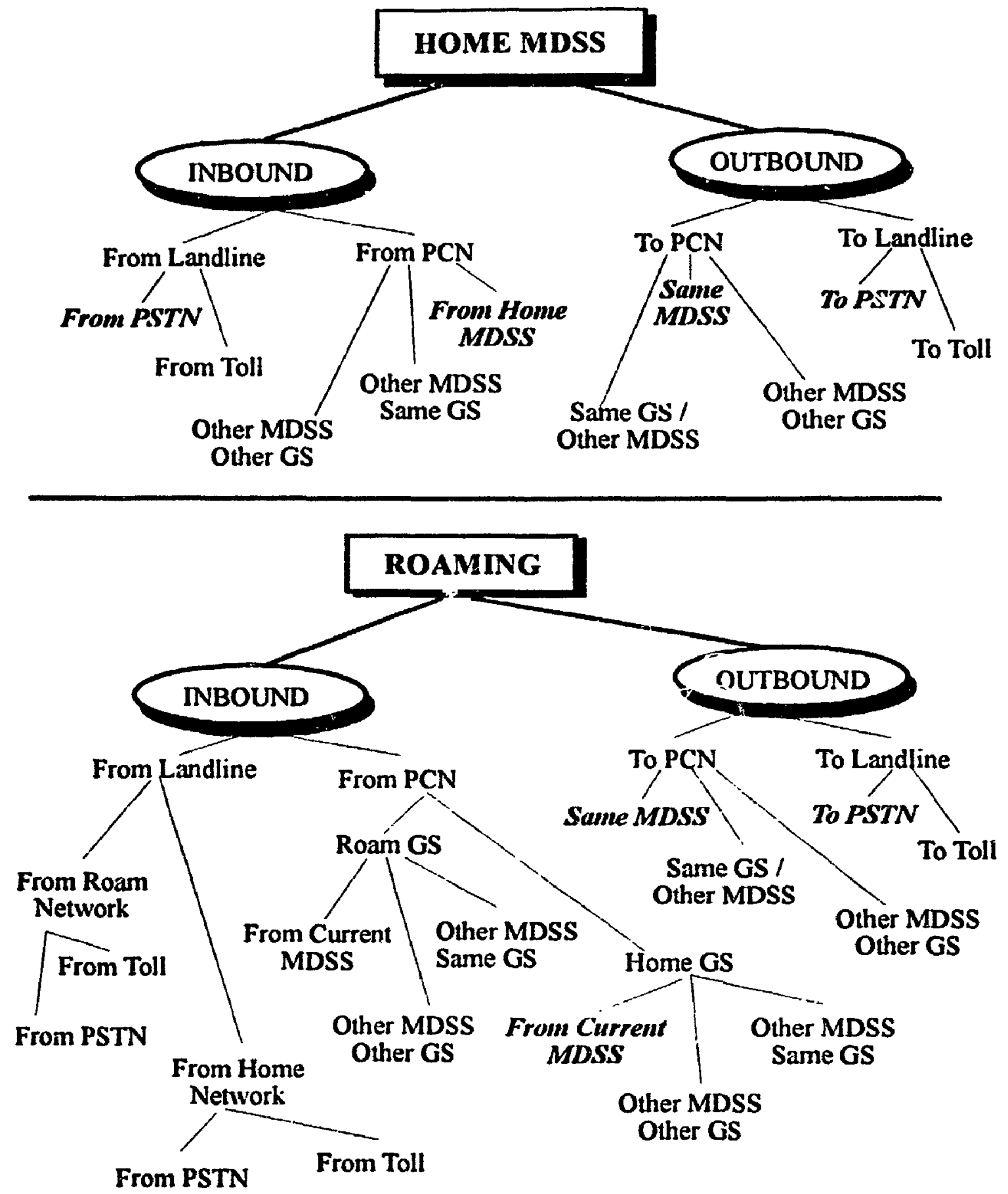

Figure 5B

PCN Network Call Routing Flow Diagram 


\subsection{Radio Network Hand-off Routing}

Another consideration to the overall tracking of the target phone and the actual acquisition of the required communication for the intercept is the call routing through the multitude of PCN radio base stations. The mobility of the target and the rerouting of his or her communications path during an active call must be monioored to ensure that there is no loss of the intercept capability. Hand-offs on the radio side of the network create a significant complication to the monitoring of the call routing, as it changes constantly as the target moves. Therefore, it creates difficulties in the acquisition and ability to maintain the intercept.

Early PCN articles and information shows that the immediate trend for service providers will be to create a seamless radio network for the consumers. This would enable any PCN user to, theoretically, place or receive a call from anywhere that he or she may be located. More realistically, initial installations will be directed towards areas where there would be, statistically, a significant amount of the general public in a small geographical location. Typically, this would include public places including shopping malls, transportation stations including airports and train stations and, also, downtown corridors of metropolitan areas. Evertually, what this means to the overall infrastructure of PCN is an extremely high amount of radio base stations. Considering that the frequency for PCN is greater than that of cellular and that the radiated power is going to be extremely iess than cellular, the number of radio base stations to provide seamless coverage could be astronomical. In turn, the hand-offs between the base stations would occur quite frequently if the phone is mobile. Following a call through numerous hand-offs will be part of the technical challenge for the continuous, uninterrupted interception of a PCN call.

The EIA / TIA has issued a standard, 1S-54, for Dual-Mode Mobile Station - Base Station Compatibility corresponding to the new digital standard for cellular comrnunications. It is assumed that this standard will be the basis for PCN and that the interoperability between the radio base stations and the portable phones in PCN would operate similarly, if not identically, to what is described in this document. Within the 
IS-54 standard there is a definition for the hand-ofi procedure for digital traffic. In section 2.6.5.4 of IS-54 the following procedure is outlined for hand-offs to a digital traffic channel during an active conversation:

1. Send mobile ACK

2. Turn off transmitter

3. Adjust power level

4. Tune to new RF channel

5. Set stored DVCC's to DVCC of received message

6. Set transmitter \& receiver to digital mode

7. Set transmit \& receive rate to equal message type field

8. Set time slot to equal message type field

9. Configure voice CODEC to rate equal message type field

10. Set time alignment offset to value indicated by the time alignment field of received message

11. Synchronize

12. Turn on transmitter

13. Reset fade timer

14. Inhibit discontinuous transmit for 1.5 seconds

15. remain in "conversation" task

This set of procedures to control the hand-off on a digital traffic channel does apply to cellular and some of the items will probably not apply to PCN inclucing procedure 6. PCN will not be dual mode, analog and digital, but strictly digital. This hand-off procedure will take place every time the PCN phone moves out of the RF coverage area for a given base station. A flow diagram, Figure $5 \mathrm{C}$ has been produced to describe the network connect resulting from a hand-off.

This flow diagram begins with the hand-off request. The PCN phone would then simply switch from the cursently utilized base station to the next available station within RF range and with an available audio channei. The phone will be intelligent enough to scan available base station signals and choose the one with the highest received signal strength, guaranteeing the highest audio quality. The network dynamically changes to accommodate the user completely unbeknownst to the user. The user's only concern during this whole process is to have an uninterrupted call with the best audio quality. 


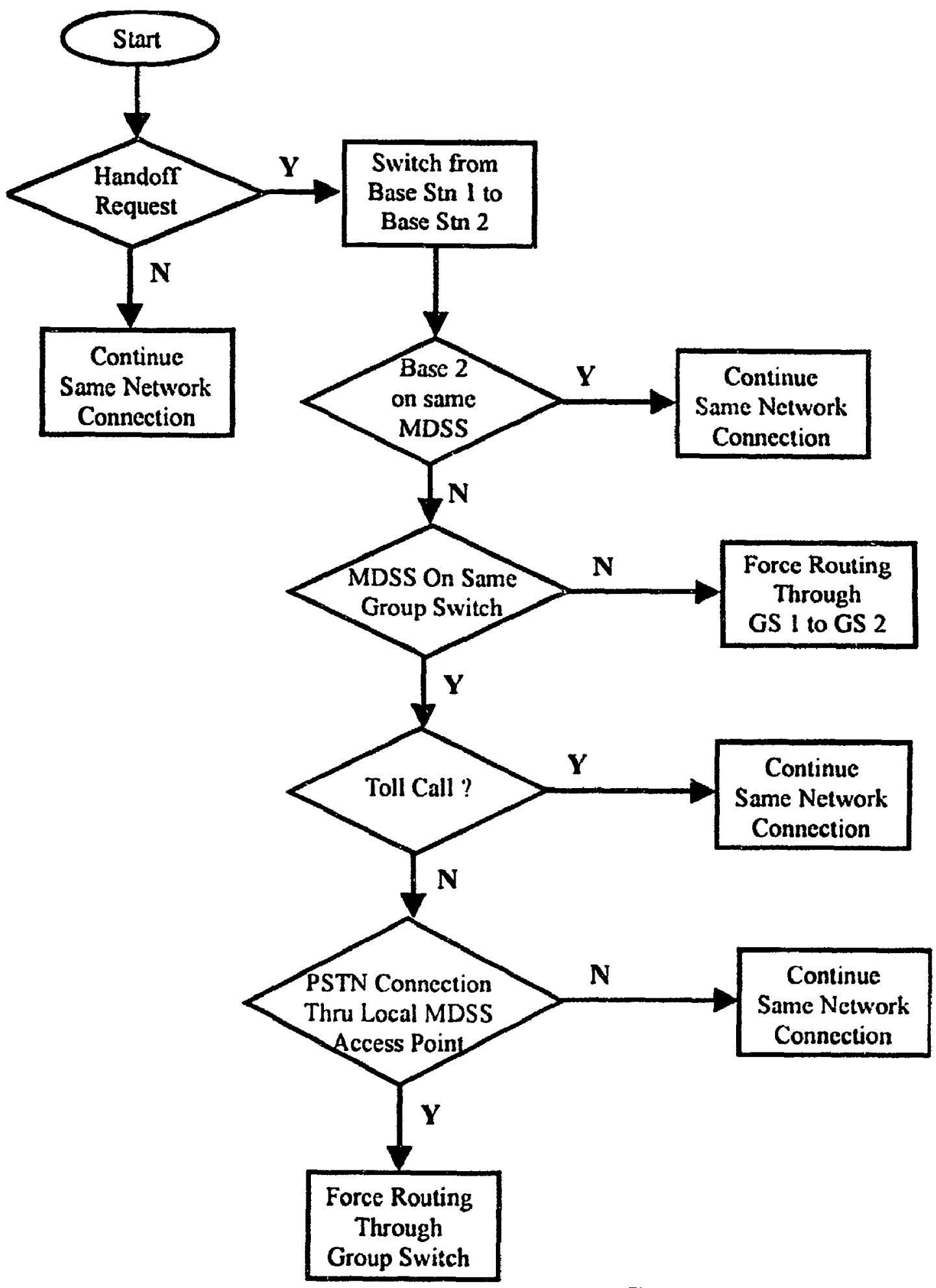

Figure 5C:

PCN Base Station Handoff Network Connection Flow Chart 
The next step within the flow diagram questions whether the non-active second base station is connected to the same MDSS as the first. If yes, the same network connection will be upheld. If no, the next iteration of the switching process is put into affect to determine if the new MDSS utilizes the same GS as the initial connection. If no, the routing is forced from the original GS to the second GS and the call is continued. If the call can remain within the group switch the actual type of call must be determined. If the call is a toll call, it would have been routed through the GS during the initial call set up so the same network connection can be maintained. If the call was not a toll call but a local call the access point to the local PSTN has to be determined. If the PSTN connection for the original call was set up through the MDSS access point the call must be rerouted to the GS. However, if the original call local access point was initially set up through the GS it will remain unchanged. So, if the call hand-off between base stations also forces the move to another MDSS the switching algorithm gets quite complicated because it then depends on the type of call, toll or local and where the initial PSTN connection was provided during the first call set up procedure.

Motorola, in cooperation with Northern Telecom, has introduced a series of radio equipment conforming to the CT2Plus standard. This product line is called "SilverLink". Within this product line is the SilverLink 6 channel base station. This radio base can support up to 6 radio transceivers and adheres to the CAI (Common Air Interface MPT1375) for CT2Plus. The equipment is specified to have a 40 charnel capability and a duplexing method called time division duplex ( transmit and receive on the same frequency). It uses binary frequency shift keying and can support up to 6 simultaneous conversations. the radiated power is listed as $10 \mathrm{~mW}$ (adjustable). Based on the detailed information listed for the Motorola base station, it is highly likely that there would have to be numerous base stations to accommodate the expansive radio coverage planned for PCN as well, since its limit is 6 simultaneous conversations, a high density of radio equipment where there would be statistically a high usage area. Therefore, in conclusion to these observations and based on manufacturer's specifications, radio hand-offs will occur quite often. 


\subsubsection{Radio Base Station Functionality}

The actual radio base station is a target point in the RF portion of the network for the interception of communications. The technology of the radio base station has improved since the introduction of cellular base stations. Some of the inherent administrative and communications control problems that developed within cellular networks can be attributed to the fact that the majority of the network intelligence was put at a central processing point, far from the actual radio access equipment. However, the industry learned through their mistakes, through millions of dollars in telephone fraud and has put substantially all of the validation and call control processing close, if not within the radio access point equipment. Therefore, immediate operational processing can take place during call setup rather than after the call has already been connected.

The Motcrola PCN telepoint base station specifications outlines the overall network control processing that is available within the unit and are as follows:

1. Registration:

- change PIN

- change class of service

2. Operational

- call detect

- RF link establishment / re-establishment

- generate ciphering constant

- track number of bad PIN entries

- zapping / unzapping

- decode ciphering PIN

- validate PIN

- validate class of service

- voice prompts

- PSTN link establishment

- log calls

- end call

- follow-on call

- end RF link

- diagnostics 
- allow emergency calls

3. Special Actions List / Record

- registration

- handset zap / unzap

- change class of service

- de-register

4. Call Log

- handset serial number

- called number

- date / time of link establishment

- date / time of call answered

- RF link duration

- PSTN link duration

- PSTN service used

5. Network Controller Communications

- upload call log, special actions record, health status

- download special actions list, base configuration

- emergency upload calling, special actions record

As outlined, the PCN RF base station equipment has more than simply radio transceivers. There is significant network administrative and control logic residing within it. The Motorola base station boasts that it can hold in local memory up to 10,000 handset serial numbers in a "black" list for handsets to be zapped and 600 handset serial numbers that have been zapped. Therefore, during call setup and validation it can be determined, prior to call connection, if the phone is authorized. If it is not, the base station can issue a command to zap the handset. Zapping a phone will actually erase certain handset memory information disallowing it from any further use on the PCN network. The user would have to physically return it to a service provider's outlet for revalidation.

Northern Telecom has introduced a product line adhering to the CT2Plus wireless telephone standard called "Companion Wireless Business Communications System". The radio base station portion of the product line in somewhat comparable to the Motorola product however this particular Northern Telecom design is based on an internal business oriented coverage. The Motorola base station is designed towards the public PCN application. Yet, the "Companion" product line does conform to the 
CT2Plus standard and the handset can roam outside the private radio coverage area created by the "Companion" infrastructure into a public PCN network.

Differing from the Motorola design architecture, the "Companion" product line has separated the RF portion of the base station from the control logic portion. In the application of the "Companion "product line, the design is based on the fact that the system will connect to an existing PABX system. It is designed to enhance the existing telephone communications system, providing the ability for communications mobility in the workplace. Its radio coverage will be limited to the specific facilities that the company owns and will it not allow access to other CT2Plus public users. The physical area that it has to provide coverage will be strictly prohibited to the premise of the equipment's owner and only a predetermined maximum number of users can be on this private network. This island of PCN could actually reside within the coverage area of a public system, but by design the private business level of the communications network should supersede the public system for those users who have authorization to use it.

For further comparison the design details for the "Companion" base station are:

- cell radius 20-70 meters within a building dependent on the building construction

- open environment cell radius up to 200 meters

- able to carry 2 simultaneous calls on each base station

- up to 4 base stations can be grouped together to provide up to 8 simultaneous calls

- a total of 40 voice channels with $100 \mathrm{kHz}$ channel spacing

- time division duplex

- $32 \mathrm{kbits} / \mathrm{sec}$ adaptive differential pulse code modulation (ADPCM)

- 10 mWatts maximum RF effective radiated power

$-944 \mathrm{MHz}$ to $948.5 \mathrm{MHz}$

- conforms to the CT2Plus standard

The "Companion 100 Controller" is the portion of the product line that introduces a level of intelligence to the wireless telephone network. It provides the following features:

- handset authorization

- capacity up to 127 base stations 
- capacity to support up to 48 cells

- wireless user capacity up to 80

- in building coverage up to 240,000 square meters dependent on building design

- interconnects to numerous PABX equipment

- allows the ability to control existing PABX features through the wireless network

- conforms to the CT2Plus radio protocol

There are minimal actual telephony features provided via the "Companion" system. This system is dependent on the existence of a PABX type telephone switching system and provides only the mobility and freedom of wireless technology to the phone network. All the telephony features available to the wir eless handset are those available through the existing wireline business communications system. However, the "Companion" system does provide for the limited mobility of the users through the control of all the radio base stations on the network, security of the RF communications path through digital technology, integrated automatic user authorization and the junction to the wireline communications system. This product line also, mosi importantly, adheres to the CT2Plus standard allowing for the roaming of the "Companion" wireless handset outside the private network into the public PCN systems.

In the overall PCN call processing scenario the actual radio base station has been accorded much more responsibility within the network. This has two fundamental benefits. To the consumer it provides almost immediate access to network service with a minimization of delays for routine validation and control processing during call setup. For the service providers it affords a much more thorough and sophisticated method for the validation of users and, therefore, the possible elimination of fraudulent calls being placed through the network.

\subsection{CT2Plus Call Processing Details}

Canada has adopted CT2Plus as the national standard for PCN telephone communications. Therefore, to develop a strategy for the interception of PCN 
communications in Canada, the call processing details for CT2Plus have to be identified. The Radio Advisory Board of Canada radio standards specification (RSS) 130 entitled CT2Plus class 2: Specification for the Canadian Common Air Interface for Digital Cordless Telephony, Including Public Access Services outlines all the necessary detail to understand the call processing scenarios required to operate PCN adhering to the CT2Plus standard. In the scope and organization section of this document it is made clear to the reader the purpose of the document. The specification is "to be used for the interworking between fixed and portable radio units in Canada, operating in the frequency band allocated for digital cordless telephone service."[23] More specifically " the equipment is intended to convey digitally-encoded speech or digital data with associated digital signaling, via a radio channel, to and from a nearby fixed station, or network of fixed stations." More importantly to the overall plan of PCN, this specification also provides the necessary detail to "allow a user to migrate from one cordless telephone environment (public, domestic, private branch exchange, Centrex) to another with a single cordless telephone."

The CT2Plus specification outlines the details associated to all call processing requirements within the radio network. Particularly, the Class 2 standard adopted by Communications Canada adds two protocol erihancements to the CT2 Common Air Interface (CAI) ; the addition of common signaling channels (CSCs) and a protocol for synchronous hand-off on an expanded number of radio channels. These enhancements only affect signaling layers 1 and 2 .

Signaling in layer 1 for CT2Plus class 2 service outlines the methods for:

1) time division duplexing of bi-directional data on a CSC

2) the multiplexing of D and SYN channels onto a CSC

3) the multiplexing of CSCs onto a radio channel

4) handshaking on a CSC

5) two way digital link initiation on a CSC

6) synchronous link re-establishment protocol.

Signaling in layer 2 provides for:

1) acknowledged and unacknowledged information transfer over the link

2) error detection

3) error correction by re-transmission and correct ordering of messages

4) identification of link endpoints (ID code handling) 
5) link maintenance

It is stipulated that Class 2 operation is mandatory for all equipment designed to conform with the Canadian CT2Plus Class 2 operation. It is obvious that these enhancements are the basis for the cordless telephone unit to roam through differant PCN environments including private and public communications networks.

\subsubsection{CT2Plus Common Signaling Channel Functionality}

To be able to track the target as he or she moves through the network, the CT2Plus standard provides details for the digital signaling between the radio handset and the base station. All transactions during the call setup procedure occur on the common signaling channel. Again, this type of detail is required to afford the intercept designer adequate information so the intercept system can maintain the intercept as the target moves through the network. furthermore, significant detail is brought forward in the next sections to describe how dynamic the CT2Plus signaling scheme is and, therefore, how complicated it would be to actively track and intercept.

The Common Signaling Channel (CSC) introduced by the Class 2 standard for CT2Plus provides the signaling path between the Cordless Fixed Part (CF) and the Cordless Portable Part (CPP) of the PCN telephone equipment. Both of these two generic types of devices are grouped into what is termed as Cordless Telephone Apparatus (CTA). The CPP is basically what has been termed as the PCN handset. The CFP is the PCN base station. Each radio frequency carrier assigned tc a CSC supports twelve simultaneous multiplexed signaling channels in a superframe. The CFP and the CPP must have access to all frequencies reserved for CSC use but can be restricted to the limited capability of the RF portion of the equipment. The CPP should have no limitations in this particular technical detail so that no matter where it may be located it will have the ability to receive the CSC.

The superframe structure of the CSC is multiplexed to provide the twelve concurrent signaling channels. This superframe structure is referred to as Multip'ex 4 or "MUX4". On each of the 12 multiplexed signaling channels three bursts are alternately 
transmitted and received each frame during a period of 6 milliseconds. Each transmit and receive slot from the CFP, therefore, is 1 millisecond long. Then there is 66 milliseconds until the same frame appears again on the CSC. The entire 12 multiplexed signaling frames, one superframe, covers a perind of 72 milliseconds. On any given CSC the initial transmission burst is broadcast by the fixed part equipment. The CPP vill synchrenize its timing to the CFP which, in this specification, is the master.

The base station of CFP is the portion of the RF network equipment that controls the CSC. It has a dynamic channel allocation strategy incorporated directly into it's programming to provide for a robust RF network architecture. The CFP will choose a CSC according to the following algorithm. If the CFP powers up or comes back operational after a reset it shall monitor all available CSCs to locate a free CSC. The monitoring of a CSC to determine if it is truly free incorporates signal strength measurements on the three adjacent inbound time slots of the CSC from CPP to CFP on at least five separate frames over a period of 20 to 100 frames. A free CSC is defined as any CSC with a local field strel. th below an absolute maximum of $40 \mathrm{~dB}$ relative to $1 \mathrm{uV} / \mathrm{m}$. Or in the situation where this condition does not hold true, a free CSC is then any CSC which has the lowest field strength of all CSCs as measured to a nominal resolution of $6 \mathrm{~dB}$ or better.

The second scenario when the CFP will select a free CSC is if a CFP in a cell had been maintaining a signaling stream on a CSC and stopped transmitting the stream within the last 10 seconds and seeks to re-establish a signaling stream on a CSC. In this case the last CSC used shall be rescanned according to the above mentioned criteria to determine if it is free. If it is free this will be the CSC used by the base station unless there is a known interference problem on this particular CSC. In the case where interference is encountered on a CSC or is anticipaied on a CSC the CFP is allowed to rescan for a free CSC and move it's signaling to this free CSC. However, this reestablishing of a CSC cannot occur within 10 seconds of the last re-establishment by the CFP.

There is a restriction on CSC usage by any one CFP. In general the CFP can only establish a signaling stream on one CSC at a time. In the case where the CFP is moving it's CSC to another channel due to the detection or anticipation of interference, a dual CSI can be operational for up to 30 seconds. Also, the specification details the 
response times allowed over the CSC for both directions of radio transmission. The allowed interval for an outgoing call, when the CPP initiates the link over the CSC to the CFP, and the CFP providing the handshake signal on a traffic channel shall be less than 2 seconds. For the incoming call scenario, when the CFP initiates the link to the CPP over a CSC, and the CPP providing the handshake message back to the CFP over a traffic channel will be less than 2.5 seconds.

It is also mandatory, in the overall system architecture, for the handset device (CPP) to lock onto a CSC to receive control data continuously from the network. After initial power up, reset or the completion of the call it is necessary for the CPP to rescan for the strongest CSC. Internally, the CPP will begin a timer, "Tmon", which is calculated for a 30 frame duration or 2.16 seconds. During this period the CPP will scan for the best CSC signal quality available to it from a service provider that it is registered to use. Upon the receipt of the CFP_INFO code word which is broadcast a minimum of once every 20 frames on every CSC, the CPP will reset the timer and logically consider itself locked onto the strongest CSC. The timer is reset every time it receives the CFP_INFO code word. If the timer runs out prior to receiving the valid code word it will consider itself to have lost synchronization and force re-scanning.

\subsubsection{CSC Layer 1 Signaling Functionality}

The main differences that are introduced to the signaling scheme for CT2Plus verses simple cordless telephones are located within layer 1 and layer 2 protocols. Layer 1 signaling controls the link set up from the CFP to the CPP over a CSC, link set up from a CPP to a Cl P over a CSC and synchronous link re-establishments or hand-offs. This fundamental improvement in consumer cordless communications technolngy introduces an extreme complication in the administration of a communications intercept. Cordless telephones are physically attached to a conventional telephone circuit and can be simply intercepted. A target that has the freedom to move from one base station to another introduces a serious complication to the conventional intercept scheme. 
The link establishment from a PCN base station (CFP) to a PCN handset (CPP) is defined as a response to an incoming ring similar to that of a PSTN line. When a ring is detected a CFP or, in some cases, multiple CFPs will transmit a handshake code word repeatedly over the CSC. This code word contains the CPP's portable identification code (PID) which is 27 bits long and the 16 bit cell identity code transmitted in the link identification code (LID) field. The code word is transmitted over the control signaling channel on consecutive frames over a period of 8 frames or 576 milliseconds unless, of course, if the requested CPP responds back to the call or if the maximum link estabiishment time-out expires or if the originating call from the PSTN is discontinued.

The three possible outcomes to the CSC query to establish a link between a CPP and a CFP are that the process is successful and a link is established when a CFP recognizes and accepts a response from the target CPP with the correct ID code. There is the possibility that no response is received by the CFP in the allowed time. When no response is received the CSC may re-attempt the link setup procedure or the link setup procedure could be attempted over a traffic channel. The third situation is when no ringing is detected or is ceased from the PSTN with a time-out period of 7 seconds.

The portable handset is designed to check the CSC for calling information at least once every 8 frames. If no link establishment request is detected the handset will do nothing but wait until the next period to perform the receive test again. In the situation where a link establishment request is detected the CPP will either respond back to the CFP with the PID and LID fields or the PID and the poll decline LID message. The second response is when the situation or personality programming actually denies the connection request and the call is not connected through to the PCN handset.

A handset, CPP, riay be the particular device in the system that wishes to initiate a call. There is a fundamental difference with this link establishment request compared to the CFP request scenario. Many CPPs are sharing the same CSC link, there sre, there is a possibility that more than one CPP may request a link to be established at the same time. To overcome this possible contention for the same radio signaling channel , the CT2Plus standard outlines a random back-off algorithm to elevate any such type of contention. 
When a CPP wishes to create a call it will monitor the CFP outbound CSC for a CFP_INFO code word which will indicate to the handset that the channel is available to be seized. On the next frame the CPP will transmit a single handshake code word on the inbound time slots. From that point the CPP will not re-transmit on the CSC until it has seized the channel. The CPP will start a timer at this point in the process, "Tcscres". If no response is heard back from the CFP, the identical CFP_INFO code word is received, the handset will begin to run the back-off algorithm before it retries the request for the link. The CPP will generate an 8 bit random number with a uniform distribution from 0 to 255 . If the number is greater than 128, which is the default setting of the logical test parameter for this algorithm, it will wait one frame and generate the random number and the algorithm's test once again. If the random number generated is less than or equal to 128 the CPP will immediately attempt the link set-up procedure from the beginning once sain.

If the CPP receives a handshake code word back from the CSC in response to its request containing the correct PID and before the "Tcscres" timer expires, it has successfully seized the channel and may begin to broadcast on the next frame. The timer is set for 2 frames or 144 milliseconds. The CFP will tran $₫$ mit the handshake code word on the next two successive outbound frames after the detection of a suitable handshake code word from a CPP on a frame following the transmission of a CFP_INFO code word. If the timer expires prior to receipt of the response code word the CPP may begin the link set-up procedure again but on a different CSC. In all cases during a link establishment request generated by a CPP to a CFP the attempts to establish a link will cease after 5 seconds has lapsed.

\subsubsection{CSC Hand-off Signaling Functionality}

The common signaling channel layer 1 protocols also take care of synchronous link reestablishment procedures or hand-offs. The hand-off procedure is a fundamental addition to PCN cordless communications, migrating from the dedicated handset to base station concept to one that allows the user to roam freely anywhere he pleases with uninterrupted wireless telephone communications and creating difficulties in maintaining an active intercept on all target communications to and from the handset. 
Considering the low power of the RF equipment in PCN, it is highly likely that handoffs could occur quite frequently especially if the user is moving quickly.

The process begins within the base station equipment, the CFP. It is the responsibility of the CFP to maintain a list of three free candidate traffic channels for hand-off. The list could possibly be different for every active call ongoing within the CFP These three channels shall be classed as free traffic channels based on intermittent or actual continuous monitoring for a period between 200 milliseconds and 4 seconds. If the monitoring is intermittent, the decision whether the channel is free will based on a minimum of 5 distributed samples. The logical decision will remain valid for only 2 seconds after the decision process has completed. After the $\mathbf{2}$ seconds has elapsed it is necessary to repeat the monitoring process. If three channels cannot be located those remaining channels that have the lowest measured field strength will be included in the list to bring the total to three. There is a provision in the Class 2 specification if the CFP cannot scan channels. In this situation the list will te filled with only the channel zero.

The CFP will transmit the candidate list with three channels to the handset (CPP) via the Candidate Channels link supervisory message. This list is resent to the CPP whenever there is a change is in the list generated by the monitoring procedure in the CFP. The firsi channel on the candidate list transmitted to the CPP will be the preferred channel to switch to when a hand-off is requested. The CPP will respond back within 288 milliseconds to the CFP via the Channel Confirm message and the CFP will immediately adopt the three candidate channels in a "Confirmed List". The CPP could, however, responc back not accepting some or all of the suggested hand-off channels from the CFP. The CPP will respond back with three channels in its order of preference. A zero will be inserted for channels that are unacceptable to the CPP based on its own field strength measurements of the suggested channels. The primary candidate inforination broadcast back to the CFP will then be chosen as the primary candidate for hand-off assignment. If the CPP responds back with the primary candidate channel as zero, this is an indication that none of the suggested channels transmitted by the CFP are acceptable. If a zero message is sent back to the CFP the CFP will rescan and monitor for different free traffic channels and re-attempt the process again. If a hand-off or Class 2 re-establishment message is completed the three confirmed channels in the CFP's list will be reset to zero. 
There may also be a situation where the currently used base station will process a handoff to another CFP as the user is moving outside the radio coverage range of the serving base station. In this case the serving CFP will broadcast a candidate channel list of free traffic channels on another CFP. If the CPP responds back with the appropriate channel confirm message, the serving CFP will forward the confirmed channel list over the network to the target CFP. This should allow for the smooth hand-off between multiple CFPs. However, if there is a situation where all the shannels are busy in the target CFP or it is blocked due to some local condition the serving CFP will immediately transmit its own candidate channels list resetting the previously sent message.

A hand-off can be initiated by either the CFP or the CPP by transmitting one or more Class 2 Link Re-establish layer 2 messages. A 300 millisecond timer is maintained by each of the CFP and the CPP and if no valid code word has been received before the time out of this timer a hand-off shall be initiated. A hand-off will not occur within 300 milliseconds of successfully completing a hand-off. The link re-establish message from the CFP contains a channel number field identifying the traffic channel that the call will continue on after the hand-off. Based on the confirmed list already established, the CFP will transmit a LINK_GRANT message for a period of 120 to 430 milliseconds. If no response is received from the CPP the same message will be broadcast on the next confirmed channel. This process will continue up to 4 times and if no response is received no further attempts are permitted. The confirmed list has three channels available and the fourth is the channel used just previous to the hand-off.

If, during the hand-off procedure, the CFP has only zero channels in its confirmed channel list it will attempt to re-establish the link on the first assigned free traffic channel within the limit of 1 to 35 of the approved channels for the service. If no response is heard on the first channel it will attempt this procedure on the second free traffic channel located in the available service channel assignments. If the hand-off occurs under the control of this second scenario it is highly likely that the hand-off will not succeed. This is the reason that the specification reconfirms the ultimate importance for the cordless fixed part of the communications network to keep an up to date and valid confirmed channels list and to process the candidate channel procedure as quickly as possible. 
A hand-off can also force a change of traffic channel to another CFP. If the target CFP receives a message over the network that the serving CFP has transmitted or received a Class 2 Link Re-estaulish message and has a valid confirmed channel list the target CFP can begin processing the hand-off. The message from the serving CFP will also contain the first channel that the CPP will try to begin transmitting on in an attempt to minimize any drop off period during the hand-off. The target CFP can begin transmitting information on one of the free channels for up to 3 seconds in advance of the initiation of the hand-off. Once the Link Re-establish message is received via the network a timer begins that will last from 120 to 430 milliseconds. The target CFP will begin transmitting the LINK_GRANT message on the first confirmed channel in the list. If a response is not received from the CPP prior to the timer expiring it will attempt to establish the link on the second confirmed channel in the list and again on the third if the timer expires once again. In this scenario the third attempt is the last and if the link is not established the call is disconnected.

Similar to the scenario previously outlined, if the target CFP only has zero chanuel assignments in the confirmed channel list it can attempt to re-establish the link on the first free traffic channel within the range of 1 to 35 of the available service channels. The timer holds true in this case and once it exoires the target CFP will attempt the same procedure on the second free channel. If it is not successful after the second channel the procedure is suspended.

A fall back procedure for hand-offs has also been provided for within the Class 2 specification. A CFP may initiate a hand-off by using the same Link Re-establish message and may set the SKP bit to a " 1 " in the message. If the CPP receives this message with the SKP bit set it will ignore the channel and frequency range data and immediately attempt to re-establish the link via the Common Signaling Channel rather than via data signaling over the traffic channel.

The cordless handset (CPP) has five distinct hand-off procedures depending on the specific conditions the hand-off procedure was initiated in. The hand-off procedures are, however, not dependent on whether the hand-off was ordered due to an interference situation or a mobility hand-off.

In the case when the CPP requested the hand-off it will review its confirmed channel list. If there are channels in the list other than the zero channel, it will begin scanning 
the channels for valid MUX2 data from the transmitting CFP. It will scan the channel; for a period of 1200 milliseconds. It will begin the scan on the pre-chosen prime candidate and dwell on this channel for 50 milliseconds providing time for the CFP to begin to transmit. If the CPP receives valid MUX2 data and receives a LINK_GRANT message it will respond back to the CFP with an ID_OK message and will begin to use the traffic cha:nel. When the CFP accepts the hand-off the network will re-route the call to the appropriate CFP along with state variables and any unfinished layer 3 messages required for messaging to continue. If the 1200 millisecond timer expires prior to receiving a valid LINK_GRANT message from the CFP the CPP will immediately attempt to re-establish the link on a the desired service provider's CSC. A call will not hand-off to a CFP from another service provider different from the one that the call was originally established.

The second case for hand-off processing in the CPP is when the CPP initiates the handoff request and has no channels in its list other than the zero channel. In this case the CPP will scan channels the service provider's assigned channels 1 through 35 inclusive for the valid MUX2 data from the CFP beginning with the present channel. It will scan these channels for a period of 1500 milliseconds dwelling on the present channel for $\mathbf{5 0}$ milliseconds. If a valid LINK_GRANT message is not received the CPP will revert to attempting to re-establish the link via the CSC.

The third and fourth cases are similar to the first and second in the hand-off procedures but it applies to the situation when the CFP requests the hand-off. If the CFP requests the hand-off and the CPP has channels :n its list other than zero the procedure is identical to the first case above except the scan time is reduced from 1200 milliseconds to 900 milliseconds. If the CPP has only the zero channel in its list it will proceed identically to the second case except the scan time is reduced from 1500 milliseconds to 1200 milliseconds.

The fifth case for hand-off request handling in the CPP is the case when the CFP generates the hand-off request and the SKP bit is set to 1 in the Link Re-Establish message. In this situation the CPP shall skip the scan channels for valid MUX2 data procedure and immediately begin to re-establish the link via the CSC. 


\section{CHAPTER 6}

\section{Concepts for the Interception of Communications on a PCN}

\subsection{General}

One of the objectives of this thesis is to identify st:ategies to support legally authorized interception of communications on Personal Communications Networks. Law enforcement requires the ability to obtain information transmitted via many different means. The most obvious and most highly publicized is their ability to perform wiretaps on conventional telephone lines as new technological methods for the general public to communicate information are introduced, law enforcement and intelligence agencies must follow with the development of intercept techniques. PCN is the one of the most technically complex form of public telecommunications to be ever offered. The basic develc pment of PCN and the features was based on the consumers' needs and wants. No effort was taken in the development of PCN or the development of the universal standards to take into account law enforcement's need to intercept the communications. Therefore, a strategy must be developed based on the standards and actual examples of implementations of PCN infrastructures to create a method to intercept.

The intricacies of telecommunications over Personal Communications Networks have been described with numerous topics including the inherent sectrity aspects of PCN and the dynamic network switching capabilities. All these issues are taken into account in the strategies for the interception of PCN communications. Nevertheless, to perform a court authorized wiretap as set forth in Part VI of the Criminal Code of Canada the law enforcement agency must adhere to strict rules and guidelines to maintain compliance to the authorization. Hence there are technical practices and techniques that must be adhered to so as to not jei,jardize the quality and admissibility of the wiretap evidence as well as protecting the actual wiretap from detection by the targeted individual. In accordance with Part VI of the Criminal Code of Canada, to obtain an authorization to perform a wiretap all other methods of investigation must be exhausted. Therefore, typically when a wiretap authorization is obtained the 
investigation needs critical evidence to finalize the evidence gathering and bring that investigation to an arrest and finally a conviction in court.

\subsection{Intercept Technical Requirements}

The legalities outlined in the section describing Part VI of the Criminal Code of Canada and obtaining an authorization for an intercept of private communications can be translated into very specific technical requirements. To be able to present the recording captured frem the intercept all evidentiary rules must be met.

The basic requirements must be adhered to in all instances. In all cases the wiretap authorization names the party or parties that can be intercepted. Typically, in a wireline case where a physical connection is made to the target lines, all other communications captured via the intercept made by an individual not named in the authorization cannot be recorded. The authorization strictly limits the intercept to only those individuals named in the authorization. Steps must be taken by law enforcement to guarantee that only those individuals named in the authorization are intercepted and no one else. Technically, in the non-wireline situation where the named party or the "target" has an identifying number that is transmitted as part of the call setup or the device used to transmit the communications has a unique identifier such as electronic serial number, the originator can be identified to the satisfaction of the court. It is obvious in a hard wireline case which number is being intercepted due to the fact this type of intercept requires an electrical connection to the target line. Again, in the nonwireline RF case, the court may not agree that the unique information derived from the radio type intercept is sufficient to warrant that the intercept is taking place against a named party. Usually in these circumstances the court will add a condition to the authorization. The intercept must be live monitored by an agent of the law enforcement agency, a "monitor", to determine in real-time, as the call is active, if the intercept is actually capturing communications directly involving the nameri target. If the call does not include as one of the parties, the named target, the monitor will perform a function referred to as minimization. Minimization will stop the actual intercept and cease the recording of that particular call. Once the party hangs up the telephone the process is reset and the next subsequent call intercepted will be handled in 
the identical manner. Independent of the terms and conditions applied by the court, the technical means on a non-wireline RF intercept must be designed such that the specific unique identifying information can be entered into the equipment and no other communications from any other source will ever be intercepted. This has to be attested to in court.

Continuity of the evidence must also be attested to in the court. All calls that took place between the time the authorization began to the time it was terminated must be presented. Therefore, evidence cannot be selective in what calls are presented. All the calls during the authorization period are turned over to the court as evidence. If the situation was that the judge had put a condition of live monitoring on this intercept, the part in which was actually listened to by the monitor during the period in which they made the decision to record or minimize would be presented. A call, once minimized, would have no available audio past that particular point of the call. But nonetheless these calls would appear in the evidence to prove to the court that the live monitoring condition was adhered to and there was no loss in continuity of the calls during the authorization period.

It is very important not only to capture all the voice communications but all the signaling associated to the call and any non-voice type communications forwarded over the channel being intercepted. Signaling or call setup information or, as sometimes referred to as, signal related intelligence, is quite important as part of the overall intercept since it could afford the investigation some significant information. For example, frequently dialed numbers by the target shows the investigator that there may be some more significant link between the target and this frequently dialed individual. Therefore, as more and more signal related intelligence is gathered a wider conspiracy group is formed around the original named target. Furthermore, an authorization could be sought on the basis of known interaction with a party named in the investigation and a communications intercept could begin on this second individual. Another example would be the fact that the target was dialing sequences which correspond to foreign countries. This could be an indication to the monitor and the investigator to listen and analyze this particular call immediately.

This signal related intelligence on the target channel includes such information as dialed digits, any further touch tone key strokes made after the call connection was made referred to as over dial digits. These over dial digits are transmitted when connected to 
services such as pagers, computer controlled voice mail or dialing a cellular phone using a roaming access number. These sequences can also be used by a telephone subscriber to control telephone features such as setting up a conference call, call forwarding the phone to another or picking up another call from the call waiting feature. These signals have to be passed back to the recording facility through means of in-band signaling within the audio spectrum. All signal related intelligence must be able to be transmitted through a 300 to $3000 \mathrm{~Hz}$ band limited channel.

Simple call progress tones such as ring back tones or "ringing" is also important to the overall intelligence that can be gathered from the target line. The actual number of times a phone rings is sometimes used as a method of signaling between two parties. Non-voice signals such as facsimile messages must be captured and the integrity of the captured data transmission must not be affected by the characteristics of the return routing path back to the monitoring point or the actual recording device or media. The signal to noise ratio created by the actual intercept device must not degrade due to equipment or lines utilized by the intercepting agency.

In a very flexible, dynamically featured telecommunications market place it is important to be able to provide a technical means to intercept all communication forms associated to the target line. Calls automatically routed to a voice mail service or to a radio pager must also be captured. Changes in these dynamic features must be reforted back to the recording point so that traiking of the ca'l routing through the misplicated telephone network can be observed and strategies put into affect to continue an active intercept on the named target. All calls originating as an outbound call on the target phone or calls coming into the target phone must be acquired. Cáil direction should not limit, technically, the ability to intercept a call. Also, in the case of cellular telephones, all calls created outside the home service area while in roaming mode must be intercepted and routed to the law enforcement agency's recording facility.

In a conventional wireline intercept case, once the actual physical point in the telephone network is decided upon for the intercept to take place the intercepted communications must then be routed via standard telephone lines back to a pre-defined location for recording. The "tap" must be undetectable by the target including the use of sophisticated electronic countermeasures such as a time domain reflectometer. Also, the tapping device should not affect the target line signal quality whaisoever. The recording facility must have the ability to live monitor the intercepted communications, 
append the time and date to it for record keeping, playback the call at any time after the recording and have the ability to perform some post processing. Post processing could be used in situations where encryption has been used by the target to provide some level of security to the communications and decryption has to take place.

In the case of cellular communications, there are two viable locations where the communications can be obtained. Firstly, the required audio can be obtained at the Mobile Telephone Switching Office (MTSO). At this point the same technique and requirements exist as in the case for a wireline telephone intercept. There is a second point where the target communications can also be obtained. The radio link between the targeted cellular phone and the cellular radio base station can be monitored and the communications obtained. However, the legal requirements governing the lawful intercept still remain. The agency performing the intercept must be able to identify the target through some technical means so that the monitoring of all other cellular subscribers does not inadvertently take place and only communications to and from the target are intercepted. Independent of the technique used to intercept cellular cummunications, either via radio intercept or wired intercept at the MTSO, all signaling, audio and subscriber features must be captured to guarantee all information and intelligence from the target is collected.

If all these technical criterion are satisfied the quality of the evidence presented to the court under the Part VI authorizaiion is of the highest standard and the probability of placing any doubt upon the integrity of the evidence based on technical issues is extremely unlikely.

\subsection{Problems With the Interception of Cellular Communications}

\subsubsection{General}

Early in the implementation stage of cellular communications the public, namely the criminal element, was made aware that the technology used in cellular communications prohibited law enforcement from intercepting their communications. It is a well known 
fact that individuals that wanted security from interception by law enforcement conducted much of their communications in a mobile mode on their cell phone. Law enforcement was forced to respond with the development of a method to facilitate the interception of cellular cummunications. All legal aspects associated to the interception of private communications had to be upheld. It proved to be a difficult task. Never before was there a requirement to intercept telephone communications from a mobile source while the radio network allowed the user to maintain a usable radio link by providing the facility to hand off between subsequent radio base stations.

A technique was developed to intrscept mobile cellular communications utilizing computer controlled radio receivers. This method to provide the necessary intercept of private cellular communications had both advantages and disadvantages limiting the scenarios when it would be effective. The development took many years and, not until recently, has a product been oftered to law enforcement in North America that meets the necessary requirements for a legal off air intercepi and has been technically dependable.

\subsubsection{Problems With RF Based Cellular Intercepts}

An option available to law enforcement agencies for the interception of communications from a cellular phone is a method that would intercept the communications via a means incorporating radio receivers. Cellular communications transmitted over the cellular system radio chainels are plain language, analog, narrow band FM and can be easily acquired through conventional FM receivers. However, this methodology must still adhere to the legal requirements for the interception of private communications. Therefore, there must be a means where only the communications from the target cellular phone is captured, excluding all other communications on the cellular network. Such a device would typically be only used in cases where a wireline solution is not available. A typical scenario that may dictate the use of an RF intercept is when a target obtains a cellular phone for a very short period of time. For example, a cellular phone can be rented with a rental car. In this case, once the unique identification information is obtained about the rented phone the time it would take to install a wireline intercept on the cellular switch could be hours. In this time period all the communications by the target could have already been completed and, therefore, not captured by the law enforcement agency. Typically, such a device as a radio based 
cellular intercept system would only be used on one investigation at a time and to guarantee the quality of the evidence, the equipment would only be used against one target ai a time or in some situations, one cellular telephone at a time.

The use of conventional off the shelf radio scanners will have the ability to eavesdrop on cellular voice communications as long as they can tune to the $800 \mathrm{MHz}$ band where cellular radio communications is assigned for North America. A radio based intercept system for law enforcement for the interception cellular communications must have the ability to identify the target communications through a technical means and lock onto only those communications authorized for interception. A simple solution to this would include a method to monitor control channel signaling on the cellular radio network and decode the data transmissions looking for information from or destined to the targeted phone. During the call setup procedures for both an inbound and outbound call the Electronic Serial Numuer (ESN) and/or the Mobile Identification Number (MIN) for the cellular phone is transmitted over the radio control channel. Either of these two data sequences would furnish enough information to uniquely identify the target phone. Therefore, if the law enforcement cellular radio intercept system monitors the control channel for the specific ESN or MIN for the targeted phone and only when one of these two data structures is decoded correctly the intercept system tunes to the assigned voice channel, the technical restriction has been accomplished. Only the communications to and from a specific phone with the preassigned unique identifier would be intercepted. The complication occurs when you review the complexity of the cellular radio network and observe how many active control channels are available to a cellular phone at any one time. A basic design criteria in a cell phone is the ability to concurrently monitor up to three different control channels based on the strongest receive signal strength. This should minimize the probability of blocking because the cell phone could use any of the three to carry on a call set up procedure. If the phone monitors three control channels, it would only be obvious that an intercept system would monitor the same number to increase the probability of intercept.

The essence of a current design for cellular radio intercept does incorporate multiple receivers controlled by an internal computer, configured and monitored by an external portable computer. One receiver is tasked to monitor the strongest control channel. Another receiver is incorporated to be tuned to the forward audio channel after data had been intercepted on the control channel associated to the target and then a voice channel assigned. The third and final receiver was tuned to the reverse audio channel for the 
situation where the receiver is in actual RF range of the target cellular phone and could receive this signal. Three control channels are not being monitored concurrently which would be required to simulate the receive functionality of the target cellular phone. Also, the design is limited to perform one voice intercept at a time due to the limited number of receivers available. It should allow the support of multiple ESN's and MIN's within it's configuration table. This should not prove to be a significant operational limitation because, typically, the device would be used on one specific case at a time against one specific target.

This limitation was based on the single control channel receiver design and the inherent mobility of a target through numerous cells. The RF range of the intercept device chooses a default control channel based on the strongest received signal at the input of the intercept system. This is not necessarily the same control channel that the target is locked on to. Therefore, if the target phone does initiate a call and transmits control channel signaling, the intercept system may not be actively monitoring that particular radio control channel. As a result, the cellular phone identification information is not captured and in turn the audio will not be intercepted. The design of the intercept system should allow for operator intervention and should permit the ability to force the control channel receiver to the one the operator directly selects and off the default control channel. This functionality, with a trained operator, will allow the radio intercept device to monitor the control channel that the target cellular phone is also monitoring and provide for a higher probability of interception of the target communications.

Another limitation due to the single control channel receiver design of the intercept system is the fact that during the initial power up configuration of the intercept system the law enforcement operator will have to choose which of the two available cellular systems the intercept device will tune to. The two cellular systems, wireline and nonwireline, have been assigned a set of distinct radio frequencies for control channel use. Each of these set are different between the two cellular systems. The operator will then have to make a choice between either wire-line or non-wire-line system. With the newer technology phones, the target can easily be authorized on both systems and switch between the A and B services from the keypad of the same phone at their leisure. Also, a change by the target between the two radio systems does not prompt any radio transmission from the target phone to indicate to the monitoring agent that the phone has moved off one set of control channels and is now actively functioning on 
the other. If the target does move, with the single control channel receiving sy'tem, the intercept would immediately be lost.

The limitation therefore is twofold. The simple designed receiver system allows for monitoring of only one control channel at a time on one cellular system. The target can move through multiple cells switching control channels automatically and without notice to the intercept system. The target can also force the switching between the two cellular systems causing further complication to the interception capability and lessening the probability of intercepting all calls to and from the target phone. The only design recourse available to the RF system designers would be to incorporate multiple receivers in the RF system to allow for numerous control channels to be monitored simultaneously and, ideally, enough to cover both the wireline and nonwireline control channel set.

\subsubsection{Limitation Due to Cellular Phone Characteristics}

Cellular telephones have inherent design characteristics that strictly limits the transmit power from the cellular telephone. Initially, this fact did not pose any technical problem to the interception of cellular communications as sidetone information was rebroadcast from the cellular base station on the forward voice channel. Therefore, both sides of the conversation were mixed, through the intentional insertion of sidetone on the forward channel, on the one analog radio channel which is transmitted at a much more stronger radiated power compared to the actual target phone. The entire conversation easily intercepted by tuning to the one voice channel and there was no necessity to have to tune to the reverse voice channel from the cellular phone. A radio scanner could also easily intercept a complete cellular telephone conversation by simply tuning to the base station transmit channel which is extremely more powerful than the signal emanating from the actual phone. In a situation where no sidetone is transmitted over the forward channel of the cellula. system a problem is introduced in recovering the audio information from the cellular phone side of the conversation. The main limitation that affects the ability to intercept is the inherent low RF output power of the devices and the necessity to intercept a full duplex analog radio transmission. 
The maximum transmission power allowed by the Department of Communications and the Federal Communications Commission is 3 watts. This power output is only available on mobile cellular telephones. Transportable and portable cellular phones have less output power than this. Typical power for a portable phone is 600 milliwatts. It should also be noted that output power is controlled by the cellular network. If the base station detects that the input signal is well over the necessary received signal strength requirement a message is broadcast to the phone forcing it to reduce it's output power. These low levels of RF power may be sufficient for the phone to communicate to the cellular base station but does force an RF based intercept device to be in closer proximity so that transmissions emanating from the phone are within receive range. At $800 \mathrm{MHz}$ and with only 600 milliwatis radiating from a portable phone it could be possible that the intercept receiver would have to be within visual range of the target phone's user.

The other design characteristic in cellular communications is that the RF transmissiuns are transmitted full duplex concurrently over two different radio frequencies. The channel that transmits from the base to the cell phone over the forward channel and the phone to the base link is the reverse chrnnel. As mentioned previously, the forward channel from the cellular base station can be intercepted from quite a distance away due to the high power and higher gain base transmit antennas. In the analog design for cellular systems a feedback loop was intentionally provided on the forward channel to repeat the voice information received from the reverse channel. This was designed into the system to provide what is characterized as sidetone. An individual using a standard wireline telephone expects to hear himself a little in the receiver of the phone. To facilitate this expected condition cellular network designers forced the rebroadcast of the reverse voice information back out on the forward channel. This condition provides the most ideal situation to simplify RF interception of celiular communications. With sidetone both sides of the conversation were broadcast on the more powerful forward channel. Therefore, this allowed law enforcement to have a little more freedom in their location because the reverse channel would not have to be intercepted off the air.

Recent modifications to the cellular base stations on the Cantel network in Canada have introduced the ability to accommodate digital cellular phones. Resulting from this new additional capability the forward channel transmissions have been affected. No longer is sidetone information transmitted on the forward channel because digital transmissions 
would be interfered with. The sidetone is generated internally within the cellular phone. Consequently, interception of both sides of the conversation is not as trivial. The voice information from base to cellular device can still be easily monitored on the forward audio channel but to obtain the other side of the conversation the reverse audio channel must be captured. The limitations here are inherent to the transmit power of the cellular phones described previously. To be able to capture the reverse channel the intercept receiver must be in relatively close proximity to the transmitting phone. This limitation does pose difficulties in the covert operations necessary to intercept the communications and have the intercept system operator remain physically undetected. It could affect the operation to such an extent as to eliminate the possibility of performing an RF cellular iniercept.

\subsubsection{Operational Considerations for Cellular Intercepts}

It is a known fact that law enforcement agencies can perform authorized interception of cellular communications. Once an authorization is obtained to intercept communications from a target cellular phone the law enforcement agency has to decide on whether the intercept will be a wireline type, targeting the cellular switch to obtain the required communications or initiating a radio based intercept technique. The operational aspects of perforining cellular intercepts shows advantages and disadvantages to each of these options.

Operational considerations must be reviewed as part of the decision process on the implementation choice for the cellular intercept. If the target owns and uses a cellular telephone a more permanent, long term intercept could be installed. The wireline option, once installed, is not manpower intensive and typically all the communications are intercepted at the local switch and forwarded to the law enforcemert monitoring facility for recording. This is the long term solution and leads itself to the situation where the target does not often leave the coverage of one Mobile Telephone Switching Office (MTSO). The intercept bridging device would be placed on a designated line within the MTSO where all communications to and from the target appears while he or she is within the service are of this MTSO. 
Operationally reviewing the wireline option, it does not impose significant complexity to law enforcement in their attempt to intercept cellular communications. The coverage area for each of the MTSO's is quite large and usually covers a very large geographical area. The exception to this is in Toronto Ontario, Montreal Quebec and Vancouver British Columbia. Each of these three cities has more than one switch installed to support the heavy volume of cellular communications in their respective metropolitan areas. Yet these multi-switch installations are all linked with control signaling transmission circuits and voice circuits. Theoretically, voice information appearing on one of the metropolitan switches could be easily routed to another via the existing voice and data circuits. This would restrict the appearance of the targeted communications to only one of the linked switches and, from this single point, the law enforcemeri agency could attached their bridging device and forward the information back to their monitoring facility. Nevertheless, neither one of the two cellular service providers have unore than 20 MTSO's throughout Canada. Law eniorcement agencies, at the most, would only have to connect to 20 switches throughout Canada to guarantee the interception of a target's communication no matter where they would appear in the network. This assumes that the user does not subscribe to both service providers. In this case the number would be doubled to a maximum of 40 . Operationally, utilizing a wireline technique for the intercept of cellular communications does not seem too compiex yet the limitation is the time that is required to actually install the intercept circuit. Once the court authorization is obtained and the cellular service provider advised of the target telephone number, it could take up to a few days to actually install the intercept equipment. this may not pose a problem if critical information is not expected within that period. If key information is expected to be communicated over the target's cellular phone in the short term a wireline solution may not be able to be installed quickly enough to guarantee the intercept of that message.

In today's market an individual can rent $\mathrm{c} c$, ular phones easily. Obtaining adequate information about the unique identification information for the rented phone and forwarding it to the cellular service provider su that they may establish an intercept will take time. The court authorization must also be worded in such a manner to cover the situation where a rented phone is going to be used by the target and the communications intercepted. Subsequently, with the time delays all the communications that took place over that ro ted phone for that period would have been missed. In the worst case the phone could have been rented and two hours later 
returned, never allowing enough time to enact a wireline intercept. This scenario presents an operational limitation to the wireline solution for cellular intercept.

Since the cellular radio system is still analog in nature, performing an RF type intercept is still a viable second alternative. A radio based intercept system could be employed to capture the targeted cellular communications. The technical limitations and complexity to this solution have been previously described. Assuming that these technical considerations have been met only operational considerations to this technique remain.

In the case mentione I previously, an RF system could be programmed to intercept the rented phone as soon as that unit's ESN or unique MIN has been confirmed from the rental company and cbtained by law enforcement through a court order. Law enforcement would have the ability to intercept all communications by the target even if the phone is only in his or her possession for a matter of hours because the RF intercept system could be deployed immediately. Operationally however, it is a little more difficult because the radio intercept system must be maintained within close proxinity to the target to ensure interception of the target phone's active control channel signals. If the equipment has the ability to monitor numercus control channels simultaneously, the requirement of monitoring the exact control channel as the target phone is eliminated. This assumes that one of the multiple control channel receivers is actually receiving signals from the control channei that the target telephone is utilizing. Independent of how many receivers are in the radio intercept system, the equipment must be within receiving range of these control channels. This does means that the equipment must be mobile if the target is also mobile. The law enforcement agents must operate a full physical surveillance on the target to guarantee that the intercept equipment is within the required range of the target to intercept the communications. This does add a significant complication to the intercept technique. Now, not only do you need a sophisticated piece of equipment, the target also has to be watched all the time to maintain his or her location so that the equipment can be within the appropriate range of the target phone. This is a limitation to this alternative but it dces not discount it completely especially when immediate deployment and installation of a cellular intercept is required. Also, for the period when authorization is in effect but the wireline intercept has not yet been put into place, the radio intercept technique is an alternative to cover off this period. 


\subsection{Strategies for the Intercept of Communications on PCN}

\subsubsection{General}

There are two obvious locations where the communications on a PCN is vulnerable to interception. Similar to the description of cellular communications, PCN communications could be made available for lawful interception either from an off the air technique or a wireline intercept method in the switching network. Operational and technical aspects of the intercept of PCN communications will be reviewed in detail and presented in the following sections for both of these alternatives.

In general, the operational aspects for a PCN intercept remain similar to a cellular intercept. The law enforcement agency will look at the ease of installation and implementation, the time required to activate the intercept and any aspects of the operation that may compromise the fact that an intercept is taking place. Neither of these alternatives actually exist today, so operational aspects of performing a PCN intercept using one method versus have not been experienced. Therefore, at this time to present specific operational advantages or disadvantages for one or the other would be speculative. Assumptions are presented in the following sections with a determination of the operational viability of both of the intercept alternatives.

The technical aspects of the intercept method takes into account the complexity of the transmission schemes utilized throughout the telecommunications service infrastructure and the ease of obtaining the plain language, analog voice information and call related signaling out of the target network. It is critical to law enforcement that information obtained through an intercept can be presented in a format that can be understood by the individual tasked to monitor the line. The translation from the unique transmission format, for example a digitally multiplexed transmission scheme, to analog voice must be done in nearly real time so that information obtained via the intercept is current and not outdated. The technical considerations also take into account the ease of accessing the appropriate communications path to guarantee that only the information to and from the named party of the authorization is obtained.

Both the technical aspects and operational aspects of both a wireline, switch based intercept and an off the air intercept technique will be presented. The technical detail 
applies to the Canadian CT2Plus stancard for the radio common air interface. At this time this standard applies only to the Canadian implementation of Personal Communications Networks. The technical and operational aspecis of the two alternatives may change based on another radio communications standard.

\subsubsection{RF / Off-Air Interception of PCN Communications}

In Canada CT2Plus has been adopted as the universal standard for the radio transmission portion of the PCN. Communications Canada has published a set of radio standards for PCN telecommunications. In these documents entitled RSS 130, Issue 2, "Digital Cordless Telephones in the Band 944 to $948.5 \mathrm{MHz}$ " and the Annex 1 to RSS 130 outlining the common air interface specifications for CT2Plus, Communications Canada has been very specific in detailing the technical methods that must be adhered to for the next generation of cordless telephone communications, namely PCN. In regard to the RF off-air intercept of PCN communications the technical problem is well defined as all CT2Plus cordless PCN phones adhere to the universal Canadian standard.

The primary technical difficulty for the RF intercept alternative for PCN intercept is that all communications to and from the target handset is in a digital format. The voice information spoken into the handset is transformed into a digital bit stream utilizing an Adaptive Differential Pulse Code Modulation (ADPCM) voice codec algorithm adhering to the CCITT recommendation G.721. The digitization rate is $32 \mathrm{kbits} / \mathrm{sec}$. This digital bit stream is then transmitted over the radio channel utilizing a 2 level, Guassian shaped, Frequency Shift Keying modulation scheme. To further complicate the data being transmitted over the radio channel, the instantaneous bit rate of the channel is $72 \mathrm{kbits} / \mathrm{sec}$. This corresponds to the fact that CT2Plus uses Time Division Duplexing (TDD) on the radio channel. TDD allows for the duplexing of both sides of the conversation over the same radio channel. The voice is digitized at a rate 32 $\mathrm{kbits} / \mathrm{sec}$ and the two voice channels using the same ADPCM voice codec algorithm combines to a rate of $64 \mathrm{kbits} / \mathrm{sec}$. Overhead and guard bands push the instantaneous bit rate up to the $72 \mathrm{kbits} / \mathrm{sec}$ rate. The data packets that are duplexed in time over the same carrier frequency are 68 bits in length. Taking into account the guard period between two consecutive packets the dwell time for communications in one direction over the link is approximately 1 millisecond. The voice information is fully duplexed 
over this radio link. The origin of each packet in the transmission is alternated from the portable to the base and back. This duplexing continues for the entire duration of the conversation. The users do not perceive the fact that their voice information transmission is actually stopped while they receive the inbound signal corresponding to the other party's speech information. The reason being that each packet of digital voice information is being transmitted at over twice the voice codec sampling rate. Therefore since the transmission rate is double, two $32 \mathrm{kbits} / \mathrm{sec}$ signals can be duplexed in time not affecting the real time reception and the reconstruction of the original analog signal. This fundamental duplexing method also applies to PCN communications utilizing TDMA as the multiple access scheme. The GSM standard for PCN is an example of technology that uses TDMA. On a single carrier frequency up to 8 different voice communication sessions are duplexed together. GSM, however, does not use TDD for the bi-directional aspect of the communication but uses a Frequency Division Duplexing methodology. The DECT proposal for PCN communications uses both TDMA and TDD to further complicate the transmission scheme.

Interception of this complex digitally duplexed transmission process would not be trivial. Assuming that adequate signal strength is obtained from both the handset and the radio base statin $n$ to capture both sides of the radio transmission, correct locked synchronization to the digital bit stream would be mandatory. This requirement would be absolutely necessary to allow for the correct digital to analog conversion of the transmitted information. However, if the digital transmission on the radio link is not captured at the correct point within a packet, the information recovered back and attempted to be transformed back to analog voice would be absolutely incorrect and unrecognizable. The information obtained from such an intercept would be useless. The attempt at obtaining the information from the interception of the bi-directional radio transmission link has one severe draw back. The handset and the radio base station only have to receive half the information and synchronization is simple since each element is a part of the complete transmission. The Common Air Interface (CAI) for CT2Plus was designed to guarantee correct synchronization between the two active radio transmitters participating in the conversation. There is no consideration whatsoever for the ability of a third radic receiver to also recover both parts of the communications. The same complication appears considering other proposed standards for PCN including GSM and DECT but is augmented by the TDMA multiple access scheme employed. 
As described previously, it is a paramount requirement that a means be employed to ensure that interception take place only on those parties or individuals named in the court authorization. In that regard, each CT2Plus handset will be coded with a unique identity code. The general specification from Communications Canada stipulates that each manufacturer must be able to support up to 2.5 nillion discrete ID codes in their portable handset design. This unique ID code is the information necessary to correctly identify the target transmitter. Also, this ID data is part of each call set up procedure over the signaling channel. Specifically, the call set up is performed over one of the Common Signaling Channels (CSC). Each of the five carrier frequencies assigned as a CSC in Canada supports 12 signaling channels, multiplexed into a 72 millisecond superframe. Exch of the 12 time multiplexed signaling channels ias a duration of 6 milliseconds on the radio channel. Each of these 6 millisecond fr ames has 6 alternating time slots, 3 for base transmit information and 3 for portable information transmission.

To be able to accurately identify the target the unique ID of their portable handset must be obtained. Assuming that this information is available to law enforcement, there is a technical problem associated to actively monitoring for this information on the assigned CSC carrier frequencies. Firstly, there are 5 assigned carrier frequencies for CSC's in Canada and each must be monitored as each handset can lock onto any one of the five independently. Again, assuming that all five channels are being monitored, the digital syncirronization problem identified on the voice channels also applies to the signaling channels. The difficulty on the CSC is that the duration of a message over the CSC is only 1 millisecond, one sixth of the frame transmission duration and one 72nd of the CSC superframe duration. Locking on to the correct point in the data transmission again is mandatory. The RF intercept device would have to be able to actively decode messages that have a transmission dwell time of 1 millisecond and that originate randomly based on inbound or outbound call occurrences. Timing becomes a strict limitation to the accurate ID decoding of target related transmissions. If recovery is attempted when not locked correctly, the information retrieved is meaningless and identification of the target handset would never occur.

One added complication to the fact the all radio transmissions in CT2Plus are in a digital format, a standard offering to the consumer will be digital security. A level of encryption will be implemented on all the information transmitted over the radio link. Northern Telecom, the developers of the CT2Plus standard, have developed as part of their wireless offering, digital encryption of radio transmissions to prevent the 
inadvertent or intentional intercept of the PCN communications. The; digital security method employed is a robust, proprietary algorithm designed to overcome the possibility of eavesdropping, maintain the anonymity of the users and to keep private their location. It was also developed to minimize the ability to place fraudulent calls over the network. Encryption further convolutes the off-air interception of a digital transmission. This aspect may completely eliminate this alternative as a possible method for communications intercept.

Besides the inherent problem associated to digital forms of transmission, one aspect already mentioned is the ability for the radio receiver to capture both sides of the radio transmission. The defined maximum transmit power for all portable handsets in the CT2Plus standard is 10 milliwatts. The base effective radiated power can be more but, since the information transmitted from the portable has to be captured directly the only way to capture both sides of the conversation is to be within the radio transmit range of the portable side of the communications. The portable side of the conversation is not repeated on any other radio channel nor is there any telephone sidetone on the base side of the transmission rebroadcasting the portable side of the conversation as was the case in the early stages of analog cellular communications. The defined radius for the 10 milliwatt transmit power is in the order of 100 feet. The strictly limited handset transmit power is a significant technical complication for any attempt at an off-air technique for PCN intercept.

A further complication to the off-air intercept of CT2Plus communications is the essential design strategy for dynamic channel allocation. The methodology behind the CSC channel selection strategy was developed to afford the greatest ability to overcome radio transmission problems and problems caused by interference. Subsequently, with this always changing CSC assignment based on communications problems experienced between the handset the radio base station broadcasting the common signaling channel, following the signaling channel assignment is all but impossible. There would be no way of simulating or estimating communications link problems between the target handsel and it's selected CSC. Therefore, the only method available to attempt to obtain the mandatory signaling information and technically identify the target is to effectively monitor all possible CSC's for the appearance of the target phone.

The dynamic channel assignments are not limited only to common signaling channels. The radio portion of the PCN monitors the channel quality of all traffic channels as the 
communications is active. If problems occur or if the signal strength falls below a certain level the radio network will force the rescanning of available traffic channels by the handset. Once one is decided on and agreed to by the network controller the handoff is initiated. The off-air intercept system would have to monitor the control data imbedded in the traffic channel transmissions and effective!y follow the hand-off. If the hand-off was unsuccessful, the intercept system would aiso have to be programmed to follow the CT2Plus fall back channel assignment algorithm and attempt to maintain a continuous active intercept.

One issue not identified yet is the fact that PCN handsets can roam. The complication of an off-air intercept for PCN is increased by at least an order of magnitude and likely to a point where it will become unmanageable. Without prior knowledge of the physical location of the target and some knowledge of available PCN networks in that vicinity, attempting to monitor the radio transmissions from the target would be impossible. To monitor the CSC's available to the handset it means that the system designed to intercept the communications must have knowledge of what base stations are in the general vicinity of the handset at all times and monitor the CSC's from those base stations. With the frequency reuse methodology, the 5 available carrier frequencies for CSC's will be reused numerous times within a community and an inconceivable amount of times within the country. Assuming that at least the city where the target is located is known the amount of base stations required to monitor would be finite but, based on a 100 foot transmission radius, the number may be too great to afford an effective method for interception.

An issue that was identified that creates a difference between PCN within Canada and PCN in the United States is the fact that Canada has a national standard for the common air interface. In Canada the transmission scheme for the radio link will be common throughout all PCN networks. This will provide for the ability of a single user to roam freely amongst all 4 of the available service providers. In the situation where he cannot establish communications on his or her subscribed to service provider he will roam into another service provider with no technical limitation. However, in the United States there has been no such standard sei. Therefore, depending on what service provider is subscribed to the radio transmission scheme may differ. Looking back into the comparison of competing multiple access schemes, one of the choices will not be compatible to any other scheme. In Canada the RF intercept technology will target one particular radio transmission common air interface and multiple access 
scheme (FDMA). In the United States one intercept system will not provide a national law enforcement agency such as the FBI the necessary technical solution to allow for the radio intercept of all possible PCN targets. Their problem within the United States in the radio intercept alternative is even more complicated than the alternative within Canada.

The off-air alternative to the interception of PCN communications would be technically extremely complicated. In an operational view point using RF means may be the easiest to actually implement. If a target is identified and information obtained about his unique PCN system identification an RF intercept system could be immediately employed against this individual. There would be no delay due to the processing necessary for the service provide to actually activate an intercept. Operationally, however, the fact the radio transmission range is in the order of 100 feet implies that the law enforcement agent operating the RF intercept system must be physically located within this radius to receive the target's signal. This close proximity to the target is unsatisfactory and would inmediately jeopardize the clandestine aspect of the operation. In general an RF technique for the interception of PCN communications is both technically difficult and operationally limited.

\subsubsection{Wireline Network Access for PCN Intercept}

Attacking the network side of the Personal Communications Network is the second available option for law enforcement in an attempt to intercept this form of telecommunications. Typically when an intercept is performed on the wireline side of a telephone network a physical connection is made to the target line with an active device to bridge all the communications off the line. The fact that the law enforcement agent attaches a device to actual lines, the question of whether a connection is made to the named party in the court authorization becomes a non-issue. The output of this single device is then typically routed through another standard telephone circuit back to a pre-established monitoring point. At this location the intercepted communications is monitored and recorded for evidentiary purposes.

In current telephone technology the majority of all residential telephone circuits are still analog and carry both sides of the conversation. Even facsimile transmissions on these 
standard circuits are still simple tones and can be captured with an analog type bridging device. Some business telephone circuits are digital in nature such as a $\mathrm{TI}$ type multiplexed, multiline service. However, a T1 demultiplexer still has to be employed at the local switching center to translate the signaling into a form that can be carried over the PSTN. Therefore, law enforcement has the ability to tap at a point in the standard wireline telephone network where the communications are in an analog format.

Reviewing Figure $6 \mathrm{~A}$ shows a significant drawback in a wireline implementation of interception in a PCN. There is no single set of wires that law enforcement can identify as belonging strictly to the target. Dependent on the particular base station being utilized for the radio link, the targ... communications could appear on any of a number of different physical circuits. Therefore, the advantage of being able to identify the target by connecting to the appropriate pair of wires is not valid in this scenario. The connection between the RF infrastructure and the network infrastructure will, no doubt, be fully digital multiplexed circuits such as TI or ISDN. It may be extremely difficult to attempt connection at this point in the network because the communications are in a digital format and may not be able to be modified into an analog format. The other difficulty lies in the fact that there will be hundreds or thousands of base stations in any city or community producing a level of comflexity that will probably eliminate this point as a viable point for attack.

The first point providing with some commonalty in the network is the Mobile Distributed Switching System (MDSS). This remote switch is a fundamental element in the standard design of all PCN's. It provides the network with some level of distributed switched and multi-layered call control. Local call control and switching is accomplished within this remote system. At this point in the PCN architecture numerous lines from assorted radio base stations are connected at one point. To relieve some of the complexity of interception of communications, law enforcement would like to have the ability to attach via a single point in the network. At that point they would ideally like to have all communications to and from the target telephone appear. This means that only one physical connection has to be established and only one return line to a monitoring station has to be installed. If the circumstances convey a situation 


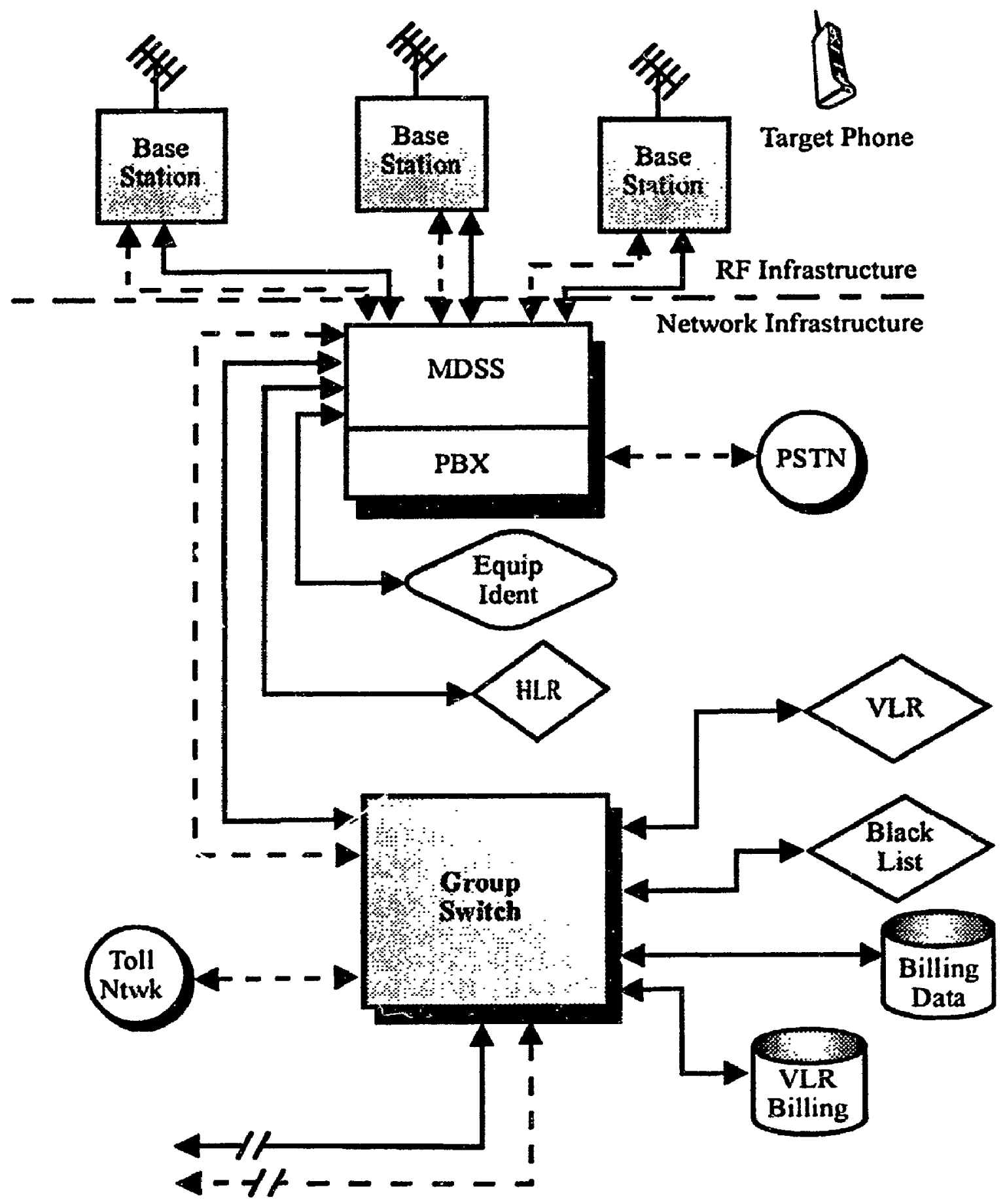

To Other MDSS's

On This Group Switch

Figure $6 A$

Basic Personal Communications

Network Architecture 
where it is known that the target will never travel outside the boundaries defined by the radio base stations attached to one MDSS, attacking this MDSS may be a solution. The MDSS does show that it has access to local dial tone on the PSTN and can also make connections between two PCN phones in it's coverage area. However, scme call routing scenarios take the communications through to the Group Switch (GS). Based on the assumption that the target is not very mobile, the desired communications may reside wunin one MDSS. Yet, if the target is at all mobile this assumption is invalidated. His or her communications path could take them through numerous base stations and in turn many MDSS's.

With respect to the technical requirements for the intercept and, again assuming that the target does not leave the coverage boundaries of the MDSS, all the necessary signaling and identification information is available at this point in the network. The target would be located within their own Home Location Register (HLR) and validation of their network access would be performed by the MDSS. During this validation procedure, there would be nothing prc. ibiting the switch from automatically creating a third party call conference that would be connected to a pre-determined circuit on the MDSS. This circuit would be routed back to the law enforcement monitoring facility. The law enforcement circuit would not be allowed to have a transmit path into the conversation but only a receive connection. This automated procedure would have the inherent ability to detect only those numbers associated to the target. Therefore, it would meet with the technical requirement to only intercept communications from the identified target and be in accordance with the terms of the court authorization. During the call set up procedures the called number or inbound number identification information could also be routed back to law enforcement for the signal related intelligence gathering.

Figure 6B shows that the PCN call routing is not strictly limited to connections through the MDSS. Calls that are shown in italic font have their audio path appear only at the MDSS switching level of the network. All other calls have to be routed to a Group Switch for handling. For example, the calls that are originated or destined to a PCN telephone that is roaming outside their home MDSS would have to be router through the GS. The GS supports the Visitor Location Register (VLR) and vasiun. . ... phones that are roaming outsice the boundaries of their own home service area. Also, diagram 6A shows that the only access to the long distance toll network is via the GS. This 

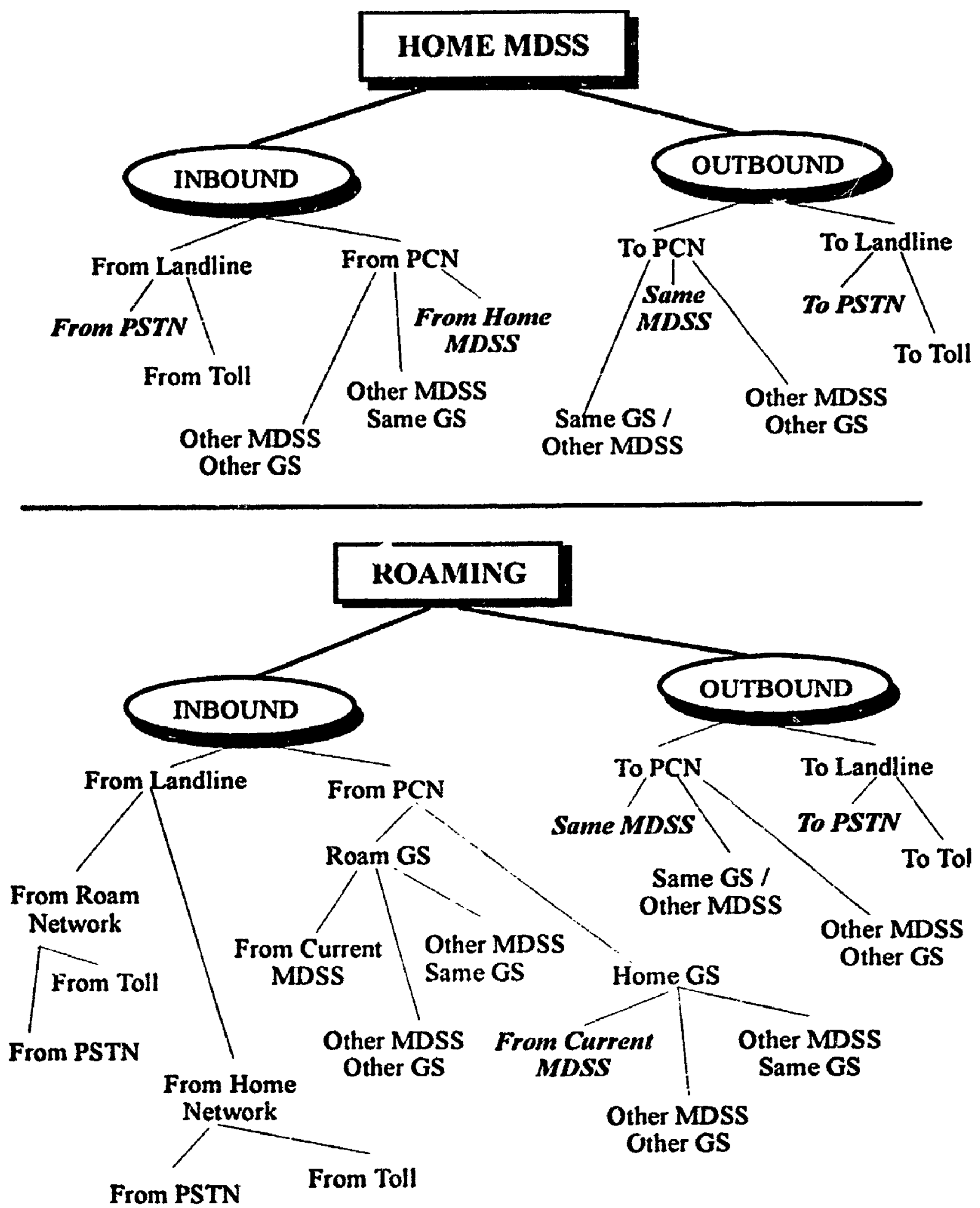

Figure $6 B$

PCN Network Call Routing

Flow Diagram 
design was pe* into place io expedite the billing of long distance toll charges. In these days of competing toll companies, long distance calls can be carried by various telephone companies from the point where the communications was originated to the destination point. Each of these companies wants their particular portion of the long distance toll and they would also like it remitted as soon as possible. One further reason that the only access to the toll network is through the Group Switch is the high level of toll fraud that has occurred in the cellular networks. With the higher level of validation required at the level of the GS, the possibility of toll fraud is decreased.

The Group Switch may be the most logical network target point for intercept of PCN communications. In the network architecture there will be one GS connected to a number of MDSS's which are in turn connected to many radio base statior s. As a single point of reference in the network where all communications could be routed for a vast geographical area, the GS seems to be the only solution. Assuming that the target does not often roam outside of a city, a single GS could be the network support for all the calls inade to and from the target phone. There is one draw back. Figure 6A. shows that there is no access to the PSTN at the Group Switch level. However, this can be circumvented in an intercept case as the GS still provides command and supervision to the entire network infrastructure and all the connected MDSS's.

As mentioned previously the MDSS can be programmed to identify all occurrences of a specific target number during the call set up and validation procedure. The three way conference bridge set up to capture the audio and call signaling information could be routed back to the Group Switch rather than an outbound circuit. In this circumstance all calls with inherent routing through the Group Switch could be captured. The GS has to perform similar validation procedures during sall set up and could, therefore, identify a target number and create a three way conference bridge to a pre-determined circuit back to the law enforcement monitoring facility. Calls that are regularly handiled at the MDSS level could be conference bridged back to the GS. In turn the GS would automatically route this call to the same pre-determined circuit. It seems that in this scenario the intercept is best obtained for a target that stays within the coverage boundaries of a PCN Group Switch. In some cases this very well could be an entire city. Operationally, the automatic identification ihrough technical means is afforded through the detection of the unique user validatio: information programmed into the target phone. Also, the law enforcement agency would only have to have a circuit 
routed from one location back to their monitoring point and it would provide for all the communications in and cut of a wide geographical area for the named target.

The assumption made is that a circuit connection between the Group Switch and the law enforcement agency can be implemented in a format that is agreeable to both parties. In general, the circuit would transmit the intercepted call in either an analog or industry standard digital format back to the monitoring facility. There would be one unique telephone circuit out of the Group Switch for every active intercept. This would guarantee to the intercepting agency and to the court that there would be no way to intermix information between two different targets. If the circuit nappens to be implemented through a standard digital multiplexed format such as a T1 circuit, the logical channels used in the multiplexer shall not be dynamic. One target and all related information to that intercept will always appear on the same logical channel in the multiplex channel bank.

One final call routing scenario must be addressed. If the target phone exceeds the coverage bounds of the Group Switch the intercept connection would be lost. This could happen in two ways. If the target roams outside of the radio cuverage of their subscribed service provider, CT2Plus allows the PCN handset to roam into one of the other three service providers' networks. This means that the user would appear as a visitor in the other network and his or her calls would be connected via the other network. The second situation is when the user roams outside of the area coverage of their home group switch into another GS service area supported by the same service provider. In the second case if this service provider chooses to link all it's Group Switches into a national nciwork there is a possibility that, through programming of the Advaniod Intelligent Network, the intercept could still be routed to the appropriate circuit on the chosen Group Switch. In the first case the only method to guarantee law enforcement coverage if the target roams is to identify to the other service provider the target information and set up an intercept on the other network. Theoretically, in Canada, this translates into a minimum of four source connections for each intercept, one from each of the service providers.

Operationally and technically the alternative of attacking the network to provide the intercept for PCN communications seems viable. There are some limitations and draw backs due to the complexity of the network infrastructure and the inherent multi-layered switching facility. However, since the backbone network is an Advanced Intelligent 
Network there is nothing precluding the network designers from introducing a law enforcement package in the switching system to accommodate a technical method for court authorized interception of communications on the PCN.

\subsubsection{An Example of a PCN Architecture for Wireline Network Access}

An example of actual network signaling proposal for a Personal Communications Network can demonstrate the inherent ability of the Intelligent Network to track all communications to and from a unique portable terminal. Further, this information can establish a basis for a lawful interception of communications through a wireline alternative on a $P C N$.

At least two papers have been published suggesting the use of a distributed architecture based upon the IEEE 802.6 Metropolitan Area Network (MAN) design. The standards publication by the IEEE was in October 1990 and was titled "IEEE 802.6 Committee: Draft of Proposed Standard 802.6 Distributed Queue Dual Bus (DQDB)". A follow on paper applying the standard to a PCN application was entitled "A Personal Communication Network Architecture Using the IEEE 802.6 MAN" [24] and was published as prazt of proceeds of the IEEE International Conference on Communications in June 1992. The second and more recent paper was published in the IEEE Journal on Selected Areas in Communications was entitled "Network Architecture and Signaling for Wireless Personal Communications" [25]. Both of these papers were authored by the same individuals and describe the use of a multi-layered MAN based on the IEEE 802.6 MAN design criteria. Also, both papers assumed that a PCN will utilize an Intelligent Network where databases maintain a mapping between each subscriber's unique Personal Identification Number (PIN) and their PCN profile as well as an estimate of the subscriber's current position. The fundamental requirement for the successful implementation of a wireline solution for the intercept of PCN communications is the ability for the network to accurately discriminate between the target and all other users as well as to track the target throughout the network so that the appropriate call routing could take place to support an intercept. These two criterion must be affirmed for the multi-layered IEEE 802.6 MAiN implementation of a PCN network infrastructure to corroborate the theory of a wireline based PCN communications technique. 
The purpose of the first IEEE 802.6 MAN research paper was separated into four distinct items, two of which directly apply to the criterion uf providing a wireline intercept technique for a PCN. The first applicable purpose was to demonstrate the use of the distributed IEEE 802.6 Metropolitan Area Network architecture to facilitate PCS deployment. The second was to describe a distributed hierarchical database design to facilitate signaling as well as location and tracking of roaming subscribers. This second point is key to the suggestion of a wireline solution for providing a feature within the IN to facilitate interception of specified communications.

Initially, as general information about the implementation of the 802.6 MAN, the paper suggests that a MAN oriented microcellular system architecture provides those service capabilities needed to support the anticipated PCN call loading demand. The MAN will support both data and voice traffic using a dual bus architecture with each bus using a $155 \mathrm{Mbit} / \mathrm{sec}$ SONET STS-3c channels. Isochronous traffic including voice and video will be supported through the use of isochronous prearbitrated slots. The allocation of the particular virtual circuit for the isochronous connection is established during call setup. A series of base stations will be connected to the MAN via heterogeneous bridges and will provide the radio coverage in public areas. A mobile control center is a critical element to the overall network design. It is connected to the MAN and has the responsibility of managing the mobile aspects of the network. Another entity referred to as the signaling termination is also connected on the MAN. It manages the fixed parts of the calls. This MAN architecture is independent of common air interface and is not affected by the specific radio communications format for data and voice traific.

Initial investigation into the throughput characteristics of the IEEE 802.6 MAN indicates that a MAN capacity of $100 \mathrm{Mbit} / \mathrm{sec}$ can support 3250 isochronous two way calls if the voice is encoded at $32 \mathrm{kbits} / \mathrm{sec}$ and has an activity factor of 0.435 . However, further investigation indicates that a single MAN architecture could not support the required throughput in a metropolitan service area. Therefore, a distributed MAN approach was derived. A backbone MAN would be interconnected to numerous access level MAN's providing for a layered appi, $\mathrm{i}_{2,}$, h to the control aspect of the network. 


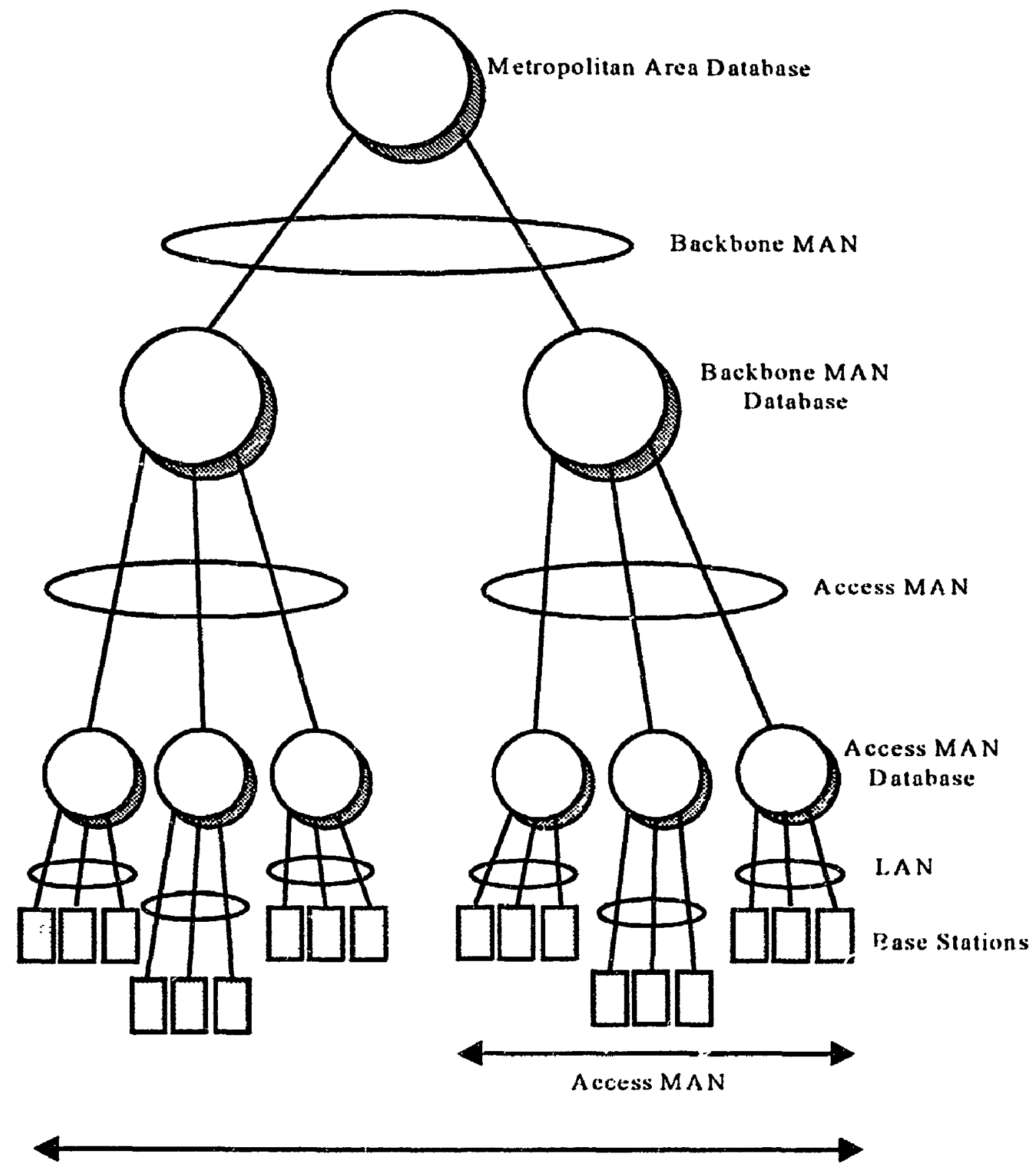

Backbor.e MAN Cluster

Figure $6 C^{\circ}$

Hierarchical Distributed Database Design 
More specifically oriented to the problem at hand, some of the functions needed to enable subscriber registration, tracking and location during call setup in a PCN can be implemented by placing databases at strategic points on the IEEE 802.6 network. Figure 6C shows the hierarchical distributed database design. At the lowest layer each of the access MAN nodes associated with a base station controller has a database portion which will list the subscribers in its control area. The broadcast nature of the MAN architecture allows each database query to be received by all partitions. Taken together these individual partitions act as a logically centralized database on the MAN. Yet, due to the distributed nature of the database a parallel processing affect is recognized to improve the overall response time. Higher level databases can be added to the backbone MAN and the Metropolitan Area (MA) levels of the network to track the subscribers' movements within each of these levels respectively. Thus the fundamental distributed database function would have the MAN level databases tracking all information from their connected base station controller and where each subscriber is located. The backbone level database to the MAN indicate the access level MA.N where the subscriber is located and so forth up to the metropolitan area data'sase. Therefore, the network database is constantly tracking the location of each of the subscribers to the level of which base station controller is service the subscriber at all times. This is critical in the functional requirement for interception of a specific target's communication on the PCN.

Many of the calls in a PCN network will be local in nature and the parties woisld often be located by querying the low level local databases. Table 6.1 shows the forecasted distribution of intended call destination probabilities. The access level MAN databases would then, in this distributed design, be queried most often. The partitioning and distribution of the databases at this level would potentially reduce the time it would take in locating the called party as well as reduce the call setup time.

Each subscriber on the network will have a home access MAN, backbone MAN and MA database. This concept follows with the generic home location register concept in the basic AIN design for a personal communications network. In the 802.6 MAN distributed database design the home and visitor databases are logically distinct but physically integrated. The databases at each level of the distributed hierarchy will contain entries for both home and visitor subscribers. 


\section{Table 6.1}

Distribution of Intended Call Destination Probabilities

\begin{tabular}{|l|l|l|l|l|}
\hline \multirow{2}{*}{ Location of Caller } & \multicolumn{4}{|c|}{ Call Destination } \\
\cline { 2 - 6 } & $\begin{array}{l}\text { Same } \\
\text { Access } \\
\text { MAN }\end{array}$ & $\begin{array}{l}\text { Same } \\
\text { Backb une } \\
\text { MAN }\end{array}$ & Same MA & $\begin{array}{l}\text { Outside } \\
\text { MA }\end{array}$ \\
\hline In Home Access MAN & 0.6 & 0.3 & 0.08 & 0.02 \\
\hline Visiting MAN on Home Backbone & 0.5 & 0.4 & 0.08 & 0.02 \\
\hline Visiting Backbone on Home MAN & 0.5 & 0.25 & 0.023 & 0.02 \\
\hline Visiting Outside Home MA & 0.5 & 0.15 & 0.015 & 0.02 \\
\hline
\end{tabular}

The visitor entry in the database will be temporary and the entry will reside only for the period that he or she resides in the visited area. When a subscribe: leaves the coverage area of their home metropolitan area its home MA database vill point to its home backbone database which will in turn point to the subscriber's hoine access MAN database. The lowest level database, the home location register, will point through a sequence of databases creating a path back from the HLR to the VLR. This information will always furnish the HLR with the current location of the subscriber. The location information for the subscriber can, therefore, be determined by querying any of the databases in either the home or visited area.

In the MAN application for networking in a PCN environment it will also be necessary for the PCN subscriber's handset to continually update its location so that the above call routing information in the HLR and VLR is up to date. If each of the base stations in the PCN periodically transmits its logical address on a predetermined radic channel or in a preselected time slot the handset could contınuously monitor for this information. Once a valid address is decoded by the handset it would have the ability to select the strongest received signal that was decodec' correctly and select this base station as its active radio communications path. As the portable handset leaves one base station contzoller coverage area and moves to another it would automatically identify and register itself in the new coverage area. With this scenario the location of each of the PCN units will be tracked throughout the network so that call routing to and 
from the unit can be accomplished quickly. Furthermore, continuous tracking of the unique identity of the PCN handset will guarantee that active call bridging and call routing can be traced for all law enforcement targets.

In the proposal for the implementation of a IEEE 802.6 MAN the authors also suggest a netwcrk addressing scheme to create a technical solution to the dynamic tracking of PCN handsets through the network. The proposal is for the use of the hierarchical CCITT Recommendation E.164 standard which is a numbering plan developed for ISDN telephone communications. The base station address based on the E.164 recommendation would inherently address the access MAN node, backoone MAN and MA associated to it. A comparison of one base station address to the next as the handset moves between them would permit the new base station controller to determine the type of network boundary crossed by the handset as it moved into the new coverage area serviced by this new controller. the signaling for the database update and subscriber tracking for each of the possible boundary crossing requires jeview of four distinct phases of the update transaction:

1) handset registration at the new location database,

2) handset deregistration in the previous location database,

3) service profile transfer to the new location database if necessary,

4) acknowledgment of the successful registration of the handset.

The possible boundary crossings craated by the multi-layered 802.6 MAN application are as follows:

1) access MAN node boundary crossing in same access MAN,

2) access MAN boundary crossing in home backbone MAN,

3) access MAN boundary crossing in visited backbone MAN,

4) backbone MAN boundary crossing in home MA,

5) backbone MAN boun. ry crossing in visited MA,

6) MA boundary crossing.

It is critical to the ability to intercept all communications to and from the target on a PCN that the handset be tracked through all boundary changes. As indicated in the layered 802.6 MAN implementation there will be up to six possible boundary changes as the target handset roams through the network. The multi-layered database design 
will provide for the tracking across every possible boundary crossing and the database information will be continuously updated will current location information. Therefore, it is apparent with this implementation of a network design for PCN, one of the key criteria for the interception of communications is accomplished; the continuous tracking of the target throughout the network.

The second criteria obligates the intercept technique to have the ability to identify the communications from only the target and not capture any other communications from any other subscriber on the network. It is generally indicated in the above information about tracking of the handset through the network. Specifically, the necessity for the handset to register itself with a base station controller as it exists one coverage area and enters another.

Yet, a better example can be demonstrated in the call setup procedures outlined for the IEEE 802.6 MAN application to PC.N networking. There are three basic call setup phases described for this application. They are;

1) request setup including identifying the callee and class of service,

2) locate callee,

3) establish the required circuits along the route between the caller and callee.

The key part of the call setup procedure that applies to the criteria set forth for the interception of the communications on the PCN is located in the request setup operation. The primary requirement for data transfer as part of the request setup procedure is the immediate identification of the subscriber. The information transferred to indicate the identity of the user is the temporary routing numter allocated to the subscriber upon entering the coverage area of the base station controller. This information plus the callee related information is passed on the mobile control center for authentication of the subscriber. Reviewing the information transferred between databases as the subscriber moves across a boundary, a temporary identity is assigned to the subscriber as he or she enters the coverage area of a new base station controller. The addressing transferred as part of the database update procedure from one base station controller to the next includes all routing information back to the subscriber's home location register. Fundamentally, the temporary identity is linked directly back to the original PIN for the user in the subscriber's HLR. The mobile control center will have the information to tie the user back to his or her unique PIN through the inherent database linking. Therefore, the identity of the target phone can be confirmed during 
all call setup procedures and the second criteria has been accomplished. It is assumed that tracking of the handset is continuous during an active call and hand-offs will not drop the intercept link because of the loss of the identity or location.

The proposal for the use of a distributed IEEE 802.6 MAN is concluded stating that the design can provide many of the capabilities needed to support a PCN. Such an architecture will more readily meet the anticipated PCN loading, signaling and service requirements in urban areas than will the existing mobile communications networks. The capacity calculations to the implementation of the distributed IEEE 802.6 MAN estimates that each MAN can cover approximately 50 city blocks with 3250 voice circuits. With the layering of several MAN's a metropolitan area wide coverage for PCN can be accomplished. Most importantly, the preliminary analysis shows that a hierarchical distributed database, partitioned at each access MAN, could link all subscribers' PIN, PCN profile and provide an estimate of current location. This database design will also accommodate the tracking of the PCN terminals while they are on the move and roaming thre agh the network to guarantee expeditious call setup proceduıs. To facilitate locati'sn updates, call setups and hand-offs the paper proposed a hierarchical address-based routing across homogeneous bridges interconnecting MAN's.

This is an example of a possible network architecture and signaling for a personal communications network. Both of the fundamental criterion for the lawful interception of communications on the PCN have been achieved. With the inherent capabilities already inherent in the $\mathrm{PCN}$ database design, call setup procedures and call routing capabilities there is nothing precluding a pointer being attached to the PIN of the target so that a third party conference bridge could be established during call setup procedures. This would link the required communications path for interception back to a point in the network where law enforcement can tap in and record it. 


\section{CHAPTER 7}

\section{Conclusions and Recommendations}

\subsection{General Observations}

In Canada, with the award of four PCN licenses, it is inevitable that Personal Communications Networks is not a technology of the future but one that is actually realized today. Also, prior to this award, Communications Canada issued a set of standards documents for the next generation cordless telephone communications, CT2Plus. CT2Plus is Canada's standard for Personal Communications Networiks.

Northern Telecom has taken a very proactive role in their PCN equipment marketing all have already released their "Companion" wireless communications systems which are fully compatible with the CT2Plus Canadian common air interface standard for PCN. Their proactive introduction of this equipment was done with the thought of future applications where the "Companion" portable handset will roam into public PCN networks. Furthermore, market research has predicted a multi-billion dollar market for PCN technology in Canada with greater than a million subscribers before the turn of the century. Also, estimates have been published indicating that PCN service providers will be very competitive in the telephone communications market. Initially, the PCN handsets will be priced in the $\$ 300$ area. Compared to cellular, phones were introduced at over $\$ 1000$ and now can be obtained for less than $\$ 50$. Air time pricing will be very inexpensive and the monthly access fee could possibly be lower than the standard wireline telephone access fee. PCN is likely to compete with the local exchanges carriers for basic residential telephone service.

Numerous trials and tests were carried out to identify advantages and disadvantages to a number of competing technologies for the next generation cordless phone technology. In Canada a standard, CT2Plus, has been chosen and all service providers for PCN will have to conform to this standard. The CCITT and Bellcore have also prepared standards for the Advanced Intelligent Network infrastructure which will be the backbone switching and communications network for PCN. The standards were 
developed with the end user, the consumer, as the number one priority. Law enforcement and the ability to intercept communications on this advanced network was never a consideration.

Law enforcement agencies throughout Canada and the United States have stated categorically that the interception of private communications is an absolute necessity. Rapid advances in consumer and communications technology has been shown as the main cause of possibly eliminating this effective investigative technique. The complexity of the communications technology has also developed to a point where access to communications in a format that can be captured and easily monitored has become very limited. The intercept of communications on Persunal Communications Networks will be a definite technical challenge for law enforcement agencies but there are possible solutions available to them.

\subsection{PCN Technology}

A review has been presentid outlining the available and competing technologies for the wireless portion of the overall PCN architecture. Fundamentally, the Canadian standard has been well defined by Communications Canada with the issuance of the "CT2Plus Class 2: Specification for the Canadian Common Air Interface for Digital Cordless telephony including Public Access Services".

The technology used for the radio link will be in a fully digital format. The voice will be coded through a universally defined algorithm and then modulated digitally and transmitted. Encryption of the data transmitted over the radio link will be a basic offering in the fundamental telephone design. Furthermore, the data transmission rate will be at a speed able to support Time Domain Duplexing. Data from the handset will be multiplexed on the RF channel with data from the base station in consecutive packets. This sophisticated transmission scheme is more complex than any other krown ordinary consumer type electronics. The fact that this technology is even being utilized is not apparent to the user. However, one of the marketing benefits that will be advertised to the consumer will be the inherent security of their communications against eavesdropping. Therefore, the RF portion of the overall network design implemented 
in CT2Plus class communications was designed to thwart the ability for interception which also includes lawfully authorized interception.

The switching and wireline communications network that will be the essential core for PCN is called AIN, Adv'nzed Intelligent Network. The multi-layered switching design will relieve any one main switch from the rudimentary call processing and also provide the necessary infrastructure to accommodate the millions of estimated consumers of this service. The AIN will provide the end user with a multitude of new features and the ability to change his or her personal PCN profile dynamically. The ultimate goal for the network infrastructure is to provide a seamless infrastructure that will track the general location of all their subscribed users and route a call to that user independently of their physical location.

These AIN features are extremely desirable to the end user. The basic wireline design philosophy for PCN centered around the users' features requirements and, in turn, the necessary architecture and network switching and communications design to support these features. Again, no consideration was made for any inherent design to support law enforcement's needs to perform a lawful intercept of communications on the PCN network.

\subsection{PCN Interception Recommendations}

There are only two possible technical alternatives available for interception of communications on a Personal Communications Network. Both of these alternatives have been described in detail identifying advantages and disadvantages to both possible scenarios. Also, not only technical complexities and difficulties were outlined but operational concerns to the law enforcement agency.

The first alternative is to attack the radio portion of the communications path. Typically, this alternative is quite viable. To capture the communications while being broadcast affords some advantages since there is no physical connection necessary to obtain the information transmitted. However, in the CT2Plus common air interface the complexity of the transmission scheme eliminates this alternative completely. The 
information that is trartsmitted is digital in nature, multiplexed in time to create a full duplex path over the same carrier frequency and the data is encrypted. Furthermore, the optimal transmit power from the handset is 10 milliwatts. The radio propagation range is in the order of 100 feet. This further substantiates eliminating this alternative because the agent attempting to perform the intercept would have to be within this small radius to receive the target signals. Within one hundred feet of the target would likely put the operation into jeopardy because the agent would be visible.

The second alternative provides the only feasible technique for the interception of communications on a PCN. Law enforcement and the ultimate designers that would have to develop this intercept technology could easily take advantage of the network intelligence to create the appropriate routing of the target's communications back to the law enforcement monitoring facility. The multi-layered switching does create some complication in guaranteeing the interception of all the target communications throughout the network. However, instructing the remote switches, as part of their call set up and validation procedures, to create a third party bridge back to the main Group Switch for identified target numbers could be implemented. All calls to an from the target phone would then appear at the Group Switch level of the switching system independent of toll of local call processing. This means that there would be a single point where the law enforcement agency wotld connect and obtain all communications to and from the target phone while they are on their subscribed network. In the long term goals, there will no doubt be a national infrastructure for the PCN public networks. In this case the inherent intelligence in the network can still be exploited. Theoretically, no matter where the target is in the network all their communications coulu be routed back to a single access point and then forwarded to law enforcement.

There is one draw back to this solution. Communications Canada allows each PCN phone the technical ability to roam onto another Canadian based public network. Therefore, if for some reason the subscriber roams outside the general coverage area of their service provider they could connect through another one of the three other service providers and continue their communications. In regard to the intercept technique, it targets only one of the networks. Communications from the target that is routed through one of the other three service providers' networks would not be captured. In this situation, if the investigating personnel from the law enforcement agency have knowledge that the target will be moving into an area not covered by the service provider they could attempt to set up a similar intercepl on the second PCN network. 
In conclusion law enforcement has only one available alternative for the provision to lawfully intercept communications on a Personal Communications Network. The law enforcement agencies must identify to the service providers that the only solution is network based. Furthermore, to ensure that law enforcement is not put into a situation where they will be unable to intercept telephone coumunications they should immediately identify this short coming to the service providers and actively develop provisions for interception of communications on a PCN. A court authorization to perform the intercept of private communications is useless when there is no technical means to accomplish that intercept.

\subsubsection{General Recommendations}

Based on the defined problem and the technical threat to the interception of private communications ior law enforcement developed in this thesis further research on this subject could be initiated. Specific simulation studies on the interception of CT2Plus communications both on the network and RF portions of the network could be undertaken. A simulation could possibly formulate a mathematical probability of success for the interception of communication in a Personal Communications Network. However, this problem may be a difficult to model so that a mathematical calculation could be derived based on the wide range of indefinite variable in the overall architecture of the network. Yet, this could be a plausible research topic. These more specific studies tased on this perceived technical threat could in fact provide more elaborate information on this complex technical problem.

With the insight provided in the recommendations for the interception of communications on a PCN, detailed research and design could be initiated into the actual development and design of an actual hardware/software solution to be implemented within the network. This task would te quite complicated because: no doubt, each of the four licensed service providers within Canada may have distinct switching networks. For example the two cellular service providers in Canada have switching networks based on two different types of switching equipment. Cantel has Ericsson switching equipment and the Bell Mobility group of service providers have Northern Telecom switching facilities. The software within the two switches will be 
different and the hardware designs will also differ. This problem could proliferate through to PCN as two of the four service providers are the Canadian cellular companies. Yet, the problem will be more complicated because there could be up to four different types of switching equipment in the Canadian PCN market. A single solution to the problem is improbable but research into the design and deve' 'vment of specific. equipment related, solution would be a beneficial extension to the research presented here.

Finally, the basic observation made through the research presented within this thesis is the fact that when PCN becomes a full fledged public communications offering law enforcement agencies will be presented with a serious technical challenge complicating or possibly eliminating their facility to intercept private communications on this new telephone network. These law enforcement agencies can only realize their intercept requirements via a means of obtaining the target communications through the switching network in PCN. This simply tianslates into the fact that the law enforcement agency must have cooperation from the PCN service provider. The service provider will have to provide the means within their switching system to technically obtain the target communications and route it back to the monitoring facility.

Typically, telephone service providers have been reluctant to provide an intercept functionality within their network. There are two basic reasons for this. Firstly, the service provider does not like to te inked to law enforcement nor publicly assist them to intercept communications from one of their subscribers. The public would perceive that the service provider promotes interception of private communications on their network and, therefore, is quite detrimental to their public relations. Secondly, installing the software and/or hardware required to provide the intercept functionality into the switching network is very costly. The initial development costs to create the switch based feature and then the cost to install and implement it throughout the network will be expensive for the service company. Further to this there will not be many subscribers to this feature. Namely only those authorized agencies allowed to intercept private corsmunications will ever request this feature and pay for the service. Comparing this to a switch feature such as call forwarding, the general public consumer base is much larger and the costs to develop, install and operate this feature will be quickly offset by consumer subscriber fees. The same source of revenue to the service provider is not available for the intercept feature and, therefore, w. uld not likely be 
cost effective for them. Nor would the service provider be able to offset their initial capital outlay early after the introduction and implementation of the service.

In the current wording of Part VI of the Criminal Code of Canada, the telephone service providers are obligated to provide assisiance to the agency who have the court authorization for the interception of private comrnunications. However, this does not strictly obligate them by law to provide a service to intercept communications on their network. In the current wording it would be highly unlikely that a service provider could be convicted of not complying to the court order if they can simply state that t'tere is no technical functionality within their switching equipment to provide for the ability to intercept private communications. Again, this proves that cooperation between the telephone service providers and the law enforcement agencies is critical to the successful development of a viable, mittually agreeable solution to this complex technical challenge.

In light of the quickly developing technology in the consumer communications market, snecifically related to telephone communications, the United States Federal Bureau of Investigation has proposed legislation to lawfully obligate telephone service providers, the common carriers, to provide a means to intercept private communications on their network. The Bill has been forwarded to the U.S. government and is entitled the Digital Telephony Bill. This Bill, if it is enacted into legislation will require that the common carriers provide a means to intercep! private communications on their network otherwise they could be charged and convicted under this law. The biggest stumbling block to the introduction of the Bill was that the common carriers explained the enormous capital expense that they would have to absorb to retrofit all their switching equipment with the intercept facility. This corresponds to a point identified earlier about the laige capital outlay for the service provider and them having no way to quickly recuperate this financial commitment. The U.S. government has, therefore, put aside up to $\$ 500$ million to compensate the common carriers and pay for the retrofit of their equipment with an intercept function. This $\$ 500$ million will fund the first four years after the legislation is enacted and after that it is assumed that the common carriers will have adequate time to develop the functionality directly into new telephone communication equipment and technology development.

This legislative solution developed in the United States could have some beneficial affect for Canadian law onforcement. Switchir. \& equipment in the United States will be 
required to have a facility in it to intercept communicatıuns. This equipment is typically marketed in Canada and would then have the same basic intercept feature in place. The fact that telephone communications is not restricted by the boundaries between Canada and the United States and there is full interoperability proves that the switching facilities in both countries are required to be absolutely compatible. Northern Telecom, who dominates the market in Canada for telephone company switching equipment also successfully markets their same switching equipment in the United States. Therefore, it is evident that those common carriers who have Northern Telecom switching equipment will approach Northern to design and develop an intercept feature so that they may comply to the Digital Telephony legislation. Canadian law enforcement would then benefit because, as stated, in the first four years after enacting the legislation the development charges will be funded by the U.S. government, and likely this would include the intercept feature in Northern Telecom switching equipment.

Personal Communications Network switching facilities will be directly affected by the U.S. legislation and there will be a legal requirement for the U.S. PCN service providers to furnish a means to intercept private communications though their network. Based on previous examples, it is highly likely that the equipment that will be installed in Canada for the switching in : $\mathrm{CN}$ will also be marketed in the United States. If this is the case, the development of the intercept feature will be accomplished for the U.S. market and Canadian law enforcement will not have to force the service providers to develop such a facility nor will they have to pay the development costs. The software/hardware solution will be achieved and other countries including Canada that have similar equipment can use tiis to their benefit.

The complexity of the technical chailenge remains yet law enforcement will be afforded the means to continue their ability to intercept communications through a legal obligation to the service providers and this will include communications on a Personal Communications Network. 


\section{References}

[1] Dorothy E. Denning, "Speakout: Wiretapping and Cryptography", IEEE Spectrum Magazine, New York, USA, March 1993, pp. 16-17

[2] No author, "Digital Telephony, Keeping Pace with Technology", FBI Law Enforcement Bulletin, Washington D.C. USA, August 1992, pp. 16-17

[3] John A. Adam, "The FBI Drafts a Law, Wanted: Wiretappable Equipment", IEEE Institute, New York USA, September / October 1992, pp. 1

[4] D.C. Cox, "Personal Communications - A Viewpoint", IEEE Communications Magazine, New York U.S.A., November 1990, pp. 8 - 20

[5] David J. Goodñan, "Trends in Cellular and cordless Communications", IEEE Communications Magazine, New York USA, June 1991, pp. 31-40

[6] Carol Wilson, "Cellular Carriers Poised to Provide PCS", Telephony Magazine, Intertec Publishing Corp., Overland park Kansas USA, December 9, 1991, pp. 60

[7] Quote: John Mooney, $\operatorname{Pr}$. znt of the National Cable Television Association, published in Telephony Magazine, Intertec Publishing Corp., Overland park Kansas USA, May 11, 1992, pp. 6

[8] Charles F. Mason, "FCC To Take Up PCS Licensing", Telephony Magazine, Intertec Publishing Corp., Overland park Kansas USA, July 13, 1992, pp. 1

[9] Jack T. Taylor, "PCS in the U.S. and Europe", IEEE Communications Magazine, New York USA, June : 922, pp. 48-50

[10] Charles Mason, "Which wireless net will lead the way?", Telephony Magazine, Intertec Publishing Corp., Overland Park Kansas USA, December 23 1991, pp. 9

[11] Charles F. Mason, "For CATV, the best defense is a good offense", Telephony Magazine, Intertec Publishing Corp., Overland Park Kansas USA, May 18, 1992, pp. $9-10$

[12] Sorin Cohn, Marc Leroux, Peter L_ff, Peter MacLaren, Richard Mo. "The New Frontier: Personal, Mobile Communications", HNR Telesis Magazine Issue 94, Ottawa, Ontario, Canada, July 1992, pp. 4-17

[13] Peter Murray, "Why Wireless For The Office?", Wireless Voice, October 1991, pp. $29-35$

[14] John Atkinson etc., "Realizing Personal and Terminal Mobility", BNR Telesis

Magazine Issue 94, Ottawa, Ontario, Canada, July 1992, pp. 80- 93

[15] No author identified, "The PCN Connection", Telephony Magazine, Intertec Publishing Corp., Overland Park Kansas USA, April 15, 1991, pp. 32

[16] George H. Heilmeier, "Strategic Technology for the Next Ten and Beyond", IEEE Ccmmunications Magazine, New York USA, December 1993, pp. 30 - 34 
[17] Kurt A. Winmer \& J. Barclay Jones, "Global Development of PCS", IEEE Communications Magazine, New Yórk U.S.A. , June 1992, pp. 22 - 27

[18] Bennett Z. Kobb, "Personal Wireless", IEEE Spectrum Magazine, New York, U.S.A., June 1993, pp. 20 - 25

[19] Larry J. Greenstein et all, "Microcells in Personal Communications Systems", IEEE Communications Magazine, New York USA, December 1992, pp. 76 - 88 [20] Michelle Beaudry, Jerry Parker, "Global System for Mobile Communications", BNR Telesis issue 94, Otiawa, Ontario Canada, July 1992, pp. 52-69

[21] Thomas K. Crawford, ""CDMA vs. T'DMA: The Great Digital Cellular Debate", Telephony Magazine, Intertec Publishing Corp., Overland Park Kansas USA, January 10, 1994, pp. $16-20$

[22] Charles F. Mason, "PCS Licensing Cornpromise Makes Picking Winners Difficult", Telephony Magazine, Intertec Publishing Corp., Ovtı aand Park Kansas USA, October 4, 1993, pp. 7, 16

[23] Submission to the Radio Advisory Board of Canada; Land, Fixed and Mobile Committee DCT Subcommittee, "CT2Plus Class 2: Specification for the Canadian Common Air Interface for Digital Cordless Telephony, Including Public Access Services", Annex to Radio Standards Specification (RSS) 130, Communications Canada, Draft 0.4, August 1992

[24] Andrew Malyan, Robert Donaldson, Victor Leung, "A Personal Communication Network Architecture Using the IEEE 802.6 MAN", Proc. of the IEEE International Conference on Communications, Chicago Illinois USA, June 1992, pp. $1247-1251$

[25] Ancrew Malyan, Leslie J. Ng, Victor Leung, Robert Donaldson, "Network Architecture and Signaling for Wireless Communications", IEEE Journal on Selected Areas in Communications Volume 11 Number 6, IEEE Communications Society, New York USA, August 1993, pp. $830-840$

[26] Jeff Benson, Frank McNally, "News Release, Framework Proposed for Personal Communications", Northern Telecom Media News Release, Number 1081-100190, Northern Telecom, Nashville Tennessee USA, October 1, 1990.

[27] Jonathan Homa, Steve Harris, "Intelligent Network Requirements for Personal Communications Services", IEEE Communications Magazine, New York USA, February 1992, pp. $70-76$ 

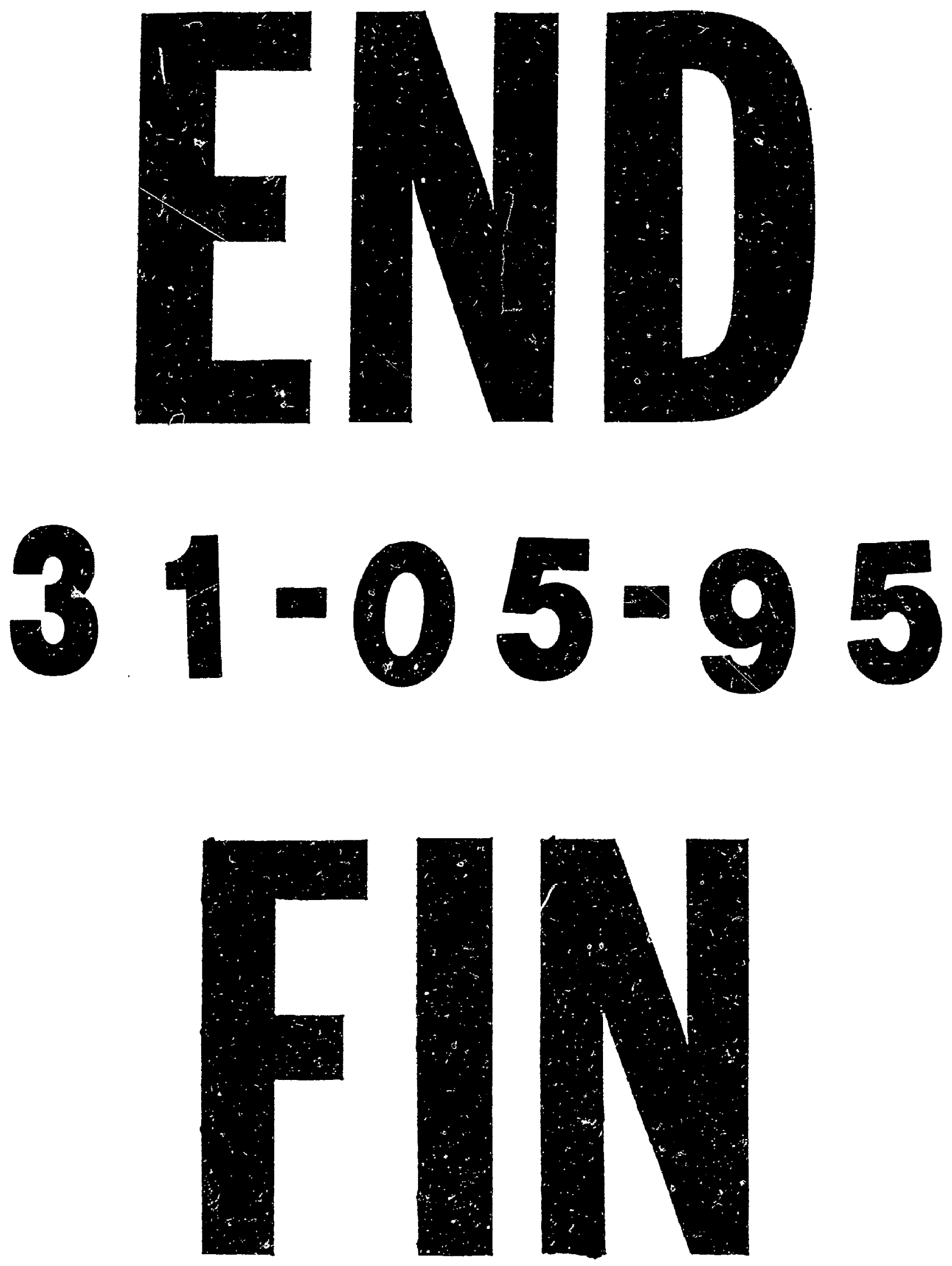